UNIVERSIDADE DE SÃO PAULO

ESCOLA DE ENGENHARIA DE SÃO CARLOS

DEPARTAMENTO DE ENGENHARIA ELÉTRICA

\title{
ANÁLISE DE DISTÚRBIOS RELACIONADOS COM A QUALIDADE DA ENERGIA ELÉTRICA UTILIZANDO \\ A TRANSFORMADA WAVELET
}

\section{Elcio Franklin de Arruda}

Dissertação apresentada à Escola de Engenharia de São Carlos, da Universidade de São Paulo, como parte dos requisitos para obtenção do Título de Mestre em Engenharia Elétrica.

ORIENTADOR: Prof. Dr. Denis V. Coury

São Carlos

2003 
Dedico este trabalho aos meus pais e irmãos. 


\section{AGRADECIMENTOS}

Ao Prof. Tit. Denis Vinicius Coury pela orientação, dedicação e por acreditar em nosso trabalho.

Aos amigos de todas as horas, em especial aos amigos do "LSEE - O Lab." que me acompanharam e participaram diretamente do desenvolvimento deste trabalho.

À Érika pela compreensão, companheirismo e incentivo.

Aos professores e funcionários do Departamento de Engenharia Elétrica da EESC/USP que de alguma forma contribuíram para o andamento deste trabalho.

À Coordenadoria de Aperfeiçoamento de Pessoal de Nível Superior - CAPES pela bolsa de estudos concedida.

Sobretudo a Deus. 


\section{SUMÁRIO}

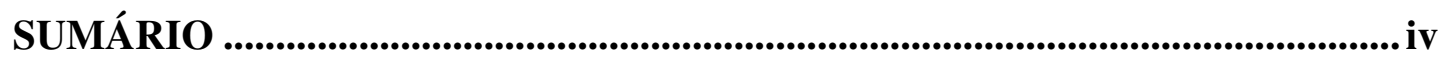

LISTA DE FIGURAS ............................................................................................ vii

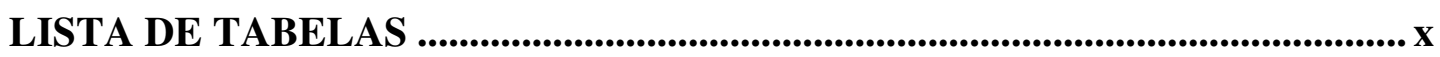

LISTA DE SIGLAS E ABREVIATURAS............................................................. xi

LISTA DE SÍMBOLOS............................................................................................ xiii

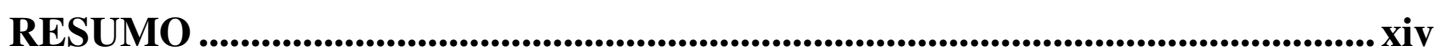

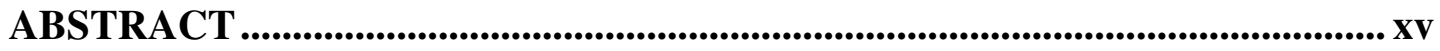

1. INTRODUÇÃ

1.1. Organização do Trabalho.............................................................................. 5

2. A QUALIDADE DA ENERGIA ELÉTRICA .............................................. 7

2.1. Fenômenos Elétricos Transitórios Relacionados com a $Q E$.............................. 7

2.1.1. Transitórios Impulsivos ............................................................................... 8

2.1.2. Transitórios Oscilatórios ........................................................................... 9

2.2. Variações de Tensão de Curta Duração Relacionadas com a QE.................. 11

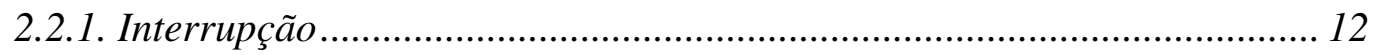

2.2.2. Afundamento de tensão de Curta Duração ................................................ 13

2.2.3. Elevação de tensão de Curta Duração..................................................... 17

2.3. Variações de Tensão de Longa Duração........................................................ 19

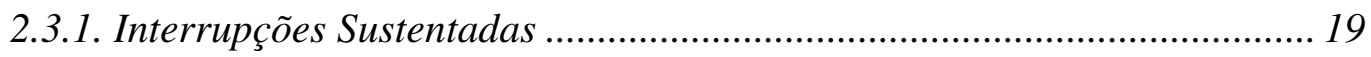

2.3.2. Afundamentos de Tensão Sustentados..................................................... 20

2.3.3. Elevações de Tensão Sustentadas .......................................................... 21

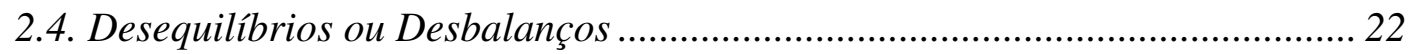

2.5. Distorções da Forma de Onda .................................................................... 23

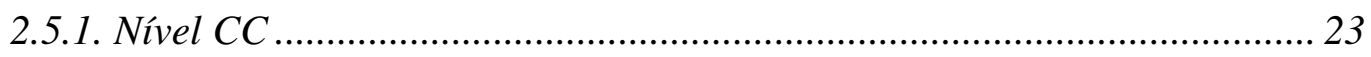

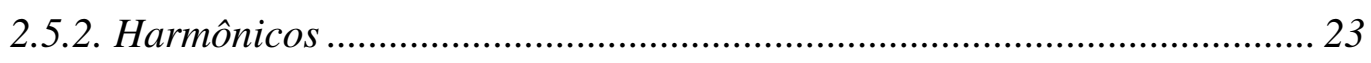

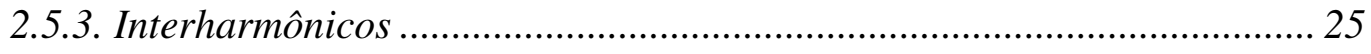

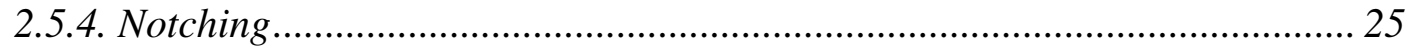

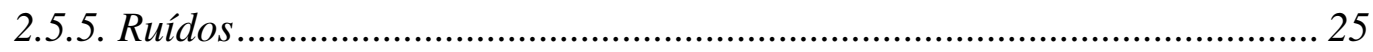

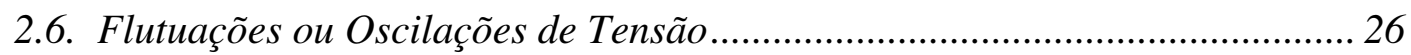

2.1.7. Variações na Freqüência do Sistema Elétrico ......................................... 27 
3. LEVANTAMENTO BIBLIOGRÁFICO ........................................................... 31

4. A TRANSFORMADA WAVELET .................................................................... 36

4.1) A Transformada Wavelet Contínua .............................................................. 37

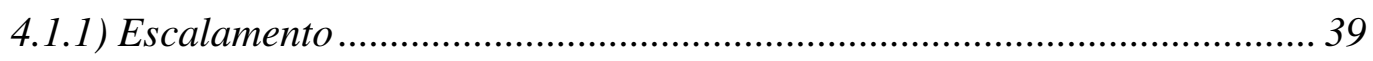

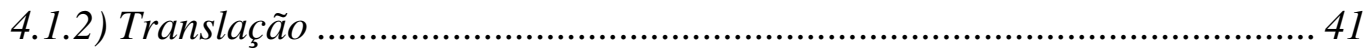

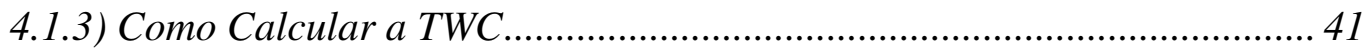

4.2) A Transformada Wavelet Discreta ............................................................... 43

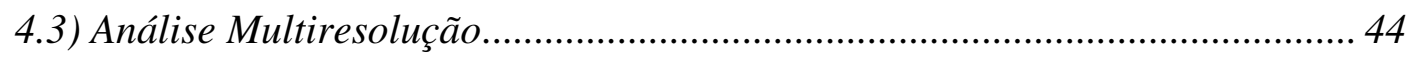

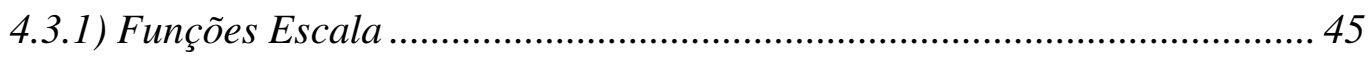

4.3.2) Análise Multiresolução com Funções Escala .......................................... 46

4.3.3) Análise Multiresolução com Funções Wavelets...................................... 47

4.3.4) O Teorema de Parseval.......................................................................... 49

4.4) A Análise Multiresolução Através de Filtragem ............................................ 49

4.4.1) Decomposição em Análise Multiresolução em Múltiplos Níveis.............. 51

5. ANÁLISE MULTIRESOLUÇÃO APLICADA A DISTÚRBIOS RELACIONADOS COM A QUALIDADE DA ENERGIA ELÉTRICA...... 53

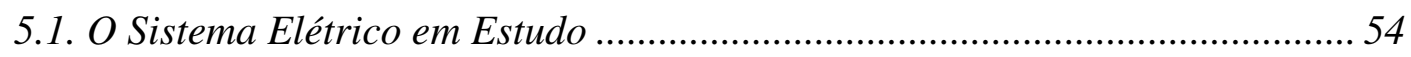

5.1.1. Caracterização de Fenômenos Através de Simulações com o Sistema

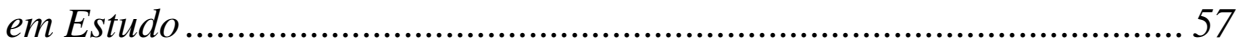

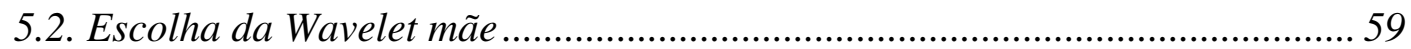

5.3. Aplicação da Técnica de AMR em Distúrbios Relacionados com a QE ......... 61

5.3.1. AMR aplicada ao Distúrbio Afundamento de Tensão............................... 63

5.3.2. AMR aplicada ao Distúrbio Elevação de Tensão ....................................... 65

5.3.3. AMR aplicada ao Distúrbio Oscilação Transitória .................................. 67

5.3.4. AMR aplicada a Ruído Incorporado ao Sinal............................................ 68

6. ANÁLISE AUTOMÁTICA DE DISTÚRBIOS RELACIONADOS COM A

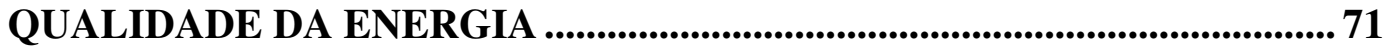

6.1. Descrição dos Sinais de Entrada para Análise ................................................. 73

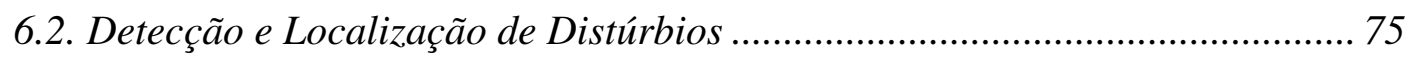

6.3. Análise do Sexto Detalhe de Decomposição.................................................... 77

6.4. Análise da Diferença entre as Energias no Sexto Detalhe ............................. 78

6.5. Análise da Quinta Versão de Aproximação do Sinal Decomposto .................. 79 
6.6. Análise dos Três Primeiros Níveis de Decomposição 80

6.6.1. Análise para Oscilações Transitórias e Ruídos 81

7. RESULTADOS OBTIDOS UTILIZANDO O MÉTODO DE ANÁLISE (ANADIQE) DESENVOLVIDO. 83

7.1. Detecção e Localização do Distúrbio...... 83

7.2. Classificação de Distúrbios 85

7.2.1. Classificação de Distúrbios com Frequência Similar à do Sinal em Regime. 86

7.2.2. Estimação da Duração e da Amplitude do Distúrbio 87

7.2.3. Classificação entre Oscilações Transitórias em Ruídos 91

8. COMENTÁRIOS E CONCLUSÕES FINAIS .94

9. REFERÊNCIAS BIBLIOGRÁFICAS. .97

APÊNDICE I 101

APÊNDICE II 108

APÊNDICE III 116 


\section{LISTA DE FIGURAS}

FIGURA 1 - Custo estimado resultante de Interrupção de até 1 min. 3

FIGURA 2 - Corrente transitória impulsiva oriunda de uma descarga atmosférica.

FIGURA 3 - Transitório proveniente do chaveamento de um banco de capacitores (600 KVAr, 13,8KV).

FIGURA 4 - Interrupção momentânea devido a um curto-circuito e subseqüente religamento. 12

FIGURA 5 - Afundamento de tensão causado por uma falta fase-terra. 14

FIGURA 6 - Decréscimo de tensão ocorrido pela partida de um motor. 14

FIGURA 7 - Tolerâncias típicas de tensão para computadores (curva CBEMA).... 15

FIGURA 8 - Elevação de tensão devido a uma falta fase-terra. 17

FIGURA 9 - Vida útil de um transformador em função da distorção harmônica de corrente. 24

FIGURA 10 - Tensão de alimentação de um conversor CA/CC. 26

FIGURA 11 - Representação de um sinal em diferentes escalas e posições 39

FIGURA 12 - Exemplo do fator de escala em uma função seno. 40

FIGURA 13 - Exemplo do fator de escala em uma função Wavelet. 40

FIGURA 14 - Translação aplicada a uma Wavelet. 41

FIGURA 15 - Cálculo do fator C de relação entre a Wavelet mãe e o sinal............ 42

FIGURA 16 - Translação da função Wavelet 42

FIGURA 17 - Exemplo de escalamento da função Wavelet para o prosseguimento nos cálculos ............................................................... 42

FIGURA 18 - Espaços encaixantes de vetores expandidos por funções escala. ...... 46

FIGURA 19 - Espaços vetoriais de funções escalas e Wavelets................................ 48

FIGURA 20 - Processo de filtragem de um sinal..................................................... 50

FIGURA 21 - Processo de diminuição do número de amostras do sinal. ................. 50

FIGURA 22 - Exemplo de filtragem com downsampling de um sinal senoidal ruidoso

FIGURA 23 - Ilustração do processo sucessivo de decomposição de um sinal em AMR. 
FIGURA 24 - Exemplo de decomposição sucessiva de um sinal

FIGURA 25 - Diagrama do sistema elétrico de distribuição analisado.

FIGURA 26 - Funções da base Wavelets: Haar (a), db4 (b), sym3 (c) e coifl

(d).

FIGURA 27 - Processo de decomposição de um sinal em AMR.

FIGURA 28 - Versões de um sinal decomposto em AMR. Versão referente à

terceira aproximação $(a)$, primeiro $(b)$, segundo $(c)$ e terceiro $(d)$ detalhe.

FIGURA 29 - Sinal de tensão em regime permanente.

FIGURA 30 - Decomposição em AMR de um sinal em regime permanente.

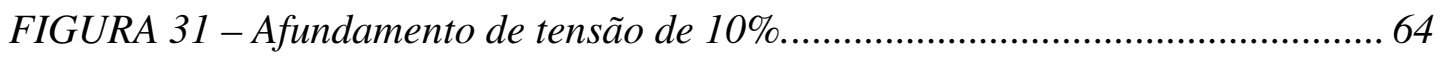

FIGURA 32 - Decomposição em AMR de um afundamento de tensão de 10\%........ 65

FIGURA 33 - Elevação de tensão de 25\% .................................................................. 65

FIGURA 34 - Decomposição em AMR de uma elevação de tensão de 25\%. ........... 66

FIGURA 35 - Análise de níveis de frequência para a energia em cada decomposição.

FIGURA 36 - Oscilação transitória proveniente do chaveamento de um banco

de capacitores. 68

FIGURA 37 - Decomposição em AMR de uma oscilação transitória proveniente do chaveamento de um banco de capacitores. 69

FIGURA 38 - Ruído branco incorporado ao sinal senoidal. 69

FIGURA 39 - Decomposição em AMR de um sinal contendo ruído branco. 70

FIGURA 40 - Primeiro detalhe de análise em AMR para: (a) regime permanente, $(b)$ afundamento e $(c)$ elevação de tensão, $(d)$ ruído, (e) oscilações transitórias e $(f)$ interrupção momentânea. 72

FIGURA 41 - Fluxograma descritivo do método classificador desenvolvido. 74

FIGURA 42 - Esquema de janelamento do sinal de entrada para detecção de distúrbios. 76

FIGURA 43 - Exemplo de detecção de um distúrbio. 76

FIGURA 44 - Primeiro (b), segundo (c) e terceiro (d) detalhes de decomposição em AMR de um distúrbio afundamento de tensão (a). 
FIGURA 45 - Exemplo de estimação da amplitude de um afundamento de

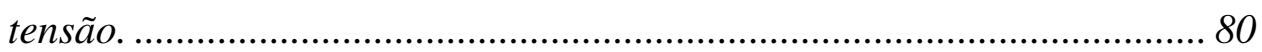

FIGURA 46 - Afundamento de tensão analisado passo a passo.............................. 84

FIGURA 47 - Janela de decomposição em AMR para detecção de um distúrbio.... 85

FIGURA 48 - Elevação de tensão (a) submetida a análise para estimação da duração e seu terceiro detalhe de decomposição em AMR (b)................. 88 


\section{LISTA DE TABELAS}

TABELA 1 - Categorias e características típicas de fenômenos

eletromagnéticos típicos nos sistemas elétricos.

TABELA 2 - Resumo das características dos distúrbios relacionados com a QE.... 30

TABELA 3 - Dados dos transformadores particulares. .......................................... 55

TABELA 4 - Dados dos transformadores de distribuição........................................ 56

TABELA 5 - Afundamentos de tensão obtidos através de simulações no sistema ... 57

TABELA 6 - Elevações de tensão obtidas através de siulações no sistema. 58

TABELA 7 - Interrupções momentâneas geradas através de simulações de faltas...... 58

TABELA 8 - Casos simulados para obtenção de oscilações transitórias 59

TABELA 9 - Detecção de um afundamento de tensão. 84

TABELA 10 - Valores de diff para diferentes distúrbios. 86

TABELA 11 - Análise de distúrbios de frequência similar à do sinal fundamental com inserção a $0^{\circ}$ para classificação e estimação da duração.

TABELA 12 - Análise de distúrbios de frequência similar à do sinal fundamental com inserção a $90^{\circ}$ para classificação e estimação da duração.

TABELA 13 - Análise de distúrbios de frequência superior à do sinal fundamental para a classificação. 


\section{LISTA DE SIGLAS E ABREVIATURAS}

\begin{tabular}{|c|c|}
\hline Afund. & - Afundamento de Tensão \\
\hline AMR & - Análise Multiresolução \\
\hline ANEEL & - Agência Nacional de Energia Elétrica \\
\hline ANSI & - American National Standards Institute \\
\hline ATP & - Alternative Transient Program \\
\hline AWG & - American Wire Gauge \\
\hline $\mathrm{BC}$ & - Banco de Capacitores \\
\hline $\mathrm{CA}$ & - Corrente Alternada \\
\hline $\mathrm{CC}$ & - Corrente Contínua \\
\hline CoifP & - Wavelet Mãe de Coiflets de Ordem P \\
\hline CPFL & - Cia Paulista de Força e Luz \\
\hline CVT & - Constant Voltage Transforms \\
\hline $\mathrm{DbN}$ & - Wavelet Mãe de Daubechies de Ordem N \\
\hline $\mathrm{DC}$ & - Direct Current \\
\hline DEC & - Duração Equivalente de Interrupção por Consumidor \\
\hline Det & - Razão entre as médias de duas janelas de dados \\
\hline $\operatorname{det} 1$ & - Valor médio do sinal contido em uma janela de dados \\
\hline Diff & - Diferença entre energias do sexto detalhe de decomposição \\
\hline $\mathrm{EC}$ & - Erro Cometido \\
\hline ED & - Estimação da Duração \\
\hline Elev. & - Elevação de Tensão \\
\hline EPRI & - Electric Power Research Institute. \\
\hline FEC & - Frequiência Equivalente de Interrupção por Consumidor \\
\hline IEEE & - Institute of Electrical and Electronic Engineering \\
\hline Inter. & - Interrupção de Energia \\
\hline $\mathrm{kV}$ & - Kilo Volts \\
\hline $\mathrm{kVA}$ & - Kilo Volt Ampere \\
\hline $\mathrm{kVAr}$ & - Kilo Volt Ampere Reativo \\
\hline LVQ & - Learning Vector Quantization \\
\hline MCOV & - Tensão de Operação Contínua Máxima \\
\hline
\end{tabular}


MCM - Mil Circular Mil

PLC - Programmable Logic Controller

QE - - Qualidade da Energia

RN $\quad-$ Redes Neurais

RNA $\quad-$ Redes Neurais Artificiais

SEP - Sistema Elétrico de Potência

SF $\quad-$ Série de Fourier

SMES - Super-conducting Magnetic Energy Storage

STFT - Short Time Fourier Transform

SymM - Wavelet Mãe de Symlet de Ordem M

T - - Transformador de Distribuição.

TC - Transformador de Corrente

TF $\quad-$ Transformada de Fourier

TP $\quad-$ Transformador de Potencial

Tp - - Transformador Particular

TQ — - Transformada Quadrática

UPS - Uninterruptible Power Supply

TW - Transformada Wavelet

TWC - Transformada Wavelet Contínua

TWD - - Transformada Wavelet Discreta 


\section{LISTA DE SÍMBOLOS}

a - Fator de escala para a Transformada Wavelet Contínua.

A - Versão de aproximação de um sinal.

$b \quad$ - Fator de translação para a Transformada Wavelet Contínua.

c - Coeficientes de expansão em funções escala.

C - Coeficientes da Transformada Wavelet Contínua.

cA - Versão aproximada de um sinal com operador downsampling.

cD - Versão de detalhes de um sinal com operador downsampling.

Ch - Ponto de Chaveamento.

$\mathrm{C}_{\psi}$ - Constante de proporcionalidade da Transformada Wavelet Inversa.

$d$ - Coeficientes de expansão em funções Wavelets.

D - Versão de detalhes de um sinal.

$\mathrm{h}_{0} \quad$ - Filtro passa baixa.

$\mathrm{h}_{1} \quad$ - Filtro passa alta.

In - Intervalo.

j $\quad$ - Fator de escala relacionado a Análise Multiresolução.

$k \quad$ - Fator de translação relacionado a Análise Multiresolução.

$\mathrm{L}^{2}(\boldsymbol{R})$ - Espaço de Lesbegue.

$m$ - Parâmetro de escala para Transformada Wavelet Discreta.

n $\quad$ - Parâmetro de translação para Transformada Wavelet Discreta.

$t \quad$ - Variável tempo.

$v \quad$ - Espaço encaixante.

$w \quad$ - Espaço de diferenças de $v$.

$x \quad$ - Variável correspondente a tempo ou espaço.

$\varphi \quad$ - Função escala.

$\psi \quad$ - Função Wavelet.

- Módulo de uma função.

|| $\quad$ - Norma de uma função.

$\langle$,$\rangle \quad - Produto Interno.$

$\wedge \quad$ - Transformada de Fourier. 


\section{RESUMO}

ARRUDA, E. F. Análise de Distúrbios Relacionados com a Qualidade da Energia Elétrica Utilizando a Transformada Wavelet. São Carlos, 2003. 114p. Dissertação (Mestrado) - Escola de Engenharia de São Carlos, Universidade de São Paulo.

O presente trabalho visa a utilização da Transformada Wavelet no monitoramento do sistema elétrico no que diz respeito a problemas de Qualidade da Energia com o intuito de detectar, localizar e classificar os mesmos. A Transformada Wavelet tem surgido na literatura como uma nova ferramenta para análise de sinais, utilizando funções chamadas Wavelet mãe para mapear sinais em seu domínio, fornecendo informações simultâneas nos domínios tempo e freqüência. A Transformada Wavelet é realizada através de filtros decompondo-se um dado sinal em Análise Multiresolução. Por esta, obtém-se a detecção e a localização de distúrbios relacionados com a Qualidade da Energia decompondo-se o sinal em dois outros que representam uma versão de detalhes (correspondente as altas frequiências do sinal) e uma versão de aproximação (correspondente as baixas frequiências do sinal). A versão de aproximação é novamente decomposta obtendo-se novos sinais de detalhes e aproximações e assim sucessivamente. Sendo assim, os distúrbios podem ser detectados e localizados no tempo em função do seu conteúdo de freqüência. Estas informações fornecem também características únicas pertinentes a cada distúrbio, permitindo classificá-los. Desta forma, propõe-se neste trabalho o desenvolvimento de um algoritmo classificador automático de distúrbios relacionados com a Qualidade da Energia baseado unicamente nas decomposições obtidas da Análise Multiresolução.

Palavras Chave: Qualidade da Energia, Análise Multiresolução, Transformada Wavelet, Classificação de Distúrbios. 


\begin{abstract}
ARRUDA, E. F. Analysis of Power Quality Disturbances Using Wavelet Transform. São Carlos, 2003. 114p. Dissertação (Mestrado) - Escola de Engenharia de São Carlos, Universidade de São Paulo.
\end{abstract}

The aim of the present dissertation is to apply the Wavelet Transform to analyze Power Quality problems, detecting, localizing and classifying them. The topic Wavelet Transform, has appeared in the literature as a new tool for the analysis of signals, using functions called Mother Wavelet to map signals in its domain, supplying information in the time and frequency domain, simultaneously. Wavelet Transform is accomplished through filters decomposing a provided signal in Multiresolution Analysis. The detection and localization of disturbances are obtained by decomposing a signal into two other signals that represent, a detailed version (high frequency signals) and a smoothed version (low frequency signals). The smoothed version is decomposed again, and new detailed and smoothed signals are obtained. This process is repeated as many times as necessary and the disturbances can be detected and localized in the time as a function of its level frequency. This information also supplies characteristics to each disturbance, allowing classifying them. Thus, this research presents a way to develop an automatic classifying algorithm of Power Quality disturbances, based only on Multiresolution Analysis.

Key Words: Power Quality, Multiresolution Analysis , Wavelet Transform, Classifying Disturbances. 


\section{INTRODUÇÃO}

As situações transitórias em sistemas de potência são comuns e, na prática, podem ser ocasionadas por descargas atmosféricas, correntes inrush de transformadores, faltas sustentadas, correntes de partida de grandes motores, ou ainda pelos efeitos de chaveamentos de capacitores.

Estes distúrbios que ocorrem nos sistemas, podem provocar inúmeras interferências indesejáveis como acionamento indevido de relés, mau funcionamento de equipamentos sensíveis, distorções em equipamentos de medição, podendo chegar até mesmo à interrupção do fornecimento de energia. Tudo isto resulta em um efeito econômico não desprezível, acarretando prejuízos tanto às concessionárias como aos consumidores. Atualmente, com uma maior utilização de equipamentos eletrônicos, exige-se cada vez mais a qualidade no sinal entregue pela concessionária.

Uma etapa importante desta questão é definir o que seria então um problema de Qualidade da Energia (QE). Entre muitos apontamentos da literatura DUGAN et al. [1] dizem que se pode classificar o assunto como qualquer problema manifestado na tensão, corrente ou desvio de frequiência, que resulte em falha ou má operação dos equipamentos de consumidores.

Atualmente, a QE é avaliada pela concessionária e órgãos governamentais através de equipamentos que medem índices específicos, como DEC (Duração Equivalente de Interrupção por Unidade Consumidora) e DRP (Duração Relativa da Transgressão de Tensão Precária), cujas definições se encontram nas Resoluções Nos 24 e 505 da Agência Nacional de Energia Elétrica - ANEEL [2] e [3], respectivamente. No entanto, estes índices estão relacionados somente com o intervalo de tempo em que o sistema permanece desligado e a freqüência de tais desligamentos. Sendo assim, estes não detectam certas alterações nas formas de onda 
e na freqüência que são, na maioria das vezes, causadas por ruídos, distorções harmônicas, certas condições de falta e chaveamento de capacitores que podem acarretar em problemas operacionais dos equipamentos.

Na década de 80, os problemas causados pela má qualidade no fornecimento da energia não eram tão expressivos, visto que, os equipamentos existentes eram pouco sensíveis aos efeitos dos fenômenos ocorridos [4]. Entretanto, com o desenvolvimento tecnológico, principalmente da eletrônica, consumidores e concessionárias de energia elétrica têm se preocupado muito com a qualidade da energia. Isto se justifica, principalmente, pelos seguintes motivos como exposto em [1]:

- Os equipamentos atualmente utilizados são mais sensíveis às variações nas formas de onda de energia fornecidas. Muitos deles possuem controles baseados em microprocessadores e dispositivos eletrônicos sensíveis a muitos tipos de distúrbios;

- O crescente interesse pela racionalização e conservação da energia elétrica, com vistas a otimizar a sua utilização, tem aumentado o uso de equipamentos que, em muitos casos, aumentam os níveis de distorções harmônicas e podem levar o sistema a condições de ressonância;

- Maior conscientização dos consumidores em relação aos fenômenos ligados à $\mathrm{QE}$, visto que os mesmos, estão se tornando mais informados a respeito de fenômenos como interrupções, subtensões, transitórios de chaveamentos, etc., passando a exigir que as concessionárias melhorem a qualidade da energia fornecida;

- A crescente integração dos processos, significando que a falha de qualquer componente traz conseqüências ainda mais importantes para o sistema elétrico;

- As consequiências resultantes de variações nas formas de onda sobre a vida útil dos componentes elétricos.

Para exemplificar os impactos econômicos da QE, a Figura 1 extraída da referência [5] mostra os custos associados a interrupções elétricas com duração de até 1 minuto para diferentes setores econômicos. 


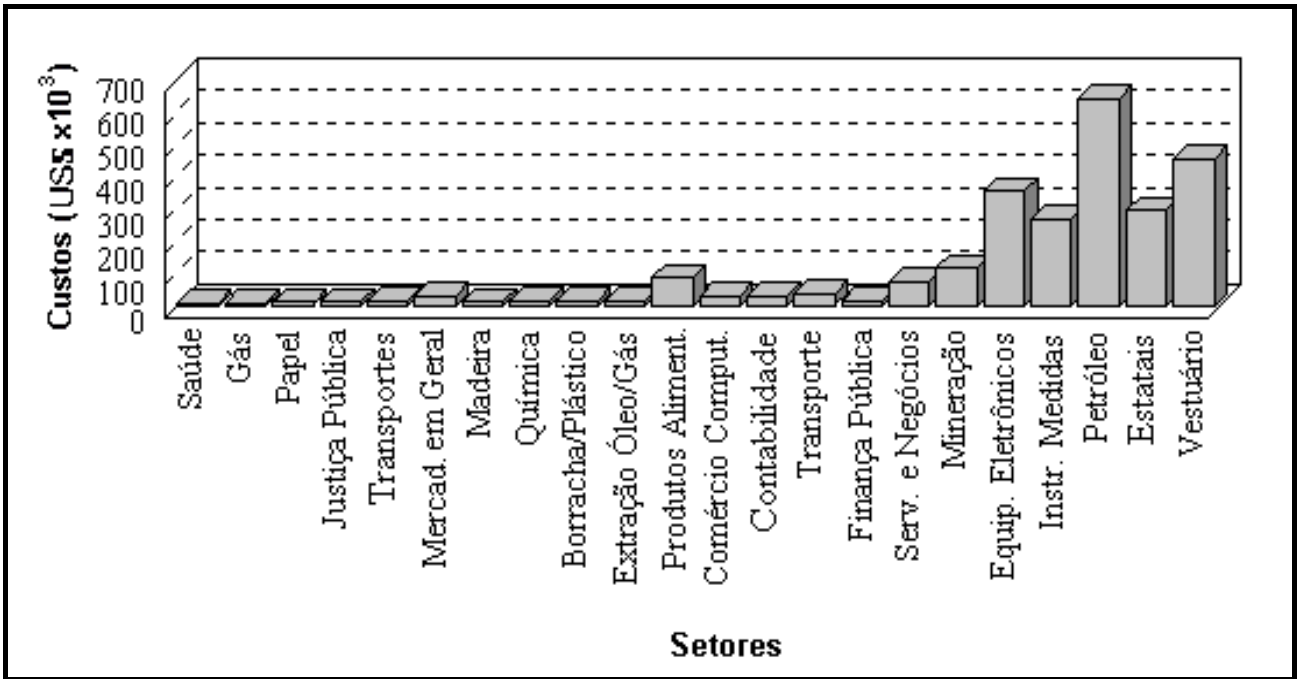

FIGURA 1 - Custo estimado resultante de Interrupção de até 1 min.

Para avaliar o quanto um sistema está operando fora de suas condições normais, duas grandezas elétricas básicas, tensão e freqüência, podem ser empregadas. A freqüência em um sistema interligado situa-se na faixa de $60 \pm 0,5 \mathrm{~Hz}$. Por outro lado, com relação à tensão, três características principais devem ser observadas:

- a forma de onda, a qual deve ser o mais próxima possível da forma senoidal;

- a simetria do sistema elétrico; e

- as magnitudes das tensões dentro de limites aceitáveis.

Entretanto, existem alguns fenômenos, aleatórios ou intrínsecos, que ocorrem no sistema elétrico causando alterações nos aspectos supracitados, deteriorando a qualidade do fornecimento da energia elétrica. Sendo assim, são utilizados métodos de análise de tais distúrbios, com o intuito de conhecê-los, permitindo-se entender a causa destes.

Técnicas utilizando ferramentas poderosas que possuem a capacidade para análise simultânea nos domínios do tempo e da frequiência têm sido desenvolvidas para a análise de fenômenos relacionados com a QE. A Transformada Wavelet (TW) é uma ferramenta que possui esta capacidade. Além do mais, a decomposição de um sinal em Análise Multiresolução (AMR) fornece valiosas informações para detecção, 
localização e classificação de diferentes distúrbios relacionados com a QE. Assim, a TW tem sido proposta na literatura como uma nova técnica para monitorar problemas relacionados à QE. A maioria destes trabalhos se desenvolvem em métodos para detecção, localização e classificação de distúrbios ou compressão de dados.

Este trabalho traz a utilização da técnica de decomposição de um sinal em AMR para o desenvolvimento de um algoritmo que analise automaticamente distúrbios relacionados com a QE. Tal técnica, que será melhor descrita no Capítulo 4, decompõe recursivamente um sinal em dois outros que correspondem aos conteúdos de baixa (versão de aproximação) e alta freqüências (detalhes). O sinal correspondente ao conteúdo de baixa frequiência é novamente submetido ao processo de decomposição gerando dois outros novos sinais. Desta forma, pode-se obter características inerentes a cada tipo de distúrbio, podendo-se detectar, localizar e classificar cada evento.

A detecção do distúrbio é realizada utilizando-se o componente de decomposição que corresponde às mais altas frequiências do sinal (primeiro detalhe). Uma janela fixa contendo 1 ciclo de amostras percorre todo o sinal com um passo correspondente à metade do tamanho da janela ( $1 / 2$ ciclo). Desta forma o primeiro detalhe do sinal de entrada é comparado com um sinal de referência onde variações indicam a presença de um distúrbio. Nesta mesma etapa do algoritmo, o distúrbio é também localizado no tempo, onde o mesmo parâmetro utilizado para detecção do distúrbio indica o tempo em que o distúrbio ocorreu.

Uma vez que um distúrbio foi detectado no sinal de entrada, uma janela contendo informações tanto de pré quanto de pós distúrbio é utilizada para a classificação. Inicialmente os distúrbios são divididos, utilizando-se a energia do sexto detalhe de decomposição, em dois grupos: distúrbios com frequência similar e distúrbios com frequência superior à frequência do sinal em regime. A técnica utilizada para a divisão dos fenômenos nestes grupos possibilita classificar diretamente os distúrbios afundamento de tensão, elevação de tensão e interrupção de energia.

Uma vez que variações no nível de energia do sexto detalhe são detectadas, o algoritmo colhe informações nos primeiros níveis de decomposição de forma a 
estimar os instantes de início e fim do distúrbio. Após isso, a quinta versão de aproximação é usada para estimar a amplitude do distúrbio. Tal versão de aproximação é utilizada por conter por completo o componente fundamental, tendo sido extraído componentes de altas freqüências que poderiam apresentar estimativas errôneas.

Um outro ramo de análise do algoritmo se desenvolve para o caso em que a análise do sexto detalhe não apresenta variações capazes de indicar a presença de distúrbios de afundamento ou de elevação de tensão ou interrupção de energia. Neste caso, o algoritmo utiliza informações dos primeiros detalhes para a classificação dos distúrbios de oscilações transitórias e ruídos.

\subsection{Organização do Trabalho}

No Capítulo 2 denominado “A Qualidade da Energia Elétrica”, são definidos vários distúrbios relacionados com a QE. A origem de tais distúrbios é também apresentada, bem como medidas para diminuir seus efeitos ou até mesmo eliminá-los.

Um "Levantamento Bibliográfico" sobre a utilização da TW em análise de QE é apresentada no Capítulo 3. Tal levantamento bibliográfico delineia as tendências científicas no que tange a análise de distúrbios relacionados com a QE.

A TW é apresentada no Capítulo 4 sendo apresentada nas formas: Transformada Wavelet Contínua (TWC) e Transformada Wavelet Discreta (TWD), que forma a base teórica para a técnica de AMR que é também descrita neste Capítulo.

O Capítulo 5 compreende a simulação de um Sistema Elétrico de Distribuição em situações típicas de origem de distúrbios relacionados com a QE. Tal simulação é feita utilizando-se o software ATP (Alternative Transient Program) que constitui uma ferramenta poderosa para este fim. É apresentado, também, um estudo referente à escolha de uma função base (Wavelet mãe) que se adeque aos estudos da QE. Ainda neste Capítulo, são analisados distúrbios relacionados com a QE submetidos à AMR, indicando a capacidade de tal técnica no estudo almejado.

Um algoritmo classificador automático é apresentado no Capítulo 6. Tal algoritmo baseia-se unicamente nas decomposições de um dado sinal em AMR. 
Estas decomposições extraem características únicas dos diferentes distúrbios, permitindo diferenciá-los.

Resultados da submissão dos eventos gerados usando-se o sistema simulado ao algoritmo classificador, são apresentados no Capítulo 7, e no Capítulo 8, são apresentados os comentários e conclusões finais com respeito ao algoritmo desenvolvido. 


\section{A QUALIDADE DA ENERGIA ELÉTRICA}

Este Capítulo visa apresentar a definição de alguns dos fenômenos elétricos relacionados com a Qualidade da Energia, bem como as suas origens, consequiências e sugestões para a mitigação destes.

Os fenômenos elétricos podem ser divididos em categorias de acordo com o seu tempo de duração, seu conteúdo espectral, bem como sua amplitude típica no sistema. Seguindo estes princípios, os diferentes distúrbios são subdivididos ao longo deste Capítulo em transitórios, variações de tensão de curta duração, variações de tensão de longa duração, desequilíbrio de tensão, distorções na forma de onda, flutuação de tensão e variações da frequência do sistema.

\subsection{Fenômenos Elétricos Transitórios Relacionados com a QE}

Entende-se por transitórios eletromagnéticos as manifestações ou respostas elétricas locais ou nas adjacências, oriundas de alterações súbitas nas condições operacionais de um sistema de energia elétrica. Geralmente, a duração de um transitório é muito pequena, mas de grande importância, uma vez que os equipamentos presentes nos sistemas elétricos estarão submetidos a grandes solicitações de tensão e/ou corrente [1].

Os fenômenos transitórios podem ser classificados em dois grupos: os chamados transitórios impulsivos, causados por descargas atmosféricas, e os transitórios oscilatórios, causados por chaveamentos. 


\subsubsection{Transitórios Impulsivos}

Normalmente causado por descargas atmosféricas, um transitório impulsivo pode ser definido como uma alteração repentina nas condições de regime permanente da tensão, corrente ou ambas, caracterizando-se por apresentar impulsos unidirecionais em polaridade (positivo ou negativo) e nível de freqüência bastante diferenciado com relação à freqüência da rede elétrica [1]. A Figura 2, extraída de [1], ilustra uma corrente típica de um transitório impulsivo, oriundo de uma descarga atmosférica.

Os transitórios impulsivos geralmente são definidos por um tempo de subida e outro de descida do impulso, os quais, também, podem ser expressos pelo seu conteúdo espectral. Para exemplificar, um impulso transitório tendo como parâmetros 1,2 × $50 \mu$ s e $2000 \mathrm{~V}$, o que significa que o mesmo atinge seu valor máximo de $2000 \mathrm{~V}$ em um tempo de $1,2 \mu \mathrm{s}$ e, posteriormente, decai até a metade de seu valor máximo no tempo de $50 \mu$ s.

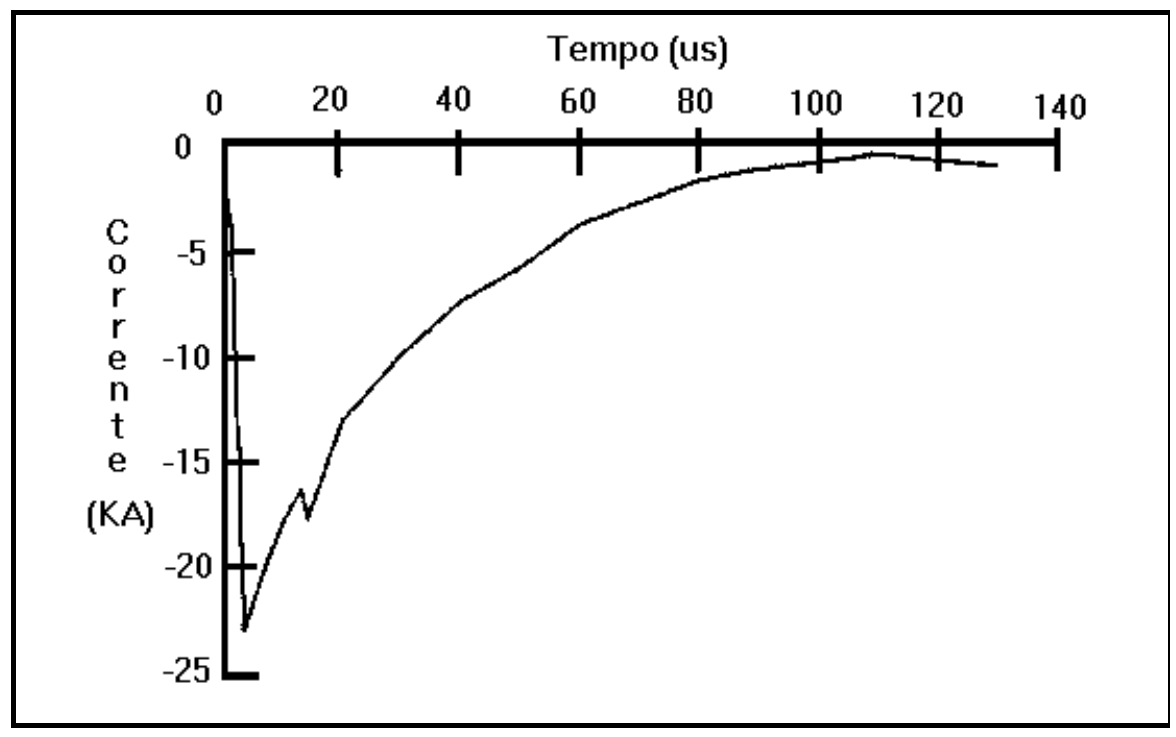

FIGURA 2 - Corrente transitória impulsiva oriunda de uma descarga atmosférica

Por se tratarem de transitórios causados por descargas atmosféricas, é de fundamental importância observar qual o nível da tensão no ponto de ocorrência da descarga. Em sistemas de distribuição o caminho mais provável para as descargas atmosféricas é através de um condutor fase, no primário ou no secundário, causando altas sobretensões no sistema. Uma descarga diretamente na fase geralmente causa 
alta sobretensão na linha próxima ao ponto de incidência e pode gerar não somente um transitório impulsivo, mas também uma falta acompanhada de afundamentos de tensão de curta duração e interrupções. Altas sobretensões transitórias podem também ser geradas por descargas que fluem ao longo do condutor terra. Existem numerosos caminhos através dos quais as correntes de descarga podem penetrar no sistema de aterramento, tais como o terra do primário ou do secundário de um transformador e as estruturas do sistema de distribuição. Os principais problemas relacionados com a QE causados por estas correntes no sistema de aterramento são os seguintes:

- Considerável elevação do potencial do terra local em relação a outros terras. Equipamentos eletrônicos sensíveis que são conectados entre duas referências de terra, tal como um computador conectado ao telefone através de um modem, podem falhar quando submetidos a altos níveis de tensão.

- Indução de altas tensões nos condutores fase, quando as correntes passam pelos cabos a caminho do terra.

Em se tratando de descargas em pontos de extra alta tensão, o surto se propaga ao longo da linha em direção aos seus terminais podendo atingir os equipamentos instalados em subestações de manobra ou estações abaixadoras. Entretanto, a onda de tensão ao percorrer a linha, desde o ponto de incidência até as subestações abaixadoras para a tensão de distribuição, tem a sua crista atenuada consideravelmente, o que tende a eliminar os efeitos advindos de descargas atmosféricas ocorridas em nível de transmissão, em consumidores ligados em nível de baixa tensão. Contudo, os consumidores atendidos em tensão de transmissão, e supostamente localizados nas proximidades do ponto de descarga, estarão sujeitos a tais efeitos, podendo danificar alguns equipamentos de suas respectivas instalações [5].

\subsubsection{Transitórios Oscilatórios}

Um transitório oscilatório é caracterizado por uma alteração repentina nas condições de regime permanente da tensão e/ou corrente possuindo valores de polaridade 
positiva e negativa. Os tipos de transitórios oscilatórios podem ser definidos em função do conteúdo espectral, duração e magnitude da tensão. Estes transitórios são decorrentes da energização de linhas, corte de corrente indutiva, eliminação de faltas, chaveamento de bancos de capacitores e transformadores, etc..

Os transitórios oscilatórios de baixa freqüência são freqüentemente encontrados em sistemas de subtransmissão e distribuição e são causados por vários tipos de eventos. O mais freqüente é a energização de bancos de capacitores, o qual geralmente resulta em oscilações de tensão com freqüência entre 300 e 900Hz, com magnitude máxima por volta de 2,0 pu, sendo valores típicos de 1,3 a 1,5 pu com uma duração entre 0,5 e 3 ciclos dependendo das características de amortecimento do sistema [1]. A Figura 3 ilustra o resultado da simulação da energização de um banco de 600 kVAr e tensão de 13,8 kV.

Considerando o crescente emprego de capacitores pelas concessionárias para a manutenção dos níveis de tensão, e pelas indústrias com vistas à correção do fator de potência, tem-se tido uma preocupação especial no que se refere à possibilidade de se estabelecer uma condição de ressonância. Tal condição pode ser satisfeita devido às oscilações de altas freqüências, entre o sistema da concessionária e a indústria, e assim ocorrer uma amplificação das tensões transitórias, bem superiores às citadas anteriormente, podendo, tais tensões atingir níveis de 3 a 4 pu.

Transitórios oscilatórios com freqüências menores do que $300 \mathrm{~Hz}$ podem também ser encontrados nos sistemas de distribuição. Estes estão, geralmente, associados aos fenômenos de ferroressonância e energização de transformadores.

Os transitórios oscilatórios de alta frequiência são geralmente o resultado de uma resposta do sistema a um transitório impulsivo, isto é, podem ser causados por descargas atmosféricas ou por chaveamento de circuitos indutivos [1].

A desenergização de cargas indutivas pode gerar impulsos de alta frequiência. Apesar de serem de curta duração, estes transitórios podem interferir na operação de cargas eletrônicas. Filtros de alta-frequiência e transformadores isoladores podem ser usados para proteger as cargas contra este tipo de transitório. 


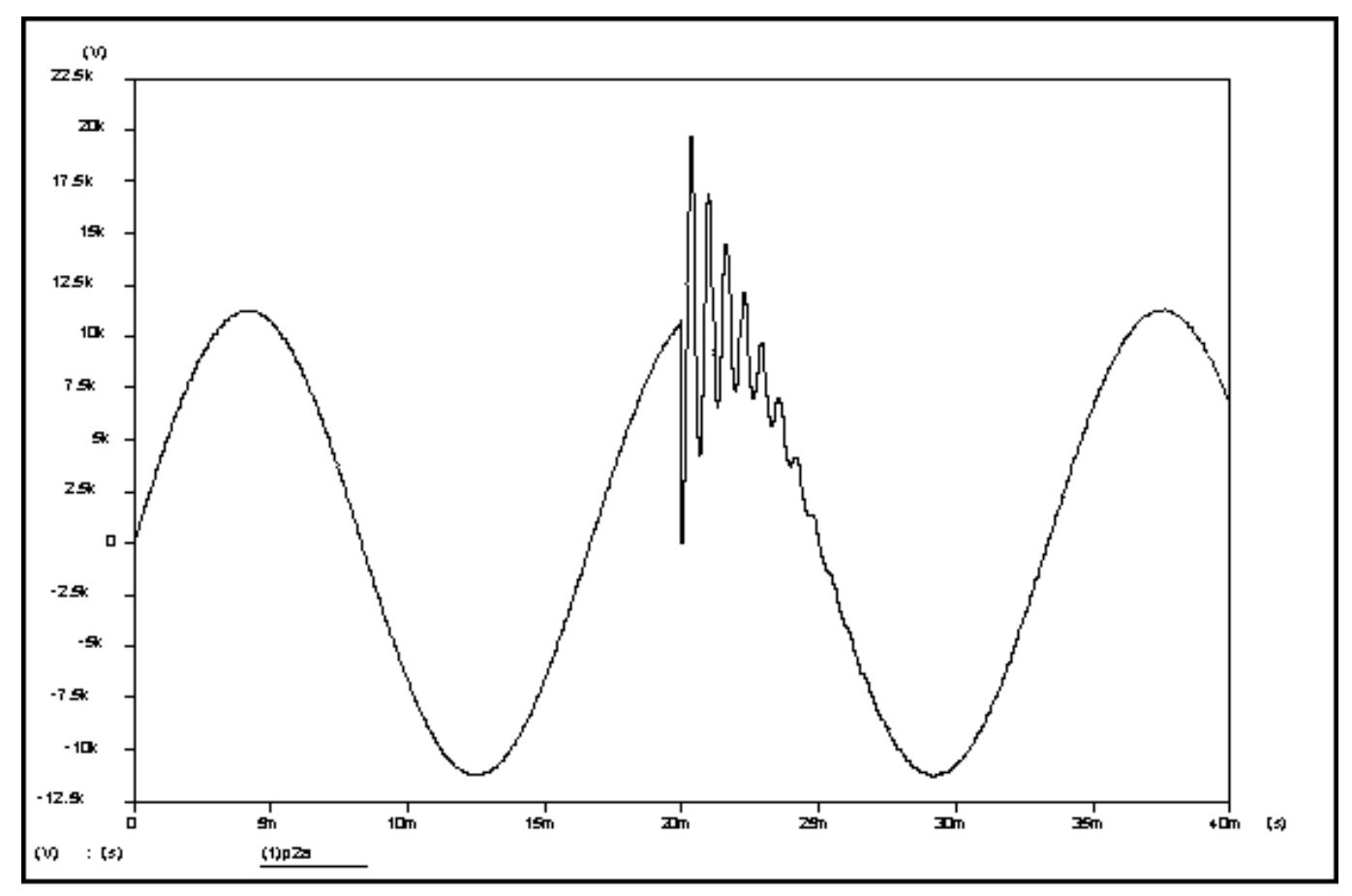

FIGURA 3 - Transitório proveniente do chaveamento de um banco de capacitores (600 KVAr, 13,8KV).

Conforme apresentado, existem diferentes meios causadores de oscilações transitórias e algumas técnicas podem ser utilizadas na tentativa de se reduzir os níveis dos transitórios causados, seja por chaveamentos ou por descargas atmosféricas. Como por exemplo os transitórios oriundos de surtos de chaveamento em redes de distribuição, podem ter seu grau de incidência e magnitudes reduzidas através de uma reavaliação das filosofias de proteção e investimentos para melhorias nas redes. Esta medida visa o aumento da capacidade da rede evitando que bancos de capacitores venham a ser exigidos [5].

\subsection{Variações de Tensão de Curta Duração Relacionadas com a $Q E$}

As variações de tensão de curta duração podem ser caracterizadas por alterações instantâneas, momentâneas ou temporárias, dependendo da duração. Tais variações de tensão são, geralmente, causadas por condições de falta, energização de grandes cargas as quais requerem altas correntes de partida ou por intermitentes falhas nas conexões de cabos do sistema. Dependendo do local da falta e das condições do 
sistema, a falta pode causar tanto um afundamento de tensão temporário, como uma elevação de tensão, ou ainda uma interrupção completa do sistema elétrico [1].

\subsubsection{Interrupção}

Uma interrupção de curta duração ocorre quando a tensão de suprimento decresce para um valor menor que 0,1 pu por um período de tempo não superior a 1 minuto [6].

Este tipo de interrupção pode ser causado por faltas no sistema de energia, falhas de equipamentos e mal funcionamento de sistemas de controle. A duração de uma interrupção, devido a uma falta no sistema da concessionária, é determinada pelo tempo de operação dos dispositivos de proteção. Religadores programados para operar instantaneamente, geralmente limitam a interrupção a tempos inferiores a 30 ciclos. Religadores temporizados podem originar interrupções momentâneas ou temporárias, dependendo da escolha das curvas de operação do equipamento [5].

Algumas interrupções podem ser precedidas por um afundamento de tensão quando estas são devidas a faltas no sistema supridor. $O$ afundamento de tensão ocorre no período de tempo entre o início de uma falta e a operação do dispositivo de proteção do sistema. A Figura 4 exemplifica uma interrupção momentânea sendo precedida por um afundamento de tensão. Observa-se que a tensão cai para um valor de $20 \%$, com duração de 3 ciclos e, logo após, ocorre a perda total do suprimento.

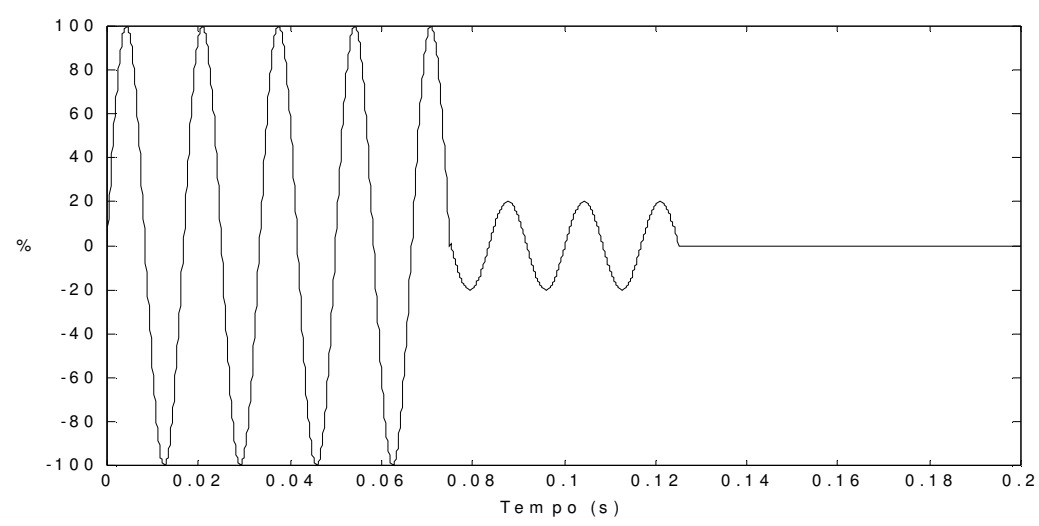

FIGURA 4 - Interrupção momentânea devido a um curto-circuito e subseqüente religamento. 


\subsubsection{Afundamento de tensão de Curta Duração}

Os afundamentos de tensão de curta duração são caracterizados por uma redução no valor eficaz da tensão, entre 0,1 e 0,9 pu, na freqüência fundamental, com duração entre 0,5 ciclo e 1 minuto [6]. Detalhes mais aprofundados para os afundamentos de tensão podem ser encontrados na referência [7].

Afundamentos de tensão com período inferior a $10 \mathrm{~ms}$ e abaixo de $10 \%$ não são levadas em consideração. Isto se explica pelo fato de que os distúrbios com período de duração abaixo de 10ms são considerados como transitórios e, quedas de tensão de curta duração menores que $10 \%$ são toleradas pela maioria dos equipamentos elétricos.

Este tipo de distúrbio está associado, principalmente, a curtos-circuitos ocorridos nas redes de distribuição. Mas pode também ser causado pela energização de grandes cargas, partida de grandes motores e pela corrente inrush de um transformador [5].

A Figura 5 ilustra um afundamento de tensão de curta duração típico, causada por uma falta fase-terra [1]. Observa-se um decréscimo de $80 \%$ na tensão por um período de aproximadamente 3 ciclos, até que o equipamento de proteção da subestação opere e elimine a corrente de falta. Neste caso o afundamento de tensão é dito ser de caráter instantâneo. Entretanto, as características do afundamento de tensão diante de uma determinada falta depende de vários fatores como: a natureza da falta, sua posição relativa a outros consumidores ligados na rede e o tipo de filosofia de proteção adotada no sistema.

Para ilustrar o afundamento de tensão causado pela partida de um motor de indução tem-se a Figura 6 [1], que apresenta o decréscimo no valor eficaz da tensão. Durante a partida de um motor de indução, este absorve uma corrente de 6 a 10 vezes a corrente nominal, resultando em uma queda significativa na tensão de suprimento. Observa-se neste caso, que a tensão, apresentada em seu valor eficaz, cai rapidamente para 0,8 pu e, num período de aproximadamente 3 segundos, retorna ao seu valor nominal [1]. 


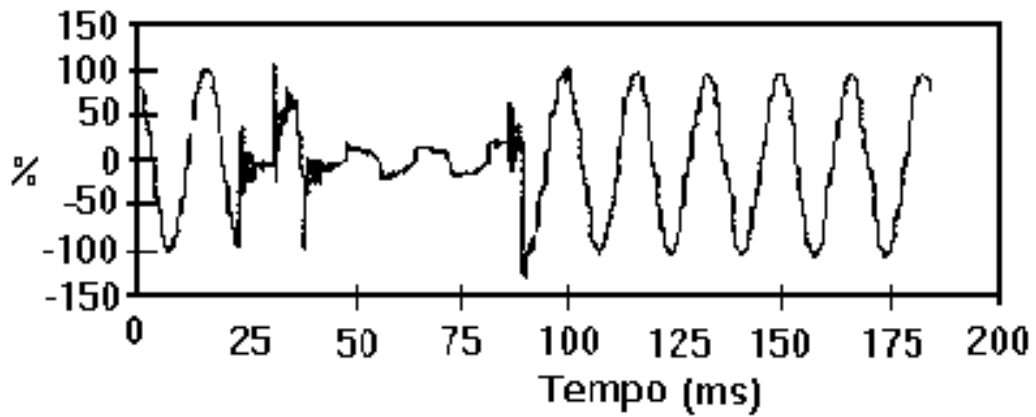

FIGURA 5 - Afundamento de tensão causado por uma falta fase-terra.

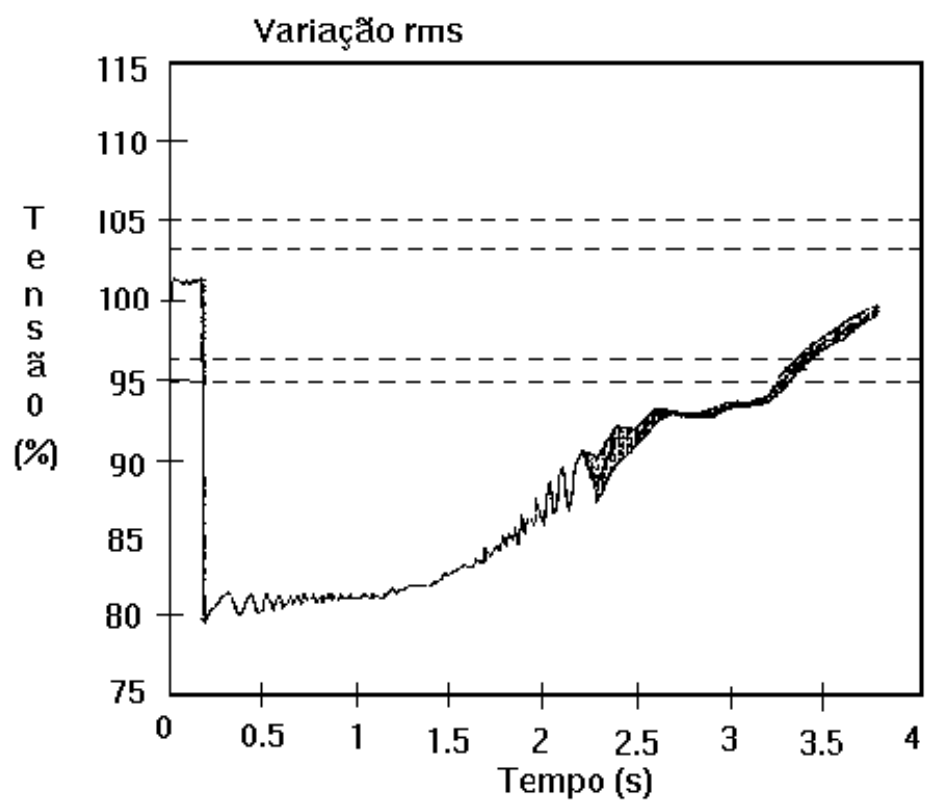

FIGURA 6 - Decréscimo de tensão ocorrido pela partida de um motor.

Como efeito deste distúrbio tem-se principalmente a má operação de equipamentos eletrônicos, em especial os sistemas computadorizados, que tem sido alvo de preocupações em órgãos de pesquisa em QE. Entretanto, determinar os níveis de sensibilidade de tais equipamentos torna-se uma tarefa difícil, devido ao grande número de medições necessárias para a coleta de dados além das dificuldades de se ter equipamentos de medição em condições reais de campo.

Sendo os computadores uma fonte de preocupação no que se refere aos afundamentos de tensão, uma vez que os dados armazenados na memória podem ser totalmente perdidos em condições de subtensões indesejáveis, foi estabelecido pela ANSI/IEEE (American National Standards Institute/Institute of Electrical and 
Electronic Engineering), limites de tolerância relativos a distúrbios no sistema elétrico. Estes trabalhos conduziram à Figura 7, onde os níveis de tensão abaixo, ou acima do valor nominal representam os limites dentro dos quais um computador típico pode resistir a distúrbios de afundamentos ou elevações de tensão sem apresentar falhas. Nota-se que a sensibilidade de um computador é grandemente dependente do período de duração do distúrbio.

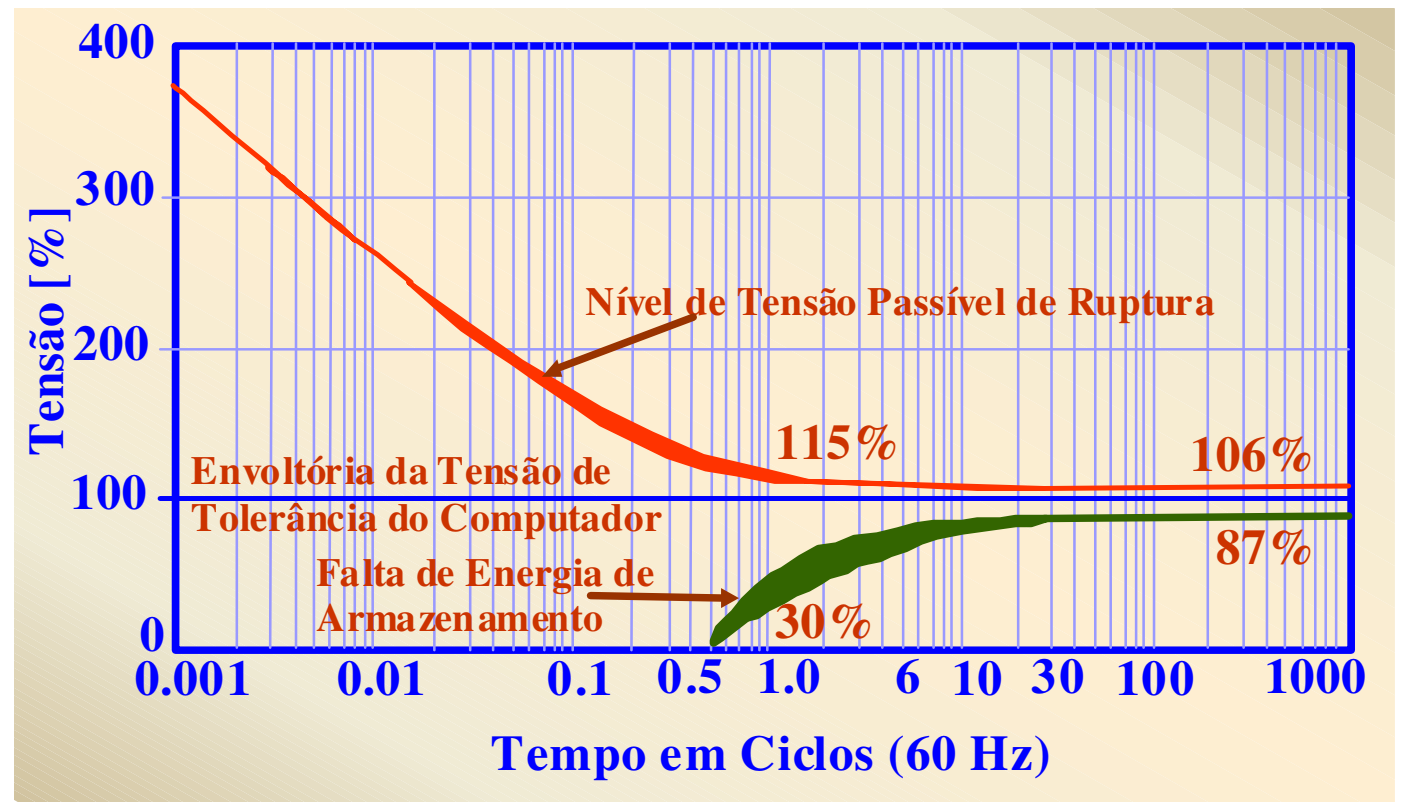

FIGURA 7 - Tolerâncias típicas de tensão para computadores (curva CBEMA).

Existem várias medidas que podem ser tomadas por parte de consumidores, concessionárias e fabricantes de equipamentos no sentido de diminuir o número e a severidade dos afundamentos de tensão de curta duração. Algumas destas medidas são [1]:

- Utilização de transformadores ferroressonantes, conhecidos também como CVT's (Constant Voltage Transformers).

Este equipamento pode controlar a maioria das condições de afundamento de tensão. São utilizados especialmente para cargas com potências constantes e de pequenos valores. Transformadores ferroressonantes são basicamente transformadores de relação de transformação $1: 1$, altamente excitados em suas curvas de saturação, fornecendo assim uma tensão de saída que não é significativamente afetada pelas variações da tensão de entrada. 
- Utilização de UPS's (Uninterruptible Power Supply).

Os tipos básicos de UPS's fundamentam-se nas operações on-line e standby. Estes dispositivos podem ser usados para períodos de interrupção acima de 15 minutos de duração. A UPS híbrida, que corresponde a uma variação da UPS standby, também pode ser usada para interrupções de longa duração.

- Utilização de conjuntos motor-gerador (M-G).

Estes conjuntos existem em uma grande variedade de potências e configurações. Este é capaz de suprir uma saída constante. A inércia do volante faz com que o rotor do gerador mantenha a rotação caso ocorra a falta de energia.

- Utilização de um dispositivo magnético supercondutor de armazenamento de energia.

Este dispositivo utiliza um magneto supercondutor para armazenar energia da mesma forma que uma UPS utiliza baterias. Os projetos na faixa de 1 a $5 \mathrm{MJ}$ são chamados de micro-SMES (Superconducting magnetic energy storage). A principal vantagem deles é a grande redução do espaço físico necessário ao magneto, quando esta solução é comparada ao espaço para as baterias. Os projetos iniciais dos micro-SMES estão sendo testados em vários locais nos EUA com resultados favoráveis [5].

- Utilização de métodos de partida de motores.

Dentre os mais utilizados pode-se citar os seguintes métodos de partida:

- Partida suave (Soft Started);

- Partida por meio de autotransformadores;

- Partida por meio de resistência e reatância;

- Partida por meio de enrolamento parcial;

- Partida pelo método estrela-triângulo.

- Melhorar as práticas para o restabelecimento do sistema da concessionária em caso de faltas.

Isto implica em adicionar religadores de linha, eliminar as operações rápidas de religadores e/ou disjuntores, adicionar sistemas do tipo Network e melhorar o projeto do alimentador. Estas práticas podem reduzir o número e/ou a duração de interrupções momentâneas e afundamentos de tensão, mas 
não podem garantir por completo a eliminação das faltas nos sistemas das concessionárias.

- Adotar medidas de prevenção contra faltas no sistema da concessionária.

Estas medidas incluem atividades como poda de árvores, colocar pára-raios de linha, manutenção dos isoladores, blindagem de cabos, modificar o espaçamento entre condutores e melhorar o sistema de aterramento.

\subsubsection{Elevação de tensão de Curta Duração}

Uma elevação de tensão de curta duração é definida como um aumento entre $1,1 \mathrm{e}$ 1,8 pu na tensão eficaz, considerando-se a freqüência do sistema, com duração entre 0,5 ciclo a 1 minuto [6].

Assim como os afundamentos de tensão, as elevações de tensão estão geralmente associadas com as condições de falta no sistema, principalmente no que diz respeito ao curto-circuito fase-terra, visto que nestas condições as fases não defeituosas experimentam uma elevação de tensão. Esta elevação de tensão pode atingir num sistema a 4 fios multi-aterrado, valores próximos a 1,25 pu [5]. Este fenômeno pode também estar associado à saída de grandes blocos de cargas ou à energização de grandes bancos de capacitores, porém, com uma incidência pequena se comparada com as sobretensões provenientes de faltas fase-terra nas redes de transmissão e distribuição [1]. A Figura 8 ilustra uma elevação de tensão típica, que poderia ser causada por uma falta fase-terra.

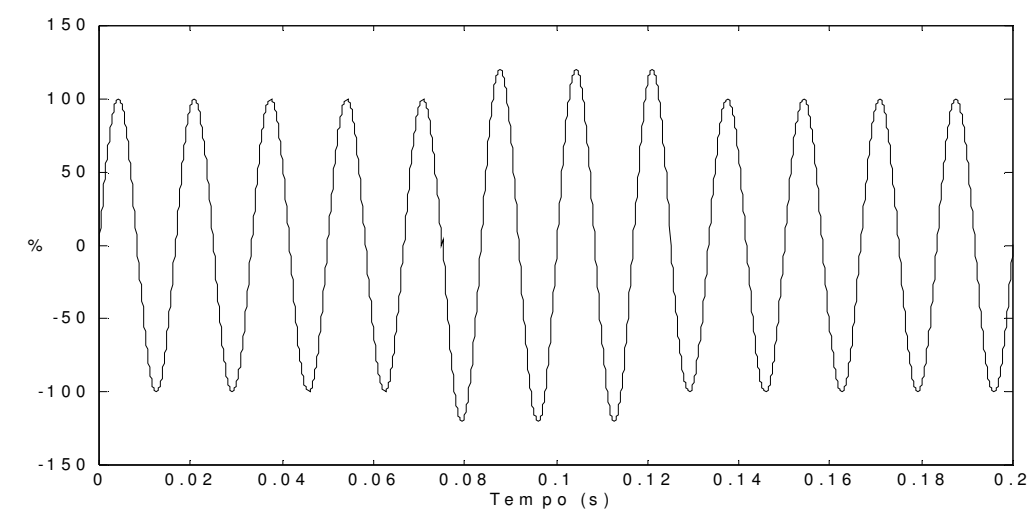

FIGURA 8 - Elevação de tensão devido a uma falta fase-terra. 
A severidade de uma elevação de tensão durante uma condição de falta é função do local da falta, da impedância do sistema e do aterramento. A duração da elevação de tensão está intimamente ligada aos ajustes dos dispositivos de proteção, à natureza da falta (permanente ou temporária) e à sua localização na rede elétrica. Em situações de elevação de tensão oriundas de saídas de grandes cargas ou energização de grandes bancos de capacitores, o tempo de duração das sobretensões depende da resposta dos dispositivos reguladores de tensão das unidades geradoras, do tempo de resposta dos transformadores de tap variável e da atuação dos dispositivos compensadores que porventura existam no sistema [1].

Dependendo da freqüência de ocorrência do distúrbio pode-se ter como consequiência das elevações de tensão de curta duração em equipamentos, falhas dos componentes. Dispositivos eletrônicos incluindo computadores e controladores eletrônicos, podem apresentar falhas imediatas durante uma condição de elevação de tensão. Já os transformadores, cabos, barramentos, dispositivos de chaveamento, Transformadores de Potencial (TP's), Transformadores de Correntes (TC's) e máquinas rotativas podem ter sua vida útil reduzida. Um aumento na tensão em um período de curta duração em alguns relés pode resultar em má operação dos mesmos, enquanto outros podem não ser afetados. Uma elevação de tensão em um banco de capacitores pode causar danos ao equipamento. Aparelhos de iluminação podem ter um aumento da luminosidade e dispositivos de proteção contra surto, podem ser destruídos quando submetidos a elevações de tensão que excedam suas taxas de MCOV (Maximum Continuous Overvoltage) [1].

Dentro do exposto, a preocupação principal recai sobre os equipamentos eletrônicos, uma vez que estas elevações de tensão podem danificar os componentes internos destes equipamentos, conduzindo-os à má operação, ou em casos extremos, à completa inutilização. Vale ressaltar mais uma vez que, a resistência a distúrbios de um equipamento não depende apenas da magnitude da elevação de tensão, mas também do seu período de duração, conforme ilustra a Figura 7, a qual mostra a tolerância de microcomputadores às variações de tensão.

Diante de tais problemas causados por elevações de tensão de curta duração, este distúrbio sugere que seja mantida uma atenção por parte de consumidores, 
fabricantes e concessionárias, no intuito de eliminar ou reduzir as consequiências oriundas deste fenômeno.

\subsection{Variações de Tensão de Longa Duração}

As variações de tensão de longa duração podem ser caracterizadas como desvios que ocorrem no valor eficaz da tensão, na freqüência do sistema, com duração superior a 1 minuto [1]. Atualmente, índices que caracterizam variações de tensão de longa duração encontram-se definidos na Resolução 505 da ANEEL [3].

Estas variações de tensão podem se dar como afundamentos de tensão, elevações de tensão ou interrupções sustentadas. Todas elas são geralmente causadas por variações de carga e operações de chaveamento no sistema [5].

\subsubsection{Interrupções Sustentadas}

Quando a tensão de suprimento permanece em zero por um período de tempo superior a 1 minuto, a variação de tensão de longa duração é considerada uma interrupção sustentada. Interrupções de tensão por um tempo superior a 1 minuto são freqüentemente permanentes e requerem a intervenção da concessionária para reparar o sistema e restaurar o fornecimento de energia [1].

As interrupções sustentadas podem ocorrer devido à manutenção programada ou não. A maioria delas ocorrem de forma não programada e as principais causas são falhas nos disjuntores, queima de fusíveis, falha de componentes de circuito alimentador, etc.. Já o outro caso de interrupção sustentada, ocorre geralmente para executar a manutenção da rede, ou seja, serviços como troca de cabos e postes, mudança do tap do transformador, alteração dos ajustes de equipamentos de proteção, etc..

Seja a interrupção de natureza sustentada ou inesperada, o sistema elétrico deve ser projetado e operado de forma a garantir que:

- O número de interrupções seja mínimo;

- Uma interrupção dure o mínimo possível e

- O número de consumidores afetados seja pequeno. 
A conseqüência de uma interrupção sustentada é o desligamento dos equipamentos, exceto para aquelas cargas protegidas por sistemas no-breaks ou por outras formas de armazenamento de energia.

\subsubsection{Afundamentos de Tensão Sustentados}

Um afundamento de tensão é caracterizado por um decréscimo no valor eficaz da tensão a valores menores que 0,9 pu, considerando-se a freqüência do sistema, e com período de duração maior que 1 minuto [1].

Os afundamentos de tensão são decorrentes principalmente do carregamento excessivo dos circuitos alimentadores, os quais são submetidos a determinados níveis de corrente que, interagindo com a impedância da rede, dão origem a quedas de tensão acentuadas. Outros fatores que contribuem para as subtensões são: a conexão de cargas à rede elétrica, o desligamento de bancos de capacitores e, conseqüentemente, o excesso de reativo transportado pelos circuitos de distribuição, o que limita a capacidade do sistema no fornecimento de potência ativa e ao mesmo tempo eleva a queda de tensão.

Dentre os problemas causados por afundamentos de tensão de longa duração, destacam-se:

Redução da potência reativa fornecida por bancos de capacitores ao sistema;

Possível interrupção da operação de equipamentos eletrônicos, tais como computadores e controladores eletrônicos;

$>$ Redução de índice de iluminamento para os circuitos de iluminação incandescente.

> Elevação do tempo de partida das máquinas de indução, o que contribui para a elevação de temperatura dos enrolamentos; e

Aumento nos valores das correntes do estator de um motor de indução quando alimentado por uma tensão inferior à nominal. Desta forma tem-se um sobre-aquecimento da máquina, o que certamente reduzirá a expectativa de vida útil da mesma.

As opções para melhorar a regulação de tensão são: 
Instalar reguladores de tensão para elevar o nível da tensão;

Instalar capacitores shunt para reduzir a corrente do circuito;

Instalar capacitores série para cancelar a queda de tensão indutiva;

Instalar cabos com bitolas maiores para reduzir a impedância da linha;

Mudar o transformador de serviço para um com maior capacidade, reduzindo assim a impedância da linha e

> Instalar compensadores estáticos de reativos, os quais tem os mesmos objetivos que os capacitores, para mudanças bruscas de cargas.

\subsubsection{Elevações de Tensão Sustentadas}

Uma elevação de tensão sustentada é caracterizada por um aumento no valor eficaz da tensão acima de 1,1 pu (valores típicos entre 1,1 e 1,2 pu) por um período de duração maior que 1 minuto.

As sobretensões de longa duração podem ser o resultado do desligamento de grandes cargas ou da energização de um banco de capacitores. Transformadores cujos taps são conectados erroneamente também podem causar elevações de tensão [1].

Geralmente, são instalados bancos de capacitores fixos nos sistemas de distribuição das concessionárias, com vistas a suprir energia reativa e, portanto, melhorar o perfil de tensão. Ao mesmo tempo são instalados nas indústrias bancos de capacitores, normalmente fixos, para correção do fator de potência ou mesmo para elevação da tensão nos circuitos internos da instalação. Nos horários de ponta, quando há grandes solicitações de carga, a potência reativa fornecida por estes bancos auxilia a atuação do sistema. Entretanto, no horário fora de ponta, principalmente no período noturno, tem-se um excesso de reativo injetado no sistema, o qual se manifesta por uma elevação da tensão.

Com relação às conseqüências das elevações de tensão de longa duração, estas podem resultar em falha dos equipamentos. Dispositivos eletrônicos podem sofrer danos durante condições de sobretensões, embora transformadores, cabos, disjuntores, TC's, TP's e máquinas rotativas, geralmente não apresentam falhas imediatas. Entretanto, estes equipamentos, quando submetidos a elevações de tensão 
sustentadas, poderão ter as suas vidas úteis reduzidas. Relés de proteção também poderão apresentar falhas de operação durante as elevações de tensão. A potência reativa fornecida pelos bancos de capacitores aumentará com o quadrado da tensão durante uma condição de sobretensão, enquanto que a iluminação poderá também ser aumentada em tal condição.

Dentre algumas opções para a solução de tais problemas, destaca-se a troca de bancos de capacitores fixos por bancos automáticos, tanto em sistemas de concessionárias como em sistemas industriais e a instalação de compensadores estáticos de reativos, possibilitando um controle maior do nível da tensão [5].

\subsection{Desequilíbrios ou Desbalanços}

Os desequilíbrios podem ser caracterizados usando-se diagramas de seqüências pela relação entre o componente de seqüência negativa e o componente de seqüência positiva dos sinais referenciados [1].

As origens destes desequilíbrios estão geralmente nos sistemas de distribuição, os quais possuem cargas monofásicas distribuídas inadequadamente, causando o surgimento de tensões de seqüência negativa. Este problema se agrava quando consumidores alimentados de forma trifásica possuem uma má distribuição de carga em seus circuitos internos, impondo correntes desequilibradas no circuito da concessionária. Tensões desequilibradas podem também ser o resultado da queima de fusíveis em uma fase de um banco de capacitores trifásicos.

Tais fatores prejudicam a qualidade no fornecimento de energia idealizada pela concessionária, e desta forma, alguns consumidores encontram na sua alimentação um desequilíbrio de tensão, a qual pode se manifestar sob três formas distintas:

amplitudes diferentes;

assimetria nas fases e

assimetria conjunta de amplitudes e fases.

Destas, apenas a primeira é freqüentemente evidenciada no sistema elétrico. 


\subsection{Distorções da Forma de Onda}

A distorção da forma de onda é definida como um desvio, em regime permanente, da forma de onda puramente senoidal, na freqüência fundamental, e é caracterizada principalmente pelo seu conteúdo espectral.

Existem cinco tipos principais de distorções da forma de onda [1]:

> Nível de Corrente Contínua (CC);

$>$ Harmônicos;

> Inter-harmônicos;

Notching;

$>$ Ruídos.

\subsubsection{Nível CC}

A presença de tensão ou corrente $\mathrm{CC}$ em um sistema elétrico CA pode ocorrer como o resultado da operação ideal de retificadores de meia-onda. O nível CC em redes de corrente alternada pode levar à saturação de transformadores, resultando em perdas adicionais e redução da vida útil do equipamento. Pode também causar corrosão eletrolítica dos eletrodos de aterramento e de outros conectores [1].

\subsubsection{Harmônicos}

Harmônicos são tensões ou correntes senoidais de frequiências múltiplas inteiras da frequiência fundamental na qual opera o sistema de energia elétrica. Estes harmônicos distorcem as formas de onda da tensão e corrente e são oriundos de equipamentos e cargas com características não-lineares instalados no sistema de energia [1].

A distorção harmônica vem contra os objetivos da qualidade do suprimento promovido por uma concessionária de energia elétrica, a qual deve fornecer aos seus consumidores uma tensão puramente senoidal, com amplitude e frequiência constantes. Entretanto, o fornecimento de energia a determinados consumidores que causam deformações no sistema supridor, prejudicam não apenas o consumidor responsável pelo distúrbio, mas também outros conectados à mesma rede elétrica. 
Nos períodos anteriores à década de 80 não existiam maiores preocupações com distorções harmônicas. Cargas com características não lineares eram pouco utilizadas e os equipamentos eram mais resistentes aos efeitos provocados por distorções harmônicas. Entretanto, nos últimos anos, com o rápido desenvolvimento da eletrônica de potência e a utilização de métodos que buscam o uso mais racional da energia elétrica, o conteúdo harmônico presente nos sistemas tem se elevado, causando uma série de efeitos indesejáveis em diversos equipamentos ou dispositivos, comprometendo a qualidade e o próprio uso racional da energia elétrica. O problema é ainda agravado com a utilização de equipamentos e cargas mais sensíveis à QE.

Como ilustração, a Figura 9 extraída da referência [5], mostra um perfil da vida útil de um transformador de corrente que se estabelece através de seus enrolamentos. Os resultados consideram que as componentes harmônicas, para cada situação, são superpostas a uma corrente fundamental igual à nominal do equipamento.

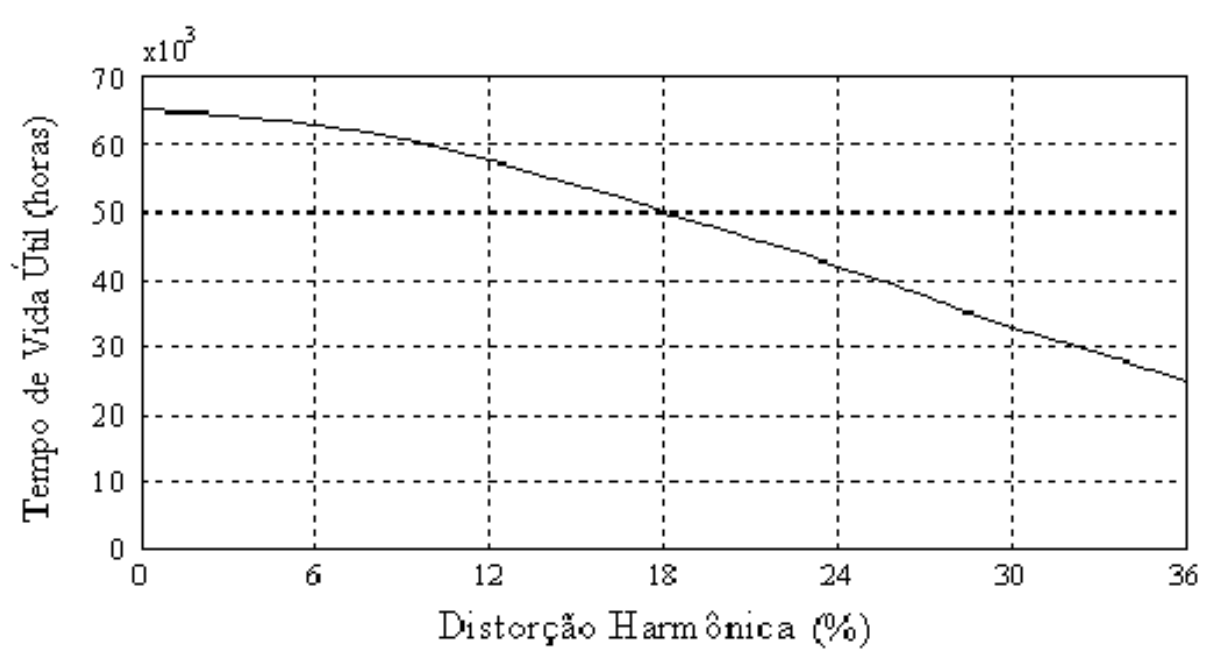

FIGURA 9 - Vida útil de um transformador em função da distorção harmônica de corrente. 


\subsubsection{Interharmônicos}

Interharmônicos são componentes de frequiência, em tensão ou corrente, que não são múltiplos inteiros da frequiência fundamental do sistema supridor $(50 \mathrm{ou} 60 \mathrm{~Hz})$. Estes podem aparecer como frequiências discretas ou como uma larga faixa espectral.

Os interharmônicos podem ser encontrados em redes de diferentes classes de tensão. As suas principais fontes são conversores estáticos de potência, cicloconversores, motores de indução e equipamentos a arco. Sinais carrier (sinal superposto ao sinal de tensão utilizado para transmissão de informações) em linhas de potência também podem ser considerados como interharmônicos [1].

\subsubsection{Notching}

Notching é um distúrbio de tensão causado pela operação normal de equipamentos de eletrônica de potência quando a corrente é comutada de uma fase para outra.

Este fenômeno pode ser detectado através do conteúdo harmônico da tensão afetada. As componentes de frequiência associadas com os notchings são de alto valor e, desta forma, não podem ser medidas pelos equipamentos normalmente utilizados para análise harmônica. A Figura 10 mostra a forma com que o notching se manifesta [1].

\subsubsection{Ruídos}

Ruído é definido como um sinal elétrico indesejado, contendo uma larga faixa espectral com freqüências menores que $200 \mathrm{kHz}$, as quais são superpostas às tensões ou correntes de fase, ou encontradas em condutores de neutro.

Os ruídos em sistemas de potência podem ser causados por equipamentos de eletrônica de potência, circuitos de controle, equipamentos a arco, retificadores a estado sólido e fontes chaveadas e, via de regra, estão relacionados com aterramentos impróprios. Basicamente, os ruídos consistem de uma distorção indesejada no sinal elétrico que não pode ser classificado como distorção harmônica ou transitório.

A faixa de frequiência e o nível da amplitude depende da fonte que produz o ruído e das características do sistema. A amplitude típica é menor que $1 \%$ da tensão 
fundamental, e os mesmos podem causar distúrbios em equipamentos eletrônicos tais como microcomputadores e controladores programáveis. O problema pode ser minimizado utilizando-se filtros e transformadores isoladores, entre outros [1].

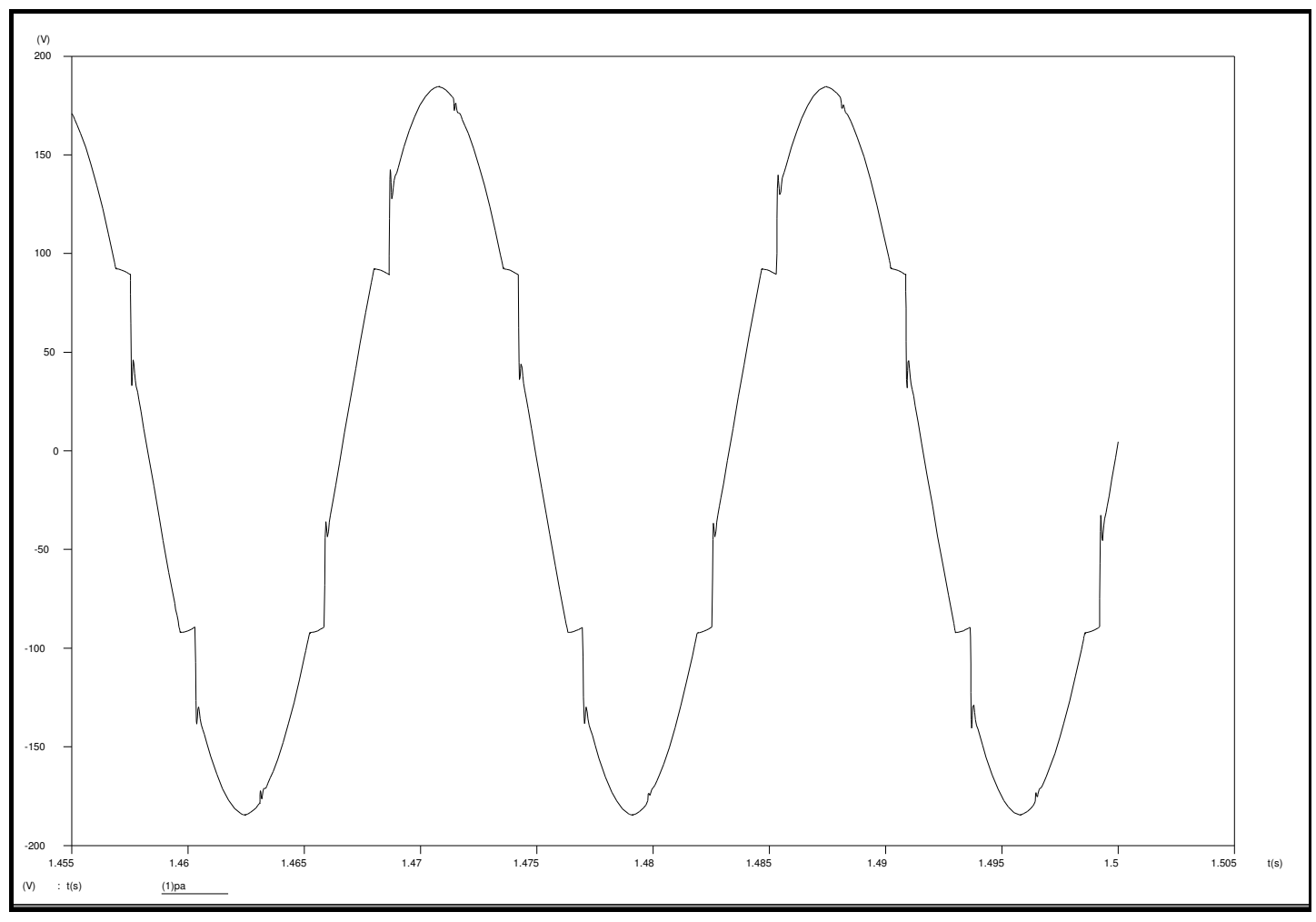

FIGURA 10 - Tensão de alimentação de um conversor CA/CC.

\subsection{Flutuações ou Oscilações de Tensão}

As flutuações de tensão correspondem a variações sistemáticas no valor eficaz da tensão de suprimento dentro da faixa compreendida entre 0,95 e 1,05 pu.

Tais flutuações são geralmente causadas por cargas industriais e manifestamse de diferentes formas, a destacar:

- Flutuações Aleatórias

A principal fonte destas flutuações são os fornos a arco, onde as amplitudes das oscilações dependem do estado de fusão do material, bem como do nível de curto-circuito da instalação.

- Flutuações Repetitivas 
Dentre as principais fontes geradoras de flutuações desta natureza tem-se:

máquinas de solda;

$>$ laminadores;

$>$ elevadores de minas e

$>$ ferrovias.

- Flutuações Esporádicas

A principal fonte causadora destas oscilações é a partida direta de grandes motores.

Os principais efeitos nos sistemas elétricos, resultados das oscilações causadas pelos equipamentos mencionados anteriormente são:

oscilações de potência e torque das máquinas elétricas;

$>$ queda de rendimento dos equipamentos elétricos;

$>$ interferência nos sistemas de proteção e

$>$ efeito flicker (cintilação luminosa).

O fenômeno flicker consiste no efeito mais comum provocado pelas oscilações de tensão. Este tema merece especial atenção, uma vez que o desconforto visual associado à perceptibilidade do olho humano às variações da intensidade luminosa é, em toda sua extensão, indesejável.

\subsubsection{Variações na Freqüência do Sistema Elétrico}

Variações na freqüência de um sistema elétrico são definidas como sendo desvios no valor da frequiência fundamental deste sistema $(50 \mathrm{ou} 60 \mathrm{~Hz})$.

A freqüência do sistema de potência está diretamente associada à velocidade de rotação dos geradores que suprem o sistema. Pequenas variações de freqüência podem ser observadas como resultado do balanço dinâmico entre carga e geração no caso de alguma alteração (variações na faixa de $60 \pm 0,5 \mathrm{~Hz}$ ). A amplitude da variação e sua duração dependem das características da carga e da resposta do regulador de velocidade instalado no sistema de geração.

Variações de freqüência que ultrapassam os limites para operação normal em regime permanente podem ser causadas por faltas em sistemas de transmissão, saída 
de um grande bloco de carga ou pela saída de operação de uma grande fonte de geração.

Em sistemas isolados, entretanto, como é o caso da geração própria nas indústrias, na eventualidade de um distúrbio, a magnitude e o tempo de permanência das máquinas operando fora da velocidade, resultam em desvios da frequiência em proporções mais significativas.

A Tabela 1, extraída da referência [1], traz um resumo dos diferentes distúrbios, mostrando as categorias e as características típicas dos fenômenos que contribuem para a perda da qualidade de um suprimento elétrico.

A Tabela 2, extraída da referência [5], mostra de forma resumida, os fenômenos que se relacionam com a $\mathrm{QE}$ com as suas respectivas causas, efeitos e propõe algumas soluções para mitigar tais fenômenos, os quais foram apresentados ao longo deste Capítulo. 
TABELA 1 - Categorias e características típicas de fenômenos eletromagnéticos típicos nos sistemas elétricos.

\begin{tabular}{|c|c|c|c|}
\hline Categoria & $\begin{array}{c}\text { Conteúdo Espectral } \\
\text { Típico } \\
\end{array}$ & Duração Típica & $\begin{array}{l}\text { Amplitude de } \\
\text { Tensão Típica }\end{array}$ \\
\hline \multicolumn{4}{|l|}{1.0 - Transitórios } \\
\hline \multicolumn{4}{|l|}{1.1 - Impulsivos } \\
\hline 1.1.1 - Nanossegundo & $5 \mathrm{~ns}$ & $<50 \mathrm{~ns}$ & \\
\hline 1.1.2-Microssegundo & $1 \mu \mathrm{s}$ & $50 \mathrm{~ns}-1 \mathrm{~ms}$ & \\
\hline 1.1.3-Milissegundo & $0,1 \mathrm{~ms}$ & $>1 \mathrm{~ms}$ & \\
\hline \multicolumn{4}{|l|}{$1.2-$ Oscilatórios } \\
\hline 1.2.1 - Baixa Freqüência & $<5 \mathrm{kHz}$ & $3-50 \mathrm{~ms}$ & $0,4 \mathrm{pu}$ \\
\hline 1.2.2 - Média Frequiência & $5-500 \mathrm{kHz}$ & $20 \mu \mathrm{s}$ & $0,4 \mathrm{pu}$ \\
\hline 1.2.3 - Alta Freqüuência & $0,5-5 \mathrm{MHz}$ & $5 \mu \mathrm{s}$ & $0,4 \mathrm{pu}$ \\
\hline \multicolumn{4}{|l|}{$\begin{array}{l}2.0 \text { - Variações de Tensão Curta } \\
\text { Duração }\end{array}$} \\
\hline \multicolumn{4}{|l|}{2.1 - Instantânea } \\
\hline 2.1.1 - Afundamento de tensão & & $0.5-30$ ciclos & $0,1-0,9 \mathrm{pu}$ \\
\hline 2.1.2 - Elevação de tensão & & $0.5-30$ ciclos & $1,1-1,8 \mathrm{pu}$ \\
\hline \multicolumn{4}{|l|}{2.2 - Momentânea } \\
\hline 2.2.1 - Interrupção & & 0.5 ciclos $-3 \mathrm{~s}$ & $<0.1 \mathrm{pu}$ \\
\hline 2.2.2 - Afundamento de tensão & & 30 ciclos $-3 \mathrm{~s}$ & $0,1-0,9 \mathrm{pu}$ \\
\hline 2.2 .3 - Elevação de tensão & & 30 ciclos $-3 s$ & $1,1-1,4 \mathrm{pu}$ \\
\hline \multicolumn{4}{|l|}{2.3 - Temporária } \\
\hline 2.3.1 - Interrupção & & $3 \mathrm{~s}-1$ minuto & $<0,1 \mathrm{pu}$ \\
\hline 2.3.2 - Afundamento de tensão & & $3 \mathrm{~s}-1$ minuto & $0,1-0,9 \mathrm{pu}$ \\
\hline 2.3.3 - Elevação de tensão & & $3 \mathrm{~s}-1$ minuto & $1,1-1,2 \mathrm{pu}$ \\
\hline \multicolumn{4}{|l|}{$\begin{array}{l}3.0 \text { - Variações de tensão de longa } \\
\text { duração }\end{array}$} \\
\hline 3.1 - Interrupção Sustentada & & $>1$ minuto & $0,0 \mathrm{pu}$ \\
\hline 3.2 - Subtensão Sustentada & & $>1$ minuto & $0,8-0,9 \mathrm{pu}$ \\
\hline 3.3 - Sobretensão Sustentada & & $>1$ minuto & $1,1-1,2 \mathrm{pu}$ \\
\hline 4.0 - Desequilíbrio de Tensão & & regime permanente & $0,5-2 \%$ \\
\hline \multicolumn{4}{|l|}{5.0 - Distorção da Forma de Onda } \\
\hline 5.1 - Nível CC & & regime permanente & $0-0,1 \%$ \\
\hline 5.2 - Harmônicos & de ordem 0-100 & regime permanente & $0-20 \%$ \\
\hline 5.3 - Interharmônicos & $0-6 \mathrm{kHz}$ & regime permanente & $0-2 \%$ \\
\hline 5.4 - Notching & & regime permanente & \\
\hline 5.5-Ruído & faixa ampla & regime permanente & $0-1 \%$ \\
\hline 6.0 - Flutuação de Tensão & $<25 \mathrm{~Hz}$ & intermitente & $0,1-7 \%$ \\
\hline $\begin{array}{c}7.0 \text { - Variação da Freqüência do } \\
\text { Sistema }\end{array}$ & & $<10 \mathrm{~s}$ & \\
\hline
\end{tabular}


TABELA 2 - Resumo das características dos distúrbios relacionados com a QE.

\begin{tabular}{|c|c|c|c|}
\hline Tipo de Distúrbio & Causas & Efeitos & Soluções \\
\hline $\begin{array}{l}\text { Transitórios } \\
\text { Impulsivos }\end{array}$ & $\begin{array}{l}\text {-Descargas atmosféricas; } \\
\text {-Chaveamentos de cargas. }\end{array}$ & $\begin{array}{l}\text {-Excitação de circuitos ressonantes; } \\
\text {-Redução da vida útil de motores, } \\
\text { geradores, transformadores, etc. }\end{array}$ & $\begin{array}{l}\text {-Filtros; } \\
\text {-Supressores de surto; } \\
\text {-Transformadores } \\
\text { isoladores. }\end{array}$ \\
\hline $\begin{array}{l}\text { Oscilações } \\
\text { Transitórias }\end{array}$ & $\begin{array}{l}\text {-Descargas atmosféricas; } \\
\text {-Chaveamentos de: } \\
\text { capacitores, linhas, cabos, } \\
\text { cargas e transformadores. }\end{array}$ & $\begin{array}{l}\text {-Mal funcionamento de equipamentos } \\
\text { controlados eletronicamente, } \\
\text { conversores de potência, etc.; } \\
\text {-Redução da vida útil de motores, } \\
\text { geradores, transformadores, etc. }\end{array}$ & $\begin{array}{l}\text {-Filtros; } \\
\text {-Supressores de surto; } \\
\text {-Transformadores } \\
\text { isoladores. }\end{array}$ \\
\hline Sub e Sobretensões & $\begin{array}{l}\text {-Partidas de motores; } \\
\text {-Variações de cargas; } \\
\text {-Chaveamento de banco } \\
\text { capacitores. }\end{array}$ & $\begin{array}{l}\text {-Pequena redução na velocidade dos } \\
\text { motores de indução e no reativo dos } \\
\text { bancos de capacitores; } \\
\text {-Falhas em equipamentos eletrônicos; } \\
\text {-Redução da vida útil de máquinas } \\
\text { rotativas, transformadores, cabos, } \\
\text { disjuntores, TP's e TC's; } \\
\text {-Operação indevida de relés de proteção. }\end{array}$ & $\begin{array}{l}\text {-Reguladores de tensão; } \\
\text {-Fontes de energia de } \\
\text { reserva; } \\
\text {-Chaves estáticas; } \\
\text {-Geradores de energia. }\end{array}$ \\
\hline Interrupções & $\begin{array}{l}\text {-Curto-circuito; } \\
\text {-Operação de disjuntores; } \\
\text {-Manutenção. }\end{array}$ & $\begin{array}{l}\text {-Falha de equipamentos eletrônicos e de } \\
\text { iluminação; } \\
\text {-Desligamento de equipamentos; } \\
\text {-Interrupção do processo produtivo } \\
\text { (altos custos); }\end{array}$ & $\begin{array}{l}\text {-Fontes de energia } \\
\text { sobressalentes; } \\
\text {-Sistemas no-break; } \\
\text {-Geradores de energia. }\end{array}$ \\
\hline Desequilíbrios & $\begin{array}{l}\text {-Fornos a arco; } \\
\text {-Cargas monofásicas e } \\
\text { bifásicas; } \\
\text {-Assimetrias entre as } \\
\text { impedâncias. } \\
\end{array}$ & $\begin{array}{l}\text {-Redução da vida útil de motores de } \\
\text { indução e máquinas síncronas; } \\
\text {-Geração, pelos retificadores, de } 3^{\circ} \\
\text { harmônico e seus múltiplos. }\end{array}$ & $\begin{array}{l}\text {-Operação simétrica; } \\
\text {-Dispositivos de } \\
\text { compensação. }\end{array}$ \\
\hline Nível CC & $\begin{array}{l}\text {-Operação ideal de } \\
\text { retificadores de meia onda, } \\
\text { etc. }\end{array}$ & $\begin{array}{l}\text {-Saturação de transformadores; } \\
\text {-Corrosão eletrolítica de eletrodos de } \\
\text { aterramento e de outros conectores. }\end{array}$ & \\
\hline Harmônicos & -Cargas não-lineares. & $\begin{array}{l}\text {-Sobreaquecimento de cabos, } \\
\text { transformadores e motores de indução; } \\
\text {-Danificação de capacitores, etc. }\end{array}$ & $\begin{array}{l}\text {-Filtros; } \\
\text {-Transformadores } \\
\text { isoladores. } \\
\end{array}$ \\
\hline Interharmônicos & $\begin{array}{l}\text {-Conversores estáticos de } \\
\text { potência; } \\
\text {-Cicloconversores; } \\
\text {-Motores de indução; } \\
\text {-Equipamentos a arco, etc. }\end{array}$ & $\begin{array}{l}\text {-Interferência na transmissão de sinais } \\
\text { carrier; } \\
\text {-Indução de flicker visual no display de } \\
\text { equipamentos. }\end{array}$ & \\
\hline Notching & $\begin{array}{l}\text {-Equipamentos de } \\
\text { eletrônica de potência. }\end{array}$ & & \\
\hline Ruídos & $\begin{array}{l}\text {-Chaveamento de equip. } \\
\text { eletrônicos de potência; } \\
\text {-Radiações } \\
\text { eletromagnéticas. }\end{array}$ & $\begin{array}{l}\text {-Distúrbios em equip. eletrônicos } \\
\text { (computadores e controladores } \\
\text { programáveis). }\end{array}$ & $\begin{array}{l}\text {-Aterramento das } \\
\text { instalações; } \\
\text {-Filtros. }\end{array}$ \\
\hline Oscilações de Tensão & $\begin{array}{l}\text {-Cargas intermitentes; } \\
\text {-Fornos a arco; } \\
\text {-Partidas de motores. }\end{array}$ & $\begin{array}{l}\text {-Flicker; } \\
\text {-Oscilação de potência e torque nas } \\
\text { máquinas elétricas; } \\
\text {-Queda de rendimento de equipamentos } \\
\text { elétricos; } \\
\text {-Interferência nos sistemas de proteção. }\end{array}$ & $\begin{array}{l}\text {-Sistemas estáticos de } \\
\text { compensação de reativos; } \\
\text {-Capacitores série. }\end{array}$ \\
\hline $\begin{array}{c}\text { Variações na } \\
\text { Frequiência do } \\
\text { Sistema Elétrico }\end{array}$ & $\begin{array}{l}\text {-Perda de geração, perda } \\
\text { de linhas de transmissão, } \\
\text { etc. }\end{array}$ & $\begin{array}{l}\text {-Pode causar danos severos nos } \\
\text { geradores e nas palhetas das turbinas, } \\
\text { etc. }\end{array}$ & \\
\hline
\end{tabular}




\section{LEVANTAMENTO BIBLIOGRÁFICO}

Com o propósito de conhecer os estudos referentes à aplicação da Transformada Wavelet (TW) para análise de distúrbios relacionados com a $\mathrm{QE}$, foram levantados alguns dos principais trabalhos realizados. Este Capítulo busca abordar os principais pontos no que se refere as aplicações a serem mencionadas.

Destaca-se inicialmente, referindo-se a aplicação da teoria de Wavelet na análise da QE, o trabalho de SANTOSO et al. [8] que utilizaram a Análise Multiresolução (AMR), com a Daubechies de ordem quatro (db4) como Wavelet mãe, para detectar e localizar vários tipos de distúrbios que estão relacionados com a QE. A idéia chave do trabalho está na decomposição de um dado sinal distorcido em outros sinais que representam uma versão de aproximação (conteúdo de baixa freqüência) e uma versão de detalhes (conteúdo de alta freqüência) do sinal original. Os autores descreveram também a base de um possível esquema de classificação de distúrbios utilizando coeficientes quadrados da Transformada Wavelet (TW), que extraem características dos diferentes distúrbios.

ANGRISANI et al. [9] apresentam um método para análise da QE combinando o uso da TWC com a AMR. A TWC foi implementada usando a função Wavelet de Morlet como função base, bem como suas propriedades de módulo máximo. A técnica de AMR foi realizada tendo como função base a Wavelet de Daubechies com 16 coeficientes. A detecção do distúrbio é feita com a utilização da ferramenta TWC e o uso da propriedade de módulo máximo se faz necessária para a estimação do tempo de duração do distúrbio. A técnica de AMR é usada para extrair do sinal que contém o distúrbio a componente fundamental. Com este método, os autores afirmam que os distúrbios mais relevantes no sistema elétrico de potência podem ser detectados, localizados e estimados automaticamente, mesmo na presença 
de ruídos e ainda, as características dos distúrbios podem ser extraídas usando um número menor de parâmetros quando comparado com os métodos até então desenvolvidos.

Uma técnica utilizando a TW também foi implementada por HUANG et al. [10] para a classificação de distúrbios relacionados com a QE. Tal técnica utilizou a Wavelet mãe de Morlet para a decomposição de um dado sinal em AMR, extraindo deste as componentes de freqüência de 60 e $600 \mathrm{~Hz}$. A componente de freqüência de $60 \mathrm{~Hz}$ indica variações de amplitude no sinal classificando distúrbios entre afundamento de tensão, elevação de tensão e interrupção momentânea. Já a componente de $600 \mathrm{~Hz}$ indica a presença de pequenas variações transitórias, classificando distúrbios como oscilações transitórias. Desta forma, a técnica descrita pelos autores, não só detecta a presença de distúrbios, mas também é capaz de classificar os distúrbios em seus diferentes tipos.

A técnica de AMR, com a Wavelet mãe de Daubechies db4, foi também utilizada por GAOUDA et al. [11] para detectar e localizar diferentes problemas de QE, sendo a base de sua aplicação focada na decomposição de um dado sinal em versões de aproximação e de detalhes. Os autores introduzem um método de classificação de distúrbios relacionando a energia do sinal distorcido com a energia de cada componente da decomposição em AMR (teorema de Parseval). A energia do sinal pode ser dividida através dos coeficientes da decomposição que é feita em diferentes intervalos de freqüência, fornecendo assim informações sobre o conteúdo de freqüência do sinal e possibilitando classificar diferentes fenômenos. Características únicas dos diferentes distúrbios podem então ser extraídas utilizandose de curvas de desvio padrão em diferentes níveis de resolução.

POISSON et al. [12] fazem comparação entre a Transformada de Fourier (TF), a TWC, a AMR e a Transformada Quadrática (TQ) que são ferramentas de representação tempo-freqüência. A utilização da TWC teve como base (Wavelet mãe) uma função complexa similar à função base de Morlet e implementada usando um algoritmo recursivo que é descrito pelos autores. A AMR teve como Wavelet mãe a função Feauveau. Tais comparações são feitas na análise de distúrbios relacionados com a QE tais como afundamento de tensão, Flicker e distorções harmônicas. Através deste trabalho os autores concluem AMR e TQ como ferramentas seguras 
para detectar distúrbios e indicar o conteúdo de freqüência existente em tais distúrbios. Apresentam ainda, a TWC como ferramenta mais segura para detecção e estimação da amplitude de afundamentos de tensão, elevações de tensão e flicker comparada com as ferramentas AMR e TQ.

ZHENG et al. [13] fazem a modelagem de componentes do Sistema Elétrico de Potência (SEP) tais como resistor, indutor e capacitor no domínio Wavelet usando-se a técnica de AMR. Os autores afirmam que esta técnica pode ser implementada usando-se qualquer Wavelet mãe ortogonal. Os modelos são classificados em transitório e de estado permanente de acordo com as diferentes propostas de análise. $\mathrm{O}$ modelo transitório é geralmente adaptado para a análise de distúrbios transitórios no sistema e o de estado permanente pode ser aplicado para análises de harmônicos e respostas tempo-freqüência.

POISSON et al. [14] desenvolveram um algoritmo baseado na TWC, tendo como Wavelet mãe a função de Chaari, para detecção e medição de distúrbios que se relacionam com a QE, onde este fornece a localização no tempo e medição da magnitude de afundamentos de tensão com muita precisão e significativas identificações de transitórios. O novo método retorna a mesma magnitude de afundamentos em mais de $80 \%$ dos casos testados pelos autores. Além do mais, tal método possibilita uma classificação precisa de eventos transitórios, e características destes eventos são facilmente extraídas de seu plano tempo-freqüência.

A técnica proposta por SANTOSO et al. [4] tem por finalidade extrair características únicas de distúrbios caracterizando-os como eventos de QE, bem como elaborar metodologias para extraí-los das formas de onda fundamental usando como ferramentas a união de uma importante transformada matemática na engenharia de potência, a TF, com a nova TW. A TF é usada para caracterizar fenômenos de estado permanente, enquanto que a TW, usando a Wavelet mãe de Daubechies db4, é aplicada para fenômenos transitórios. Outras técnicas matemáticas de análise, tais como técnicas de curvas permanentes para estimar mudanças repentinas de tensão são também usadas pelos autores. Estes caracterizam também eventos comuns em nível de distribuição afirmando que estes formam as bases para futuras caracterizações de outros eventos de QE. 
Um sistema Neuro-Fuzzy classificador de distúrbios relacionados com a QE é apresentado por HUANG et al. [15]. O sistema classificador utiliza uma Rede Neural (RN) com treinamento competitivo e um refinamento com o algoritmo LVQ (Learning Vector Quantization), que compreende um modelo supervisionado da rede de Mapeamento Auto-Organizável e o algoritmo usando a técnica Fuzzy é utilizado para otimizar o sistema contendo a RN. Tal sistema classificador utiliza como entrada de dados características do sinal original extraídas através da AMR usando Daubechies de quarta ordem como Wavelet mãe. Treze tipos de distúrbios são usados como os tipos de padrões de entrada para o Sistema Neuro-Fuzzy e segundo os autores estes são classificados com eficiência média próxima a 93\%.

SANTOSO et al. [16] apresentam neste trabalho, ferramentas para classificação de distúrbios relacionados com a QE. A fundamentação teórica exposta pelos autores compreendem a TW e Redes Neurais Artificiais (RNA), que sendo usadas juntamente com uma ferramenta para tomada de decisões, tal como voting scheme ou a teoria de evidências Dempster-Shafer, podem formar um sistema classificador de distúrbios relacionados com a QE. Os autores justificam porque ferramentas como RNA superam em eficiência ferramentas baseadas em métodos estatísticos, tais como teoria de decisão Bayesiana. No esquema teórico apresentado pelos autores, um dado sinal é transformado para o domínio Wavelet (para extração de características do distúrbio) e então é usado para alimentar uma RNA do tipo LVQ. A saída da RNA é processada por um método de tomada de decisões que fornecerá como saída o tipo de distúrbio contido no sinal de entrada. O modelo teórico apresentado pelos autores é implementado em SANTOSO et al. [17], onde resultados com eficiência superior a $90 \%$ são apresentados na classificação de seis distúrbios diferentes.

A TWD foi utilizada por YANG and LIAO. [18] para a extração de ruídos de um dado sinal para então ser analisado. Tal análise tem como objetivo detectar e localizar distúrbios existentes no SEP relacionados com a QE. Uma vez que a presença de ruídos pode vir a causar dificuldades na detecção de distúrbios, a extração deste é de grande valia. A TWD usando-se da técnica de AMR é usada, pelos autores, para eliminar a presença de ruído do sinal que contém o distúrbio, podendo desta forma ser criada uma ferramenta de monitoramento do SEP para 
detectar e localizar com maior eficiência distúrbios como afundamento de tensão, elevação de tensão e transitórios.

Um software para monitoramento automático do SEP é proposto por KEZUNOVIC and LIAO. [19]. A finalidade de tal software é detectar e classificar automaticamente distúrbios presentes em um sinal de tensão monitorado. A TW juntamente com a TF são utilizadas para a extração de características dos distúrbios. Tais características constituem a entrada de dados de um módulo do software que é baseado em um sistema Fuzzy que classifica o distúrbio em sub-módulos distinguindo oito tipos de distúrbios. A porcentagem de acerto para o sistema Fuzzy desenvolvido é, segundo os autores, de 99\%. Um outro módulo introduzido pelos autores no software desenvolvido objetiva avaliar a sensibilidade de equipamentos na presença de mudanças na forma de onda. Segundo os autores, através deste módulo o software é capaz de explicar porque uma carga específica falhou durante um afundamento de tensão, ou predizer a eficiência de uma carga durante um evento em particular. Para o caso de um distúrbio afundamento de tensão, os autores introduzem um módulo do software para a localização de uma falta que causou tal evento. Sendo assim, os autores apresentam um esquema que tende a facilitar o estudo de eventos relacionados com a $\mathrm{QE}$.

Procurou-se através das publicações citadas, apresentar alguns dos principais trabalhos realizados utilizando a Transformada Wavelet para a análise de distúrbios relacionados com a $\mathrm{QE}$.

O Capítulo que segue apresenta a teoria referente a ferramenta TW utilizada neste trabalho para o desenvolvimento de um método classificador automático de distúrbios. 


\section{A TRANSFORMADA WAVELET}

O tema Wavelets, muito desenvolvido nos últimos 20 anos, é formado pela união de idéias em campos como matemática pura e aplicada, física, ciência da computação e engenharia. Ingrid Daubechies apresenta a história das Wavelets como uma árvore com raízes profundas e em várias direções. Neste contexto, o tronco corresponderia ao rápido desenvolvimento da ferramenta Wavelets na segunda metade da década de 80, apoiada pelos esforços de pesquisadores de diferentes campos. A copa da árvore, com seus muitos ramos, corresponderia às diferentes direções e aplicações na qual Wavelets tem se tornado a ferramenta matemática base ao lado de outras técnicas [20].

A primeira menção a Wavelets apareceu no apêndice de A. Haar, em 1909 como descrito por HAAR apud LIMA. [21]. Uma propriedade das Wavelets de Haar é possuírem suportes compactos; contudo, não são continuamente diferenciáveis, o que de certa forma limita a aplicabilidade a elas relacionadas.

As Wavelets de Haar ficaram no anonimato por muitos anos até que nos anos 30, vários grupos trabalhando independentemente, pesquisaram a representação de funções usando uma base com escala variável. Naquela ocasião, usando a base de Haar, Paul Levy mostrou que estas funções sendo usadas como base, ofereciam melhores resultados quando comparados com os resultados obtidos com a utilização das funções bases de Fourier no estudo dos pequenos e complicados detalhes do movimento Browniano, movimento este, melhor explicado em UFC [22]. Por um período muito longo, as Wavelets de Haar continuaram a ser a única base ortonormal de funções Wavelets conhecida, até que, em 1985, Stephane Mallat proporcionou às Wavelets um grande impulso através de seu trabalho em processamento digital de imagens e, inspirado nos resultados de Mallat, Y. Meyer construiu a primeira 
Wavelets não-trivial (suave) [20]. Ao contrário das Wavelets de Haar, as Wavelets de Meyer são continuamente diferenciáveis.

Contudo, não possuem suportes compactos. Poucos anos mais tarde, Ingrid Daubechies usou os trabalhos de Mallat para construir um conjunto de bases ortonormais de Wavelets suaves, com suportes compactos [21].

De uma forma geral a família das funções

$$
\psi_{a, b}(x)=|a|^{-\frac{1}{2}} \psi\left(\frac{x-b}{a}\right) \quad a, b \in \Re, \quad a \neq 0,
$$

onde a variável $x$ pode corresponder a tempo ou espaço, geradas a partir das operações de dilatação (fator de escala $a$ ) e translação (fator $b$ ) da mesma função $\psi$ (Wavelets mãe) são chamadas Wavelets [23].

Como será visto, deve-se distinguir duas versões diferentes da Transformada Wavelets (TW), a contínua e a discreta:

- a Transformada Wavelet Contínua (TWC): Faz o mapeamento de uma função de uma variável contínua em uma função de duas variáveis contínuas.

- a Transformada Wavelet Discreta (TWD): Decompõe um sinal discretizado em diferentes níveis de resolução. Esta faz o mapeamento uma sequiência de números em outra seqüência de números [24].

\section{1) A Transformada Wavelet Contínua}

A ferramenta para análise de sinais mais conhecida é a Transformada de Fourier (TF), que divide as informações contidas em um sinal em diferentes frequiências através de funções bases senoidais. Podemos entender a TF como sendo uma técnica de transformação do sinal do domínio do tempo para o domínio da freqüência [25].

Para muitos sinais, a TF é extremamente usual, uma vez que o conteúdo de frequiência é de grande importância. Uma desvantagem desta técnica é a perda de informações referentes ao domínio do tempo quando o sinal é transformado para o domínio da freqüência. Quando este não possui muitas variações no domínio do tempo, isto é, o sinal é dito semi-estacionário, as informações perdidas na transformação do sinal utilizando a TF não representam perdas significativas. 
Contudo, muitos sinais de interesse contém características não estacionárias. Sendo assim, necessitamos de técnicas que retificam o problema exposto [26].

Com o objetivo de corrigir a deficiência mencionada da TF, Dennis Gabor a adaptou para analisar apenas uma pequena porção de tempo do sinal, originando a chamada Short-Time Fourier Transform (STFT), que faz o mapeamento de um sinal unidimensional em duas dimensões: tempo e freqüência. No entanto, a precisão das informações obtidas por esta forma de transformação é limitada, uma vez que esta utiliza uma "janela" de dados fixa, isto é, o conteúdo de informações do sinal, amostrado seqüencialmente, é analisado em um intervalo fixo de seu espaço de domínio [27].

A Transformada Wavelet representa o próximo passo lógico: uma técnica de "janelamento" variável. Esta Transformada permite o uso de uma janela de tempo maior para analisar informações de baixa freqüência de forma mais precisa, e pequena janela para informações de alta freqüência [27].

A família das funções $\psi(x)$ chamadas "Wavelet mãe", com escalas variáveis, são obtidas pela fixação de $p \geq 0$ (fator de normalização) e para todo $a \in \mathfrak{R}, a \neq 0$, onde temos

$$
\psi_{a}(x)=|a|^{-p} \psi\left(\frac{x}{a}\right)
$$

Para pequenas escalas (pequenos valores de $a), \psi_{a}(x)$ possui alta frequiência, e para grandes valores de $a, \psi_{a}(x)$ possui baixa freqüência [28].

Com o objetivo de localizar no tempo as funções $\psi_{a}(x)$, introduzimos o fator $b \in \mathfrak{R}$. Sendo assim temos

$$
\psi_{a, b}(x)=\psi_{a}(x-b)=|a|^{-p} \psi\left(\frac{x-b}{a}\right)
$$

Condições para que $\psi$ seja uma wavelet mãe é que esta deve possuir média zero, decair rapidamente a zero e pertencer ao espaço que contenha todas as funções com energia finita, ou seja que $\psi \in L^{2}(\Re)$, desta forma a função $\psi_{a, b} \in L^{2}(\Re)$, e

$$
\left\|\psi_{a, b}\right\|^{2}=a^{1-2 p}\|\psi\|^{2}
$$


Para $p=1 / 2$, temos $\left\|\psi_{a, b}\right\|^{2}=\|\psi\|^{2}[28]$.

A TWC de um sinal $f(x)$ dado, considerando a Wavelet mãe $\psi(x)$, é definida como [23]:

$$
(T W C)(a, b):=|a|^{\frac{-1}{2}} \int_{-\infty}^{\infty} f(x) \psi\left(\frac{x-b}{a}\right) \cdot d x
$$

onde $a$ é o fator de dilatação ou escala e $b$ é o fator de translação. A equação (4.1.4) mostra que o sinal unidimensional original $f(x)$ é mapeado em uma nova função em um espaço bidimensional em escala $a$ e translação $b$ pela (TW). O coeficiente TWC $(a, b)$ representa o quão bem corresponde o sinal original $f(x)$ com a Wavelet mãe [24]. Desse modo, o grupo de coeficientes $\operatorname{TWC}(a, b)$ associados com um sinal particular é a representação Wavelet do sinal original $f(x)$ em relação à Wavelet mãe $\psi(x)$ como é ilustrado na Figura 11 extraída da referência [27].

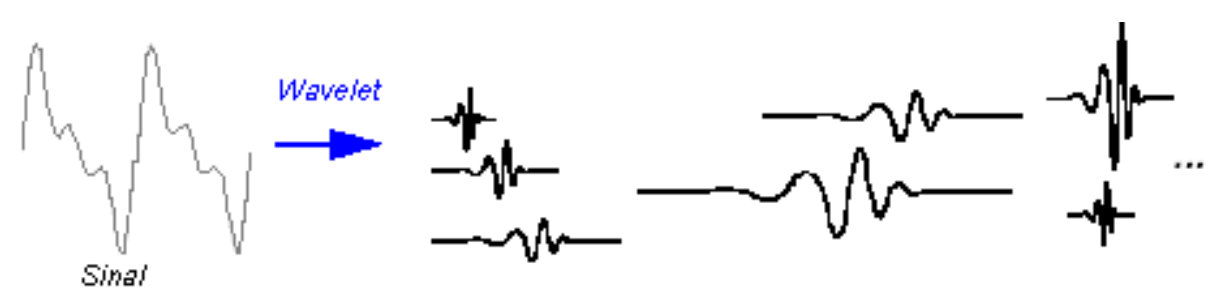

FIGURA 11 - Representação de um sinal em diferentes escalas e posições

Podemos visualizar a Wavelet mãe como uma função janelada. $\mathrm{O}$ fator de escala $a$ e o tamanho da janela são interdependentes, onde menores escalas implicam em menores janelas. Conseqüentemente, podemos analisar componentes de bandas estreitas de freqüência de um sinal com um pequeno fator de escala e componentes de bandas largas de frequiência com fatores de escala maiores, o que permite captar todas as características de um sinal particular [27].

\subsection{1) Escalamento}

Foi mencionado o fato da TW produzir um escalamento no tempo de um sinal, e agora será falado sobre escalamento e translação de funções Wavelets. 
Escalar uma Wavelet significa simplesmente dilatá-la ou contraí-la. Será detalhado aqui, o funcionamento do fator de escala que é usualmente denotado pela letra $a$. Se estivéssemos falando sobre segmentos de senóides, por exemplo, o efeito do fator de escala é muito facilmente observado, o que é ilustrado na Figura 12 [27], onde a diminuição do fator de escala " $a$ " contrai o gráfico da função:

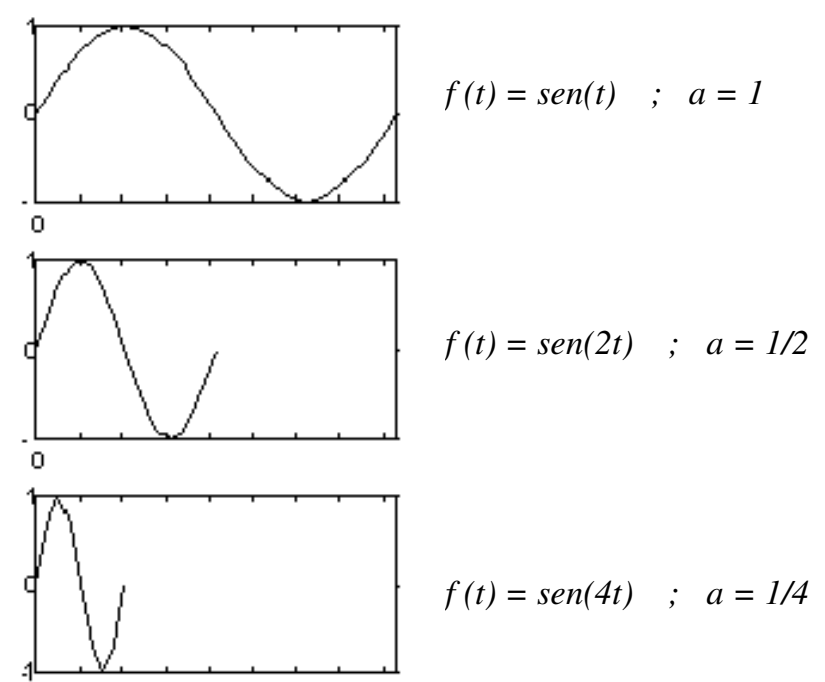

FIGURA 12 - Exemplo do fator de escala em uma função seno

O fator de escala trabalha exatamente da mesma forma com Wavelets. Quanto menor o fator de escala, mais "contraída" será a Wavelet. A Figura 13 ilustra o fator de escala atuando com funções Wavelets.

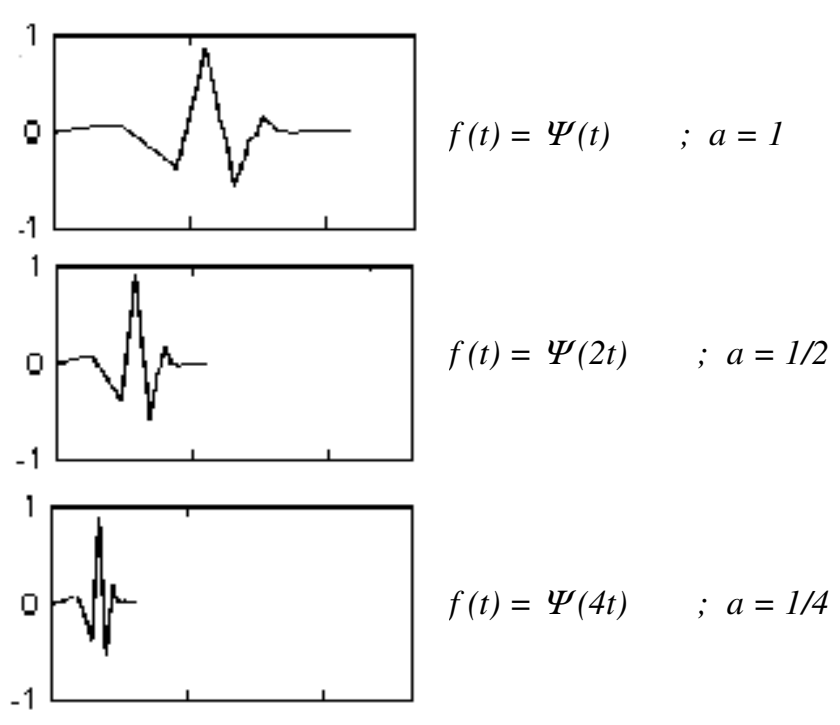

FIGURA 13 - Exemplo do fator de escala em uma função Wavelet. 
Fica claro através da Figura 12 que, para o segmento da senóide sen(wt), o fator de escala $a$ é relacionado (inversamente) com a frequiência em radianos $w$. Similarmente na Figura 13, com a análise Wavelets, a escala é relacionada com a freqüência do sinal. O que corresponde a:

- Baixa escala $a \rightarrow$ Wavelet contraída $\rightarrow$ detalhes que mudam rapidamente $\rightarrow$ alta freqüência $w$.

- Alta escala $a \rightarrow$ Wavelet dilatada $\rightarrow$ detalhes que mudam vagarosamente $\rightarrow$ baixa frequiência $w$.

\subsection{2) Translação}

Transladar uma Wavelet significa atrasá-la ou adiantá-la em relação ao eixo das abscissas, que é o que fazemos matematicamente quando escrevemos $f(x-k)$ como um atraso na função $f$ de um fator k, como pode ser visto abaixo na Figura 14.
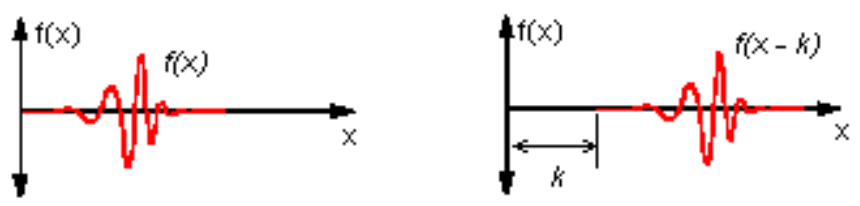

FIGURA 14 - Translação aplicada a uma Wavelet.

\subsection{3) Como Calcular a TWC}

A TWC é a integral em todo o intervalo de definição do sinal, multiplicado pelas versões escalonadas e transladadas da Wavelet mãe. Este processo produz coeficientes Wavelet que são função da escala e posição.

Será descrito em seguida uma seqüência de cálculos e/ou ações que ilustram qualitativamente a idéia de como se obter a TWC [27]:

1. Alinhe uma Wavelet com uma seção inicial do sinal original.

2. Calcule o coeficiente $\mathrm{C}=\operatorname{TWC}(a, b)$ que representa o quão intimamente relacionado está a Wavelet com a seção do sinal. Entre os coeficientes calculados, os maiores valores de $\mathrm{C}$ significam uma maior similaridade do 
sinal com a Wavelet. Note, na Figura 15, que o resultado irá depender da forma da Wavelet escolhida.

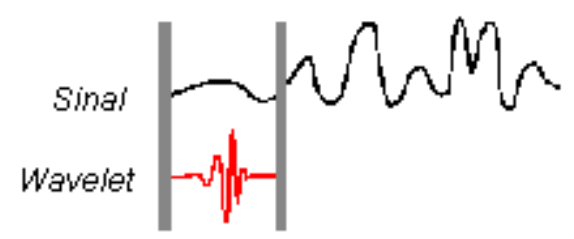

FIGURA 15 - Cálculo do fator C de relação entre a Wavelet mãe e o sinal.

3. Translade a Wavelet para a direita, como mostrado na Figura 16, e repita os passos 1 e 2 até que se tenha coberto todo o sinal.

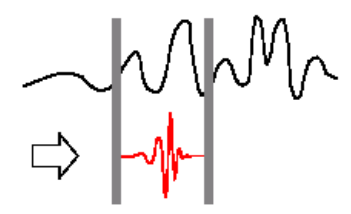

FIGURA 16 - Translação da função Wavelet

4. Escale (dilate) a Wavelet, como ilustrado na Figura 17 abaixo, e repita os passos de 1 a 3.

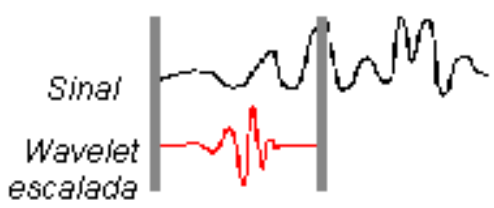

FIGURA 17 - Exemplo de escalamento da função Wavelet para o prosseguimento nos cálculos

5. Repita os passos de 1 a 4 para todas as escalas

Terminado o processo descrito acima, teremos os coeficientes da TWC para o sinal. 


\section{2) A Transformada Wavelet Discreta}

Na TWC, foi considerada a família

$$
\psi_{a, b}(x)=|a|^{-p} \psi\left(\frac{x-b}{a}\right)
$$

onde $b \in \mathfrak{R}, a \in \Re_{+}$com $a \neq 0$, com $\psi$ sendo a "Wavelet mãe".

Para se obter a Transformada Wavelet Discreta (TWD), $a$ e $b$ serão restritos somente a valores discretos. A discretização do parâmetro de dilatação se mostra natural, uma vez que se pode definir $a=a_{0}{ }^{m}$, onde $m \in Z$, e o passo de dilatação $a_{0} \neq 1$ é fixado. É assumido os valores de $a_{0}>1$ para maior conveniência [23].

Deve-se observar inicialmente que se necessita obter uma translação no domínio do tempo de forma que, quando for amostrada a função $f(x)$ no domínio da TW para os parâmetros $a$ e $b$, pode-se reconstruir a função $f(x)$ a partir da função $\operatorname{TWD}_{(a, b)}(f)$, que é a Transformada Wavelet Discreta da função $f(x)$, com a menor redundância possível. Como a largura da Wavelet muda com a mudança da escala, precisa-se correlacionar as discretizações dos fatores $a$ e $b$.

Para se obter a correta relação entre o fator de escala e a discretização no tempo, observa-se uma importante propriedade das Wavelets que é a invariância sob mudança de escala (fator $a$ ). Isto significa que ao mudar a escala $a$ da função $f$ e ao mesmo tempo, mudar a escala do espaço de variação da função pelo mesmo fator, a forma da Wavelets não muda [28]. Mais precisamente, ao se ter

$$
f_{a_{0}}(x)=a_{0}^{-1 / 2} f\left(\frac{x}{a_{0}}\right)
$$

$\log 0$

$$
T W C_{\left(a_{0} a, a_{0} b\right)}(f)=T W C_{(a, b)}(f) .
$$

É importante preservar esta propriedade da TW quando da discretização para que esta seja válida também para a TWD. Para atingirmos este objetivo precisamos incrementar o fator $b$ com o fator de escala $a_{0}$ quando mudarmos da escala $a^{m}=a_{0}{ }^{m}$ para a escala $a^{m+1}=a_{0}{ }^{m+1}$. Desta forma, podemos escolher um fator de translação $b_{0} \mathrm{e}$ 
definirmos o intervalo de variação de translação $\Delta b=a_{0}{ }^{m} b_{0}$. Conseqüentemente, para cada escala $a_{0}{ }^{m}$ a translação discretizada, segundo [28], é

$$
b_{m, n}=n a_{0}{ }^{m} b_{0}, \quad n \in Z .
$$

Finalmente, a discretização em translação e escala é definida por

$$
\Delta_{a_{0}, b_{0}}=\left\{\left(a_{0}{ }^{m}, n a_{0}{ }^{m} b_{0}\right), \quad m, n \in Z\right\} .
$$

A discretização da TW, $T W C_{(a, b)} f(x)=\left\langle f, \psi_{(a, b)}(x)\right\rangle$, para os fatores de translação e escala é dada por

$$
T W D_{(m, n)} f(x)=\left\langle f, \psi_{(m, n)}(x)\right\rangle,
$$

onde

$$
\psi_{(m, n)}(x)=\psi_{a_{0}{ }^{m}, n b_{0} a_{0}{ }^{m}}(x)=a_{0}{ }^{-m / 2} \cdot \psi\left(a_{0}{ }^{m} x-n b_{0}\right)
$$

Sendo assim a TWD pode ser escrita da seguinte forma:

$$
(T W D)(m, n):=\left.\left|a_{0}\right|^{m}\right|^{\frac{-1}{2}} \sum_{n} f(n) \psi\left(\frac{x-n b_{0} a_{0}{ }^{m}}{a_{0}{ }^{m}}\right)
$$

onde $\psi$ é a Wavelet mãe e os parâmetros $a$ e $b$ relativos a função TWC (Equação 4.1.4), são funções dos parâmetros inteiros $m$ e $n$, i.e. $a=a_{0}{ }^{m}$ e $b=n b_{0} a_{0}{ }^{m}$; fato que pode ser observado na Equação 4.2.9. Estes parâmetros são usados para gerar a família das funções Wavelets.

\section{3) Análise Multiresolução}

O efeito da mudança de escala de um sinal pode ser melhor interpretado usando-se o conceito de resolução. Para um melhor entendimento deste conceito, serão introduzidas as funções escala $\varphi(t)$ ao invés de ser iniciado diretamente com as funções Wavelets $\psi(t)$. Após as funções escala serem definidas a partir do conceito de resoluções, as funções Wavelets serão derivadas destas e a técnica de Análise Multiresolução (AMR) será melhor apresentada. 


\subsection{1) Funções Escala}

É definido como um conjunto de funções escala, a união das funções transladadas de uma função escala base por um fator de translação $k$ como é ilustrado na equação (4.3.1) que segue [29]:

$$
\varphi_{k}(t)=\varphi(t-k) \quad k \in \mathbf{Z} \quad \varphi \in L^{2}(R)
$$

O Subespaço de $L^{2}(R)$ que é expandido por estas funções é definido como

$$
v_{0}=\overline{\operatorname{Span}\left\{\varphi_{k}(t)\right\}}
$$

para todo inteiro $k$. A barra superior na equação indica que o subespaço $v_{0}$ é fechado. Dada uma função $f(t) \in v_{0}$, esta pode ser escrita como combinação linear do conjunto de funções escala $\varphi_{k}(t)$, o que é traduzido pela equação (4.3.3) que segue.

$$
f(t)=\sum a_{k} \varphi_{k}(t)
$$

Pode-se aumentar o tamanho do subespaço expandido pela mudança do fator de escala de tempo $j$ da função escala. Deve-se então introduzir na análise, via funções escala, o fator de escala $j$. Tal fator, juntamente com o fator de translação, gera uma família bi-dimensional de funções a partir da função escala base, por escalamento e translação, como é ilustrado na equação (4.3.4).

$$
\varphi_{j, k}(t)=2^{j / 2} \varphi\left(2^{j} t-k\right)
$$

sendo a expansão em $k$ dada por

$$
v_{j}=\overline{\operatorname{Span}}\left\{\varphi_{k}\left(2^{j} t\right)\right\}=\overline{\operatorname{Span}}\left\{\varphi_{j, k}(t)\right\}
$$

para todo $k \in \mathbf{Z}$. Isto significa que se $f(t) \in v_{j}$, esta pode ser expressa como

$$
f(t)=\sum_{k} a_{k} \varphi\left(2^{j} t-k\right)
$$

Uma forma de se interpretar o efeito da mudança do fator de escala $j$ é através da análise de resoluções. Esta forma de análise será melhor apresentada a seguir. 


\subsection{2) Análise Multiresolução com Funções Escala}

Para a apresentação da idéia de escalas e resoluções, será formulado o requerimento básico para Análise Multiresolução que é o conceito de espaços $v_{j}$ encaixantes, tais como [29]:

$$
\ldots \subset v_{-2} \subset v_{-1} \subset v_{0} \subset v_{1} \subset v_{2} \subset \ldots \subset L^{2}
$$

$\mathrm{ou}$

$$
v_{j} \subset v_{j+1} \quad \text { para todo } j \in Z
$$

com

$$
v_{-\infty}=\{0\}, \quad v_{\infty}=L^{2}
$$

Os espaços que contém altas resoluções, conterá também as baixas resoluções. Devido a definição de $v_{j}$, os espaços devem satisfazer a condição natural de escala

$$
f(t) \in v_{j} \quad \Leftrightarrow \quad f(2 t) \in v_{j+1}
$$

no qual elementos em um espaço são simplesmente versões escaladas dos elementos no espaço seguinte. A relação de espaços expandidos é melhor ilustrada na Figura 18 que segue.

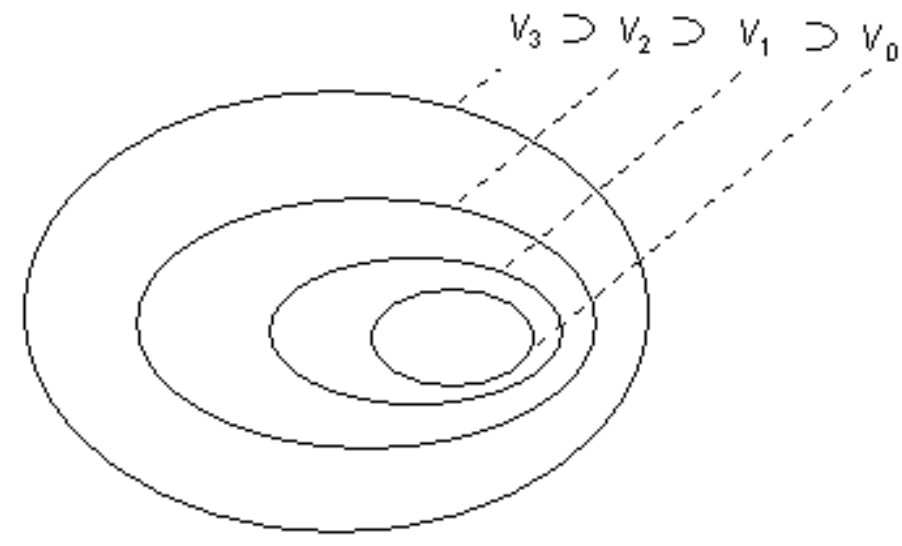

FIGURA 18 - Espaços encaixantes de vetores expandidos por funções escala. 
O encaixamento dos espaços expandidos de $\varphi\left(2^{j} t-k\right)$, denotado por $v_{j}$ e mostrado nas equações (4.3.7) e (4.3.8), ilustrado graficamente na Figura 18, é realizado pelo requerimento de que $\varphi(t) \in v_{1}$, o que significa que se $\varphi(t)$ está no espaço $v_{0}$, este estará também no espaço $v_{1}$, o espaço expandido por $\varphi(2 t)$. Isto significa que $\varphi(t)$ pode ser expresso como uma soma de valores transladados de $\varphi(2 t)$ como

$$
\varphi(t)=\sum_{n} h(n) \sqrt{2} \varphi(2 t-n), \quad n \in \mathbf{Z}
$$

onde os coeficientes $h(n)$ são uma sequiência real ou talvez complexa de números, chamados de coeficientes de função escala (ou filtro de escalamento, ou ainda vetor de escalamento) e o termo $\sqrt{2}$ é usado para normalização da função escala. Esta equação é chamada de Análise Multiresolução (AMR) ou equação de dilatação.

\subsection{3) Análise Multiresolução com Funções Wavelets}

Importantes características de muitos sinais são melhores descritas ou parametrizadas, não pelo uso das funções escalas $\varphi_{j, k}(t)$ com o incremento de $j$ para um aumento do tamanho do espaço expandido, mas pela definição de um conjunto de funções $\psi_{j, k}(t)$ ligeiramente diferentes. Estas funções $\psi_{j, k}(t)$ geram os espaços complementares àqueles expandidos por funções escala. Estas são chamadas Funções Wavelets [29].

Quando a propriedade de ortogonalidade é verificada entre as funções escala e Wavelets, algumas vantagens quando da análise de sinais são oferecidas. Dentre estas pode-se citar, cálculo fácil dos coeficientes de expansão e o teorema de Parseval que permite dividir a energia do sinal no domínio da Transformada Wavelet. O subespaço complementar entre $v_{j}$ e $v_{j+1}$ é definido como $w_{j}$. Este espaço $w_{j}$, como definido, possui todos os membros ortogonais ao espaço $v_{j}$, o que é traduzido pela equação (4.3.12) que segue.

$$
\left\langle\varphi_{j, k}(t), \psi_{j . l}(t)\right\rangle=\int \varphi_{j, k}(t) \psi_{j . l}(t) \cdot d t \quad=0 \quad j, k, l \in \mathbf{Z} .
$$


Pode-se então definir o espaço expandido, utilizando-se as funções Wavelets como

$$
v_{1}=v_{0} \oplus w_{0} .
$$

De uma forma geral pode-se escrever:

$$
L^{2}=v_{0} \oplus w_{0} \oplus w_{1} \oplus w_{2} \oplus \cdots
$$

A equação (4.3.14) é justificada quando $v_{0}$ é o subespaço expandido inicial a partir da função escala $\varphi(t-k)$. A Figura 19 ilustra os espaços encaixantes $v_{j}$ para diferentes escalas $j$, bem como os "espaços Wavelets" que são complementos ortogonais.

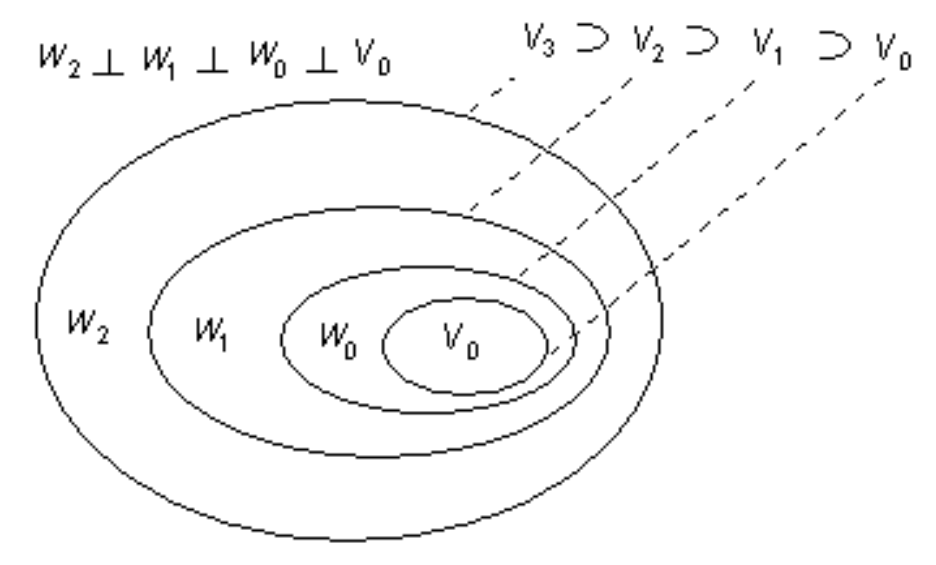

FIGURA 19 - Espaços vetoriais de funções escalas e Wavelets.

Uma vez que os “espaços Wavelets” residem no espaço de funções escala do índice seguinte, por exemplo $w_{0} \subset v_{1}$, estes podem ser representados como uma soma de funções escala da forma

$$
\psi(t)=\sum_{n} h_{1}(n) \sqrt{2} \varphi(2 t-n), \quad \mathrm{n} \in \mathrm{Z}
$$

para um certo conjunto de coeficientes $h_{l}(n)$.

A equação (4.3.15) fornece o protótipo da função Wavelet mãe $\psi(t)$ para uma classe de funções de expansão da forma

$$
\psi_{j, k}(t)=2^{j / 2} \psi\left(2^{j} t-k\right)
$$


onde o termo $2^{j}$ é o fator de escala de $t, k$ é o fator de translação e o fator $2^{j / 2}$ é o fator de normalização da função.

Foi definido um conjunto de funções $\varphi_{k}(t)$ e $\psi_{j, k}(t)$ que pode expandir todo o espaço $L^{2}(\boldsymbol{R})$. Desta forma, qualquer função $g(t) \in L^{2}(\boldsymbol{R})$ pode ser escrita da forma

$$
g(t)=\sum_{k=-\infty}^{\infty} c_{j_{0}}(k) \varphi_{j_{0}, k}(t) \quad+\quad \sum_{j=j_{0}}^{\infty} \sum_{k=-\infty}^{\infty} d(j, k) \psi_{j, k}(t)
$$

sendo esta representada como uma série em termos de funções escala e Wavelets.

Nesta expansão, a primeira soma na equação (4.3.17) fornece uma função que representa uma baixa resolução ou uma aproximação grosseira da função $g(t)$. Para cada incremento no fator de escala $j$ no segundo somatório, uma versão de resolução mais fina ou alta resolução é adicionada, o que acrescenta mais detalhes ao sinal.

\subsection{4) O Teorema de Parseval}

Se as funções escala e Wavelets formam bases ortonormais e possuem suporte compacto, existe um teorema de Parseval que relaciona a energia de um sinal $g(t)$ com a energia existente em cada componente e seus coeficientes Wavelets [23].

Para o caso geral de expansão ilustrado na equação (4.3.17), o teorema de Parseval é

$$
\int|g(t)|^{2} d t=\sum_{l=-\infty}^{\infty}|c(l)|^{2}+\sum_{j=j_{0}}^{\infty} \sum_{k=-\infty}^{\infty}\left|d_{j}(k)\right|^{2}
$$

com a energia no domínio de expansão dividida em função do fator de translação $k \mathrm{e}$ pelo fator de escala $j$.

\section{4) A Análise Multiresolução Através de Filtragem}

O processo de filtragem aqui descrito, apresenta uma forma de realização da técnica de AMR de uma forma bastante prática. Este processo baseia-se na filtragem de um sinal a ser analisado através de filtros passa alta e passa baixa, fornecendo versões do sinal original relativas aos coeficientes de funções Wavelets e funções escala, respectivamente. 
Considerando-se a Transformada Wavelet em suas formas Contínua e Discreta, fala-se usualmente em aproximações e detalhes. As aproximações são as altas escalas, isto é, as componentes de baixa freqüência do sinal. Os detalhes são as baixas escalas: as componentes de alta frequiência. O processo de filtragem é mostrado abaixo, na Figura 20, em uma forma simplificada, considerando-se somente o primeiro nível de filtragem :

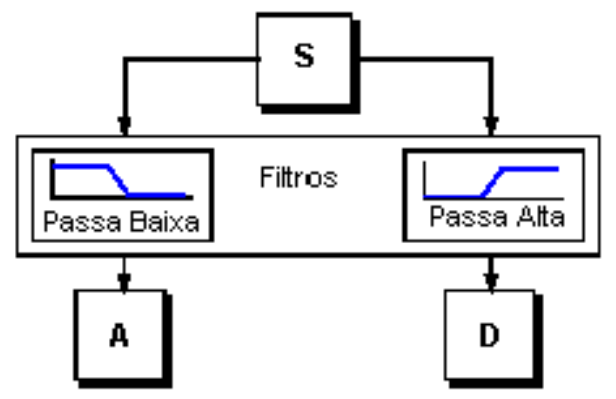

FIGURA 20 - Processo de filtragem de um sinal

O sinal original, $\mathrm{S}$, passa através de dois filtros complementares que fornecem como saída dois sinais. Infelizmente, se utilizarmos esse esquema em um sinal digital real, teremos duas vezes mais a quantidade de dados em relação aos dados iniciais. Suponha que o sinal original S consista de 1000 amostras de dados. Sendo assim as versões de aproximação (A) e de detalhes (D) do sinal original terão 1000 amostras cada um, totalizando 2000 amostras.

Para corrigir este problema, foi introduzido um operador que diminui o número de amostras (operador downsampling) [29] e [27], que considera dados intercalados, ou seja, considera o primeiro dado, rejeita o segundo, e assim por diante. A Figura 21 ilustra a operação do operador downsampling.
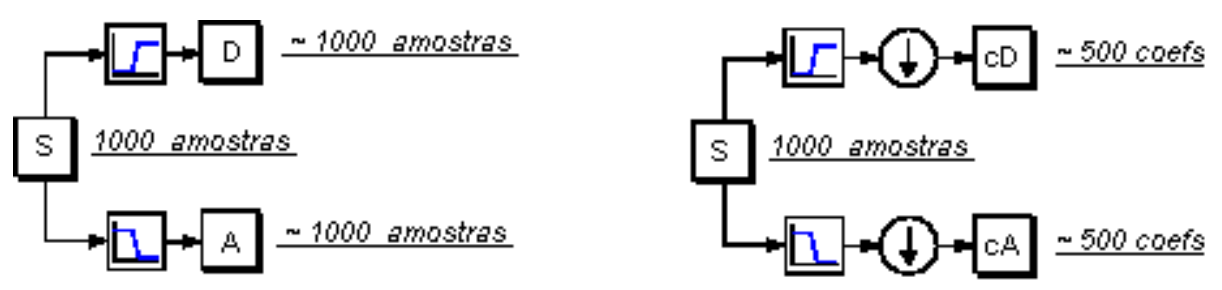

FIGURA 21 - Processo de diminuição do número de amostras do sinal. 
A Figura 21 ilustra o processo de filtragem com e sem o estágio de diminuição do número de amostras. O processo da direita, que inclui diminuição de amostras, produz os coeficientes cD e cA referentes a TWD. Para se obter uma maior apreciação deste processo, é apresentado um exemplo, Figura 22, com desenvolvimento da TWD de um sinal. O sinal utilizado para análise consiste em uma senóide com ruído de alta freqüência adicionado a ela.

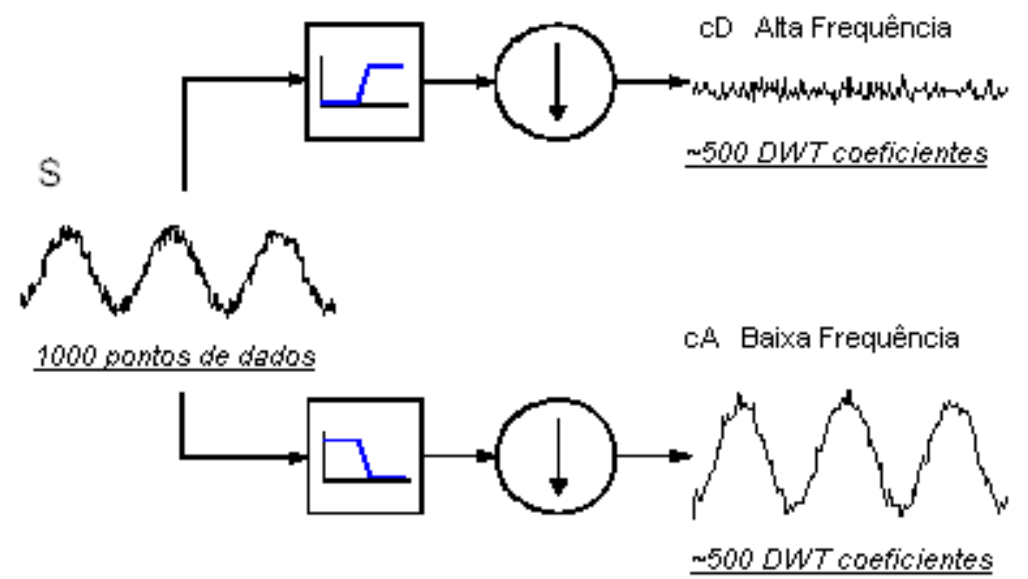

FIGURA 22 - Exemplo de filtragem com downsampling de um sinal senoidal ruidoso

Note que o coeficiente de detalhe $\mathrm{cD}$, Figura 22, consiste principalmente do ruído de alta frequiência, enquanto que os coeficientes cA contém muito menos ruído que o sinal original.

\subsection{1) Decomposição em Análise Multiresolução em Múltiplos Níveis}

O processo de decomposição pode ser iterado, com aproximações de decomposição sucessivas, como mostrado na Figura 23, de modo que um sinal é dividido em outras componentes de menor resolução. 


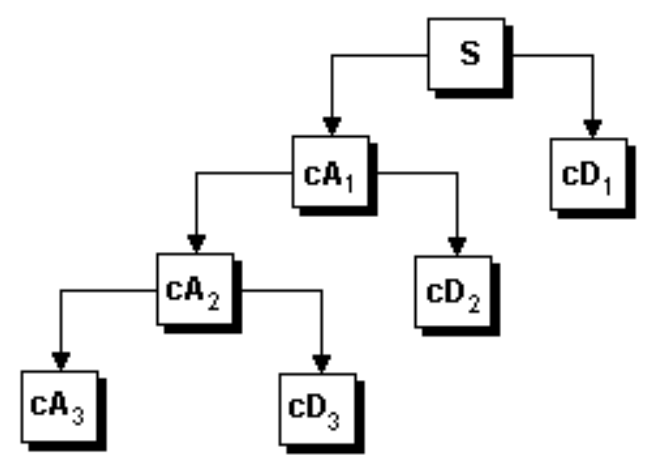

FIGURA 23 - Ilustração do processo sucessivo de decomposição de um sinal em AMR

A visualização da árvore de decomposição em coeficientes Wavelets, como mostrado na Figura 24, pode fornecer várias informações.

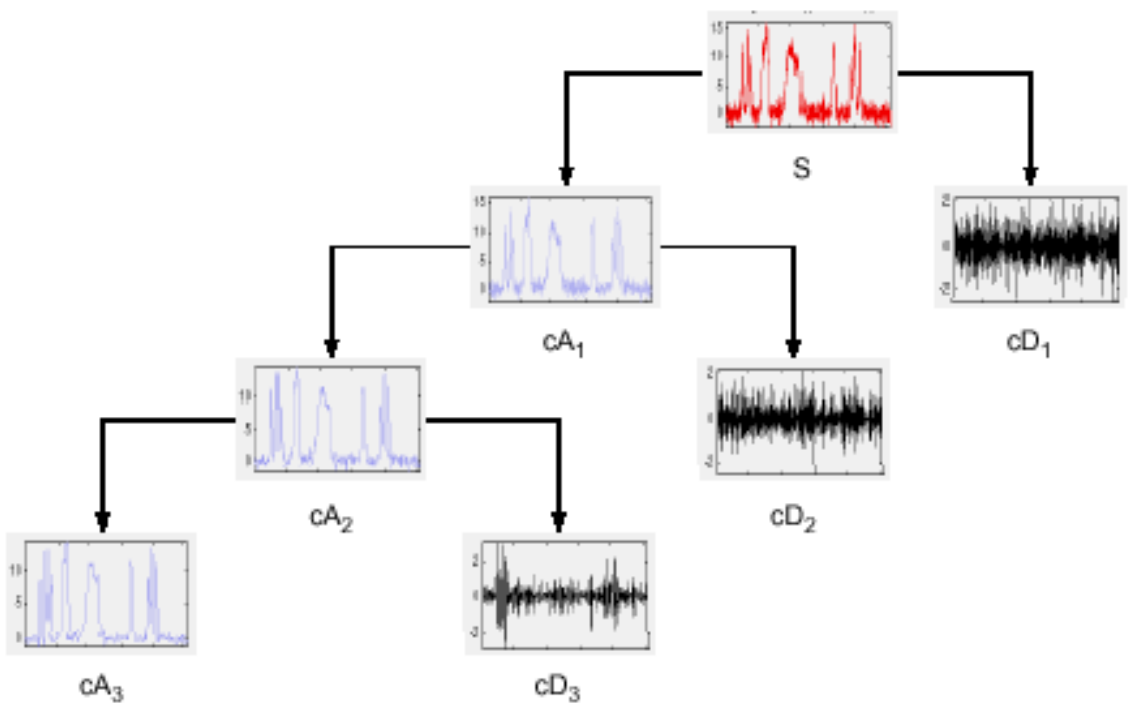

FIGURA 24 - Exemplo de decomposição sucessiva de um sinal

Uma vez que o processo é iterativo, na teoria pode-se decompô-lo indefinidamente. $\mathrm{Na}$ realidade, a decomposição pode proceder somente até que o detalhe individual consistir em somente uma amostra ou pixel para o caso de imagens. Na prática, selecionamos um número satisfatório de níveis baseado na natureza do sinal. Para os casos elétricos estudados, o número de decomposições é limitado pelo nível de frequência do sinal a ser analisado.

No Capítulo 5 e 6 a técnica exposta será empregada para a análise de sinais provenientes de um sistema elétrico de distribuição real. 


\section{ANÁLISE MULTIRESOLUÇÃ̃ APLICADA A DISTÚRBIOS RELACIONADOS COM A QUALIDADE DA ENERGIA ELÉTRICA.}

Com o objetivo de se desenvolver um classificador de distúrbios relacionados com a QE, necessitou-se a obtenção de dados que ilustrassem situações reais, ou seja, distúrbios que ocorressem no sistema elétrico. Para tanto, o simulador ATP [30] foi utilizado, tomando-se dados referentes a um sistema real de distribuição. Nas simulações desenvolvidas foi utilizada uma taxa amostral de 7,68 kHz devido a existência de instrumentos de medição e obtenção de dados que empregam frequência de amostragem similar, como por exemplo, o BMI (Basic Measuring Instrument) Modelo 7100, que apresenta um valor próximo a 7,7 kHz.

Outro ponto necessário para o desenvolvimento do trabalho foi a escolha do método a ser utilizado para desenvolver o classificador. Tendo sido escolhido a Transformada Wavelet (TW) sob a forma de Análise Multiresolução (AMR), uma questão natural foi: Qual será a função base (Wavelet mãe) a ser utilizada para a análise? Para responder tal pergunta, foram desenvolvidos estudos com diversas funções bases, devendo ser escolhida uma Wavelet mãe que fosse capaz de extrair características pertinentes aos diferentes distúrbios. Desta forma uma Wavelet mãe foi escolhida e a AMR foi empregada para analisar o comportamento dos diversos distúrbios simulados. Tal análise foi então utilizada para desenvolver um algoritmo que explorasse as diferenças apontadas nesta análise e classificasse cada distúrbio.

Este Capítulo apresenta inicialmente, na seção 5.1, o sistema elétrico simulado para obtenção dos dados referentes às diversas situações típicas de fenômenos relacionados com a QE. Na seção 5.2 está detalhado o estudo 
desenvolvido para a escolha da função base a ser utilizada. Em seguida, a seção 5.3 apresenta a técnica de AMR aplicada a alguns distúrbios com o intuito de ilustrar a capacidade da ferramenta utilizada em extrair características dos fenômenos relacionados com a $\mathrm{QE}$.

\subsection{O Sistema Elétrico em Estudo}

Como foram apresentados no Capítulo 2, exemplos típicos de distúrbios que se relacionam com a Qualidade da Energia são: afundamento de tensão, elevação de tensão, distorções harmônicas, transitórios decorrentes da energização de bancos de capacitores, etc.. Para caracterizar tais fenômenos, dispõem-se de simulações no software ATP sobre o circuito mostrado na Figura 25, que refere-se à um sistema de distribuição primário.

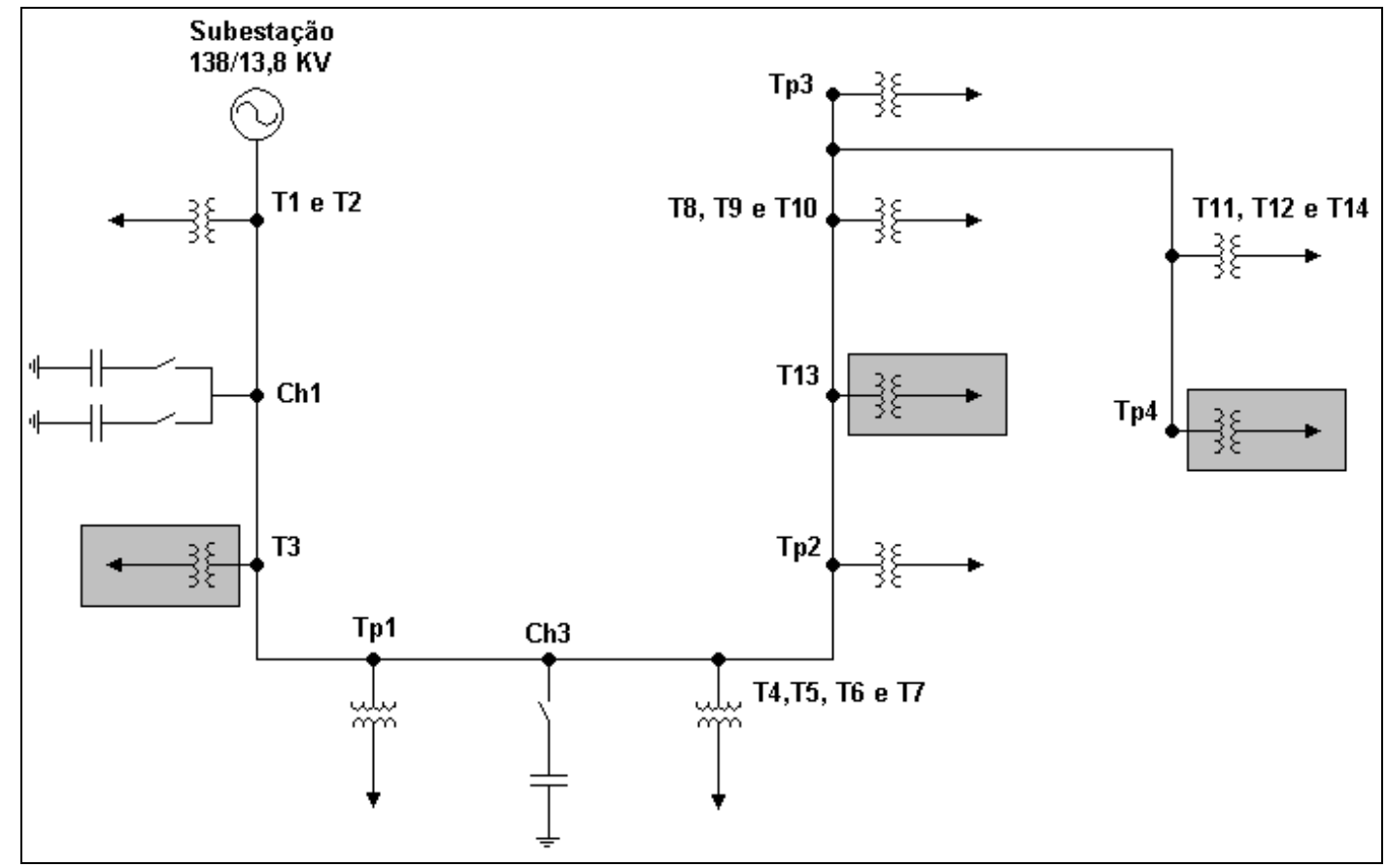

FIGURA 25 - Diagrama do sistema elétrico de distribuição analisado 
Neste circuito, o transformador da subestação $(138 / 13,8 \quad \mathrm{kV})$, os transformadores de distribuição 3 e 13 (T3 e T13) e o transformador particular 4 (Tp4), foram modelados considerando-se suas curvas de saturação, de acordo com dados obtidos da Cia Paulista de Força e Luz (CPFL). Já para os demais, considerouse somente os seus pontos de ligação com o sistema. Os transformadores particulares 1, 2 e 3 (Tp1, Tp2 e Tp3) compreenderam as cargas particulares referidas ao primário com uma parcela RL em paralelo a um banco de capacitores para a devida correção do fator de potência. Para dimensionar o banco de capacitores, as cargas foram consideradas com fator de potência original de 0,75 para posterior correção até os desejados 0,92. Os demais transformadores de distribuição compreenderam somente as cargas RL referidas ao primário, considerando-se um fator de potência geral de 0,9538. Os conjuntos formados pelos transformadores 1 e 2 (T1 e T2), 4, 5, 6 e 7 (T4, T5, T6 e T7), 8, 9, e 10 (T8, T9 е T10), 11, 12 е 14 (T11, T12 е T14) representam as cargas equivalentes desses transformadores, cujo ponto de conexão com o sistema é como indicado na figura. Cabe ainda destacar que tanto os transformadores de distribuição quanto os particulares apresentam ligações deltaestrela com resistência de aterramento de zero ohm. As Tabelas 3 e 4 apresentam dados tais como, carga nominal e fator de potência, referentes aos transformadores particulares e de distribuição respectivamente.

TABELA 3 - Dados dos transformadores particulares.

\begin{tabular}{c|cc|c|c}
\hline $\begin{array}{c}\text { Transformadores } \\
\text { Particulares }\end{array}$ & \multicolumn{2}{|c|}{ Carga Nominal (kVA) } & $\begin{array}{c}\text { Carga Incidente } \\
(\mathrm{kVA})\end{array}$ & $\begin{array}{c}\text { Fator de Potência da } \\
\text { Carga }\end{array}$ \\
\hline 1 & $2250 \quad(03$ trafos $)$ & 2500 & 0,92 \\
\hline 2 & $3000 \quad(04$ trafos $)$ & 1600 & 0,92 \\
\hline 3 & $450 \quad(02$ trafos $)$ & 456 & 0,92 \\
\hline 4 & $300 \quad(01$ trafos $)$ & 280 & 0,92 \\
\hline
\end{tabular}

Três bancos de capacitores (um de 1200 kVAr, BC 1 situado no ponto Ch1, e dois de $600 \mathrm{kVAr}$ cada, BC2 e BC3 situados nos pontos Ch1 e Ch3 respectivamente) estão instalados ao longo do sistema. O primeiro banco de capacitor é um banco de 
1200 kVAr instalado a 476 metros da subestação. Os outros dois bancos, que são de 600 kVAr, situam-se a 476 e 1176 metros da subestação, respectivamente.

O chaveamento do banco 3, realizou-se mantendo o banco BC 2 fixo (obtendo-se a condição de regime na presença do banco) com o chaveamento do banco BC 3 para a obtenção de oscilações transitórias.

O alimentador principal é constituído por um cabo nu, modelo CA-477 MCM, em estrutura aérea convencional com comprimento total de 1576 metros, e seus trechos são representados por elementos RL acoplados mutuamente, de acordo com dados extraídos da referência [31]. O sistema também possui um ramal onde estão localizados os transformadores de distribuição 11, 12 e 14 e também o transformador particular 4. Neste ramal o modelo do cabo é $1 / 0$ AWG, com comprimento de 233 metros.

TABELA 4 - Dados dos transformadores de distribuição.

\begin{tabular}{c|c|c|c}
\hline $\begin{array}{c}\text { Transformadores } \\
\text { de Distribuição }\end{array}$ & $\begin{array}{c}\text { Carga Nominal } \\
(\mathrm{kVA})\end{array}$ & $\begin{array}{c}\text { Carga Incidente } \\
(\mathrm{kVA})\end{array}$ & $\begin{array}{c}\text { Fator de Potência da } \\
\text { Carga }\end{array}$ \\
\hline 1 & 75 & 40 & 0,9538 \\
\hline 2 & 75 & 31 & 0,9538 \\
\hline 3 & 45 & 32 & 0,9538 \\
\hline 4 & 45 & 22 & 0,9538 \\
\hline 5 & 112,5 & 19 & 0,9538 \\
\hline 6 & 225 & 89 & 0,9538 \\
\hline 7 & 150 & 27 & 0,9538 \\
\hline 8 & 150 & 29 & 0,9538 \\
\hline 9 & 45 & 9 & 0,9538 \\
\hline 10 & 225 & 19 & 0,9538 \\
\hline 11 & 30 & 26 & 0,9538 \\
\hline 12 & 150 & 86 & 0,9538 \\
\hline 13 & 75 & 19 & 0,9538 \\
\hline 14 & 75 & 7 & 0,9538 \\
\hline
\end{tabular}




\subsubsection{Caracterização de Fenômenos Através de Simulações com o Sistema em Estudo}

Para a realização de testes no algoritmo é necessário a geração de um conjunto de casos abrangendo as diferentes situações que podem ocorrer no sistema. Para tanto, faltas e chaveamento dos bancos de capacitores foram simulados em diversos pontos do sistema sob condições variadas. Este sub-item apresenta os inúmeros testes realizados no software ATP com o sistema de distribuição em estudo, onde o arquivo de entrada de dados utilizado é apresentado no Apêndice I.

As Tabela 5 e 6 apresentam os resultados das simulações de faltas (fase-A terra) para obtenção de afundamentos e elevações de tensão, considerando os ângulos de incidência de falta de 0 e $90^{\circ}$. Salienta-se que foram obtidos os mesmos resultados em se tratando da amplitude dos distúrbios para os ângulos de incidência de falta simulados. Para todos os casos simulados a medição foi realizada na subestação. Nestas tabelas, os locais de aplicação das faltas estão abreviados segundo apresentado na Figura 25.

TABELA 5 - Afundamentos de tensão obtidos através de simulações no sistema.

\begin{tabular}{c|c|c|c|c}
\hline $\begin{array}{c}\text { Índice dos } \\
\text { casos }\end{array}$ & $\begin{array}{c}\text { Localização da } \\
\text { Falta }\end{array}$ & $\begin{array}{c}\text { Ângulo de } \\
\text { Incidência }(\stackrel{\circ}{ })\end{array}$ & $\begin{array}{c}\text { Resistência de } \\
\text { Falta }(\Omega)\end{array}$ & $\begin{array}{c}\text { Afundamento } \\
\text { Obtido }(\%)\end{array}$ \\
\hline 1 & T13 & 0 e 90 & 9 & 10 \\
\hline 2 & Ch3 & 0 e 90 & 6 & 15 \\
\hline 3 & Ch3 & 0 e 90 & 4 & 20 \\
\hline 4 & Ch3 & 0 e 90 & 3 & 25 \\
\hline 5 & T13 & 0 e 90 & 2 & 30 \\
\hline 6 & Subestação & 0 e 90 & 2 & 35 \\
\hline 7 & T13 & 0 e 90 & 1 & 40 \\
\hline 8 & T13 & 0 e 90 & 0,5 & 45 \\
\hline 9 & Ch1 & 0 e 90 & 1 & 50 \\
\hline 10 & Ch1 & 0 e 90 & 0,8 & 55 \\
\hline 11 & Ch1 & 0 e 90 & 0,6 & 60 \\
\hline 12 & Subestação & 0 e 90 & 0,6 & 65 \\
\hline 13 & Subestação & 0 e 90 & 0,5 & 70 \\
\hline 14 & Subestação & 0 e 90 & 0,4 & 75 \\
\hline 15 & Subestação & 0 e 90 & 0,3 & 80 \\
\hline 16 & Subestação & 0 e 90 & 0,2 & 85 \\
\hline 17 & Subestação & 0 e 90 & 0,1 & 90 \\
\hline
\end{tabular}


TABELA 6 - Elevações de tensão obtidas através de siulações no sistema.

\begin{tabular}{c|c|c|c|c}
\hline $\begin{array}{c}\text { Indice dos } \\
\text { casos }\end{array}$ & $\begin{array}{c}\text { Localização da } \\
\text { Falta }\end{array}$ & $\begin{array}{c}\text { Ângulo de } \\
\text { Incidência }(\stackrel{9}{ })\end{array}$ & $\begin{array}{c}\text { Resistência de } \\
\text { Falta }(\Omega)\end{array}$ & $\begin{array}{c}\text { Elevação de } \\
\text { Tensão Obtida } \\
(\%)\end{array}$ \\
\hline 1. & Subestação & 0 e 90 & 5 & 10 \\
\hline 2. & Tp4 & 0 e 90 & 3 & 15 \\
\hline 3. & Tp4 & 0 e 90 & 2 & 20 \\
\hline 4. & Tp4 & 0 e 90 & 1 & 25 \\
\hline 5. & Tp4 & 0 e 90 & 0,5 & 30 \\
\hline 6. & Ch1 & 0 e 90 & 1 & 35 \\
\hline 7. & Ch1 & 0 e 90 & 0,7 & 40 \\
\hline 8. & Ch1 & 0 e 90 & 0,5 & 45 \\
\hline 9. & Subestação & 0 e 90 & 0,5 & 50 \\
\hline 10. & Subestação & 0 e 90 & 0,4 & 55 \\
\hline 11. & Ch1 & 0 e 90 & 0,05 & 60 \\
\hline 12. & Subestação & 0 e 90 & 0,1 & 65 \\
\hline 13. & Subestação & 0 e 90 & 0,04 & 70 \\
\hline
\end{tabular}

Ainda em relação às simulações, foram gerados oito casos característicos de interrupção momentânea segundo a definição apresentada na seção 2.2.1. Tais casos foram obtidos através de faltas diretamente na subestação, com resistência variando entre 0,01 e 0,1 ohms e variando o ângulo de inserção de falta em $0^{\circ}$ e $90^{\circ}$. A Tabela 7 apresenta os resultados das simulações para a obtenção dos casos descritos.

TABELA 7 - Interrupções momentâneas geradas através de simulações de faltas.

\begin{tabular}{c|c|c|c|c}
\hline $\begin{array}{c}\text { Índice dos } \\
\text { casos }\end{array}$ & $\begin{array}{c}\text { Ponto de } \\
\text { aplicação da falta }\end{array}$ & $\begin{array}{c}\text { Ângulo de } \\
\text { incidência }(\stackrel{\circ}{\circ})\end{array}$ & $\begin{array}{c}\text { Resistência de } \\
\text { Falta }(\Omega)\end{array}$ & $\begin{array}{c}\text { Amplitude de } \\
\text { Interrupção obtido } \\
(\%)\end{array}$ \\
\hline 1 & Subestação & 0 e 90 & 0,10 & 92 \\
\hline 2 & Subestação & 0 e 90 & 0,08 & 94 \\
\hline 3 & Subestação & 0 e 90 & 0,05 & 96 \\
\hline 4 & Subestação & 0 e 90 & 0,01 & 99 \\
\hline
\end{tabular}

Para a obtenção de oscilações transitórias, foram utilizados os bancos BC2 e $\mathrm{BC} 3$ situados nos pontos $\mathrm{Ch} 1$ e $\mathrm{Ch} 3$, respectivamente. $\mathrm{O}$ chaveamento foi realizado no ponto $\mathrm{Ch} 3$ (banco BC3) estando o banco BC2 ligado em regime permanente. A Tabela 8 apresenta os 12 casos simulados, lembrando que o banco foi chaveado com ângulos de inserção de 0 e $90^{\circ}$. 
TABELA 8 - Casos simulados para obtenção de oscilações transitórias

\begin{tabular}{c|c|c|c}
\hline $\begin{array}{c}\text { Número de } \\
\text { Casos }\end{array}$ & Banco Chaveado & Ângulo de Incidência ( $\stackrel{)}{ })$ & Local da medição \\
\hline 1 & BC3 & 0 e 90 & Tp4 \\
\hline 2 & BC3 & 0 e 90 & T8 \\
\hline 3 & BC3 & 0 e 90 & T3 \\
\hline 4 & BC3 & 0 e 90 & T13 \\
\hline 5 & BC3 & 0 e 90 & T1 \\
\hline 6 & BC3 & 0 e 90 & Subestação \\
\hline
\end{tabular}

Para a obtenção dos casos de ruídos, foram utilizados o software Matlab e uma forma de onda característica do sistema em regime permanente. Através do software mencionado, formas de ondas foram superpostas ao sinal de regime. As formas de ondas superpostas são constituídas de ruído branco com amplitude variando entre 0,1 e $1 \%$ da amplitude máxima do sinal em regime. Estes compreendem os 10 casos de ruídos utilizados para testes do algoritmo classificador desenvolvido.

\subsection{Escolha da Wavelet mãe}

Com o objetivo de selecionar uma função base Wavelet que melhor se adeque à análise de distúrbios relacionados com a $\mathrm{QE}$, testes foram realizados com várias destas. Tais testes consistiram em submeter os distúrbios afundamento de tensão, elevação de tensão, ruídos e distorções harmônicas, gerados a uma taxa amostral de 9,6 kHz para análise, utilizando-se diversas funções bases ortogonais. Os testes desenvolvidos encontram-se relatados em um artigo apresentado no Congresso Brasileiro de Automática em Setembro de 2002 (CBA2002) [32], apresentado no Apêndice III.

Geralmente, Wavelets mais suaves indicam melhor resolução em freqüência que Wavelets que possuem variações bruscas como a Wavelet de Haar (Figura 26a), sendo o oposto aplicado para resolução no domínio do tempo. As funções: Haar, Daubechies ( $\mathrm{dbN}, \mathrm{N}=2,3, \ldots, 8)$, Symlets ( $\mathrm{ymM}, \mathrm{M}=1,2, \ldots 8$ ) e Coiflets (coifP, $\mathrm{P}=$ $1,2, \ldots, 5)$, formam o grupo de vinte e uma bases ortogonais submetidas a testes com o objetivo de detectar e localizar distúrbios relacionados com a QE. Note-se que N, M 
e P representam a ordem de tais funções, sendo algumas destas exemplificadas na Figura 26.

A técnica de ARM foi empregada para análise dos fenômenos afundamento de tensão, elevação de tensão, ruídos e distorções harmônicas, com a utilização das vinte e uma bases ortogonais para cada distúrbio mencionado.
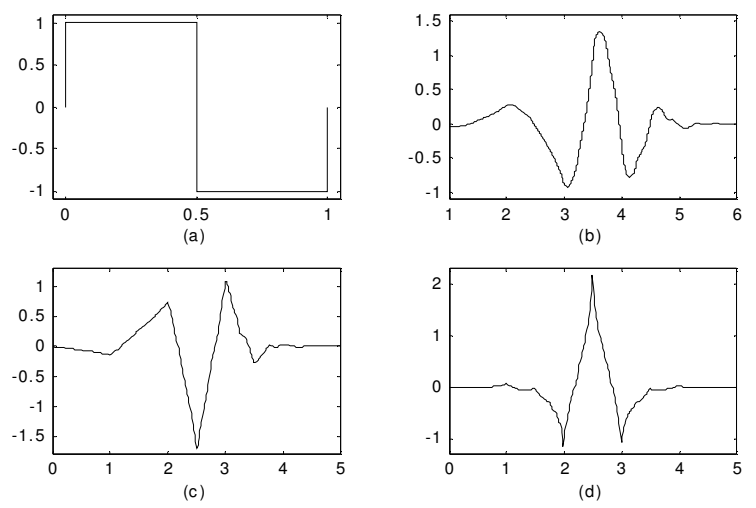

FIGURA 26 - Funções da base Wavelets: Haar (a), db4 (b), sym3 (c) e coifl (d).

A escolha de uma base para a análise de fenômenos relacionados com a QE deve considerar sua capacidade de distinção entre o nível de freqüência do sinal original e o nível de freqüência dos distúrbios. Uma base que se molde em tal premissa pode ser utilizada também para a classificação extraindo-se características inerentes a cada distúrbio, como o exemplo apresentado por SANTOSO et al. [8].

Salienta-se que o objetivo da análise foi a de escolher uma função base adequada para o desenvolvimento de um algoritmo capaz de detectar, localizar e classificar distúrbios relacionados com a QE automaticamente. Para tanto, uma função base será adequada quando esta for capaz de diferenciar todos os distúrbios e o sinal senoidal puro através de características ilustradas nas versões de detalhes em seus níveis de decomposição.

Pôde ser observado que aumentando a ordem das Wavelets mães ortogonais, seus comportamentos em suavidade oferecem melhor resolução em frequência. Sendo assim, as Wavelets de Daubechies e Symlet de ordem superior a três e Coiflets de ordem superior a dois oferecem melhores resultados em relação às bases Wavelets ortogonais utilizadas para análise de distúrbios ligados à QE. Tal resultado, associado à facilidade de cálculos que a envolve, justifica a ampla utilização da Wavelet de 
Daubechies de quarta ordem (db4) para análises em SEP. Por outro lado, por apresentarem comportamentos com menor suavidade, as demais bases $(\mathrm{dbN}, \mathrm{N}=$ $1, \ldots, 3$, symM $, M=1, \ldots, 3$ e coifP $P=1$ e 2 ) se mostraram inviáveis na aplicação em destaque neste trabalho.

\subsection{Aplicação da Técnica de AMR em Distúrbios Relacionados com a QE}

Nesta seção serão apresentados resultados obtidos da aplicação da técnica de AMR a fenômenos relacionados com a QE. A técnica de AMR, como já descrito no item 4.3, consiste na decomposição do sinal a ser analisado em dois outros sinais, uma versão que contém os detalhes do sinal e outra atenuada (ou de aproximação), através de filtros passa alta $\left(h_{1}\right)$ e passa baixa $\left(h_{0}\right)$ respectivamente. Como o sinal atenuado (proveniente do filtro passa baixa) é novamente decomposto resultando em dois outros novos sinais, detalhado e atenuado, em níveis de freqüência diferentes, estes fornecem informações diretas no domínio da freqüência e do tempo. Espera-se que estes novos sinais decompostos nos indiquem, diretamente, a existência de algum distúrbio e a sua localização, pois estes estariam dentro de níveis de frequiências diferentes do nível da freqüência do sinal fundamental. Tal procedimento de análise é ilustrado na Figura 27, onde o sinal $f(x)$ é submetido ao processo de decomposição em AMR. A Figura 28 ilustra as versões de um sinal $f(x)$ resultantes do processo de decomposições.

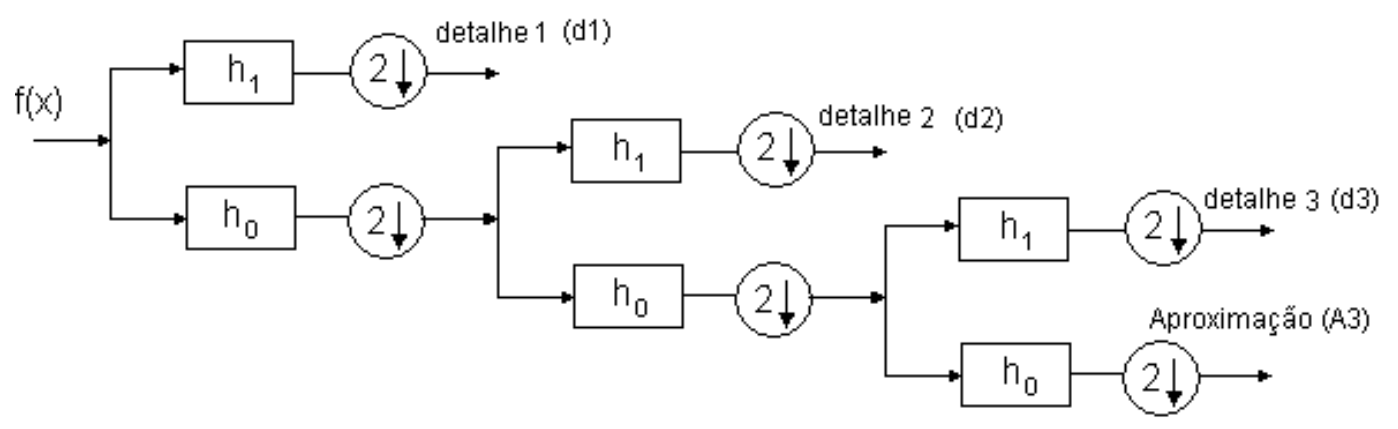

FIGURA 27 - Processo de decomposição de um sinal em AMR. 


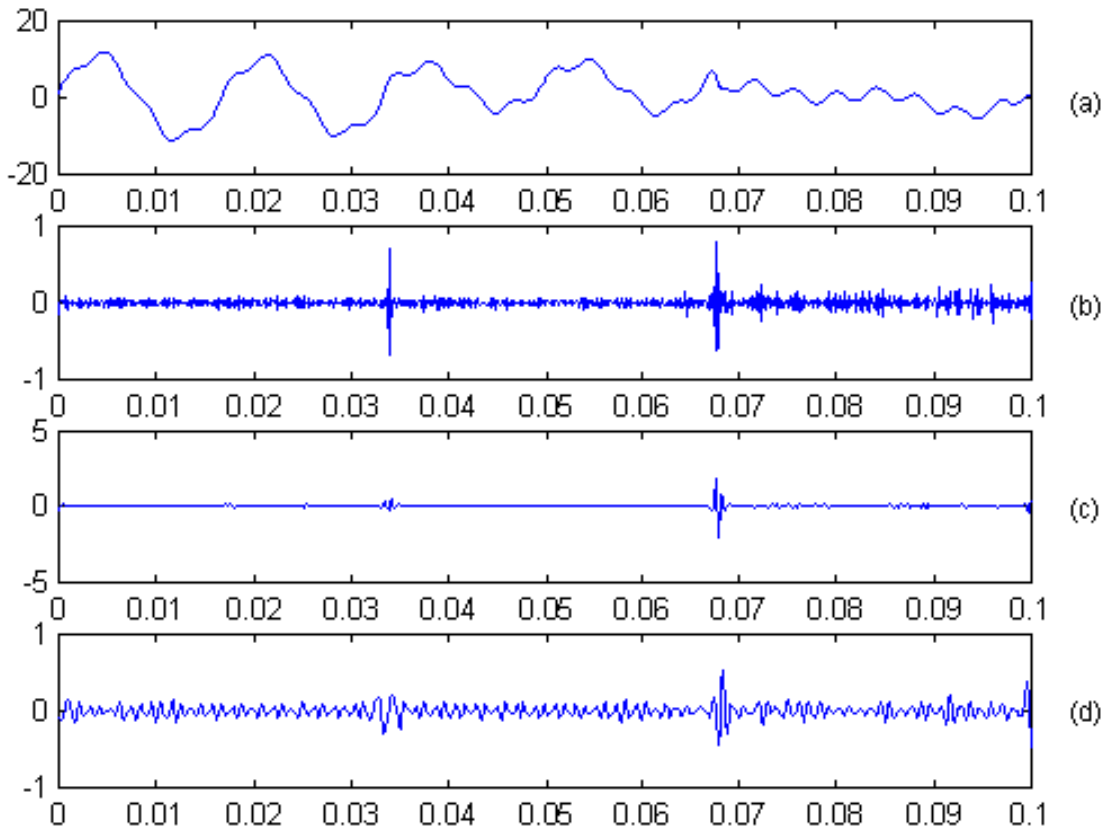

FIGURA 28 - Versões de um sinal decomposto em AMR. Versão referente à terceira aproximação $(a)$, primeiro $(b)$, segundo $(c)$ e terceiro $(d)$ detalhe.

Utilizando-se a técnica descrita, foram analisados diversas situações de distúrbios tais como: afundamento e elevação de tensão, ruído e oscilações transitórias, com o intuito de obter-se características inerentes a cada tipo de distúrbio de forma a detectá-los, localizá-los e classificá-los.

Com o objetivo de diferenciar as diferentes situações, será analisado primeiramente um sinal senoidal característico do regime permanente do sistema. As Figuras 29 e 30 ilustram o sinal de regime e suas quatro primeiras decomposições em AMR.

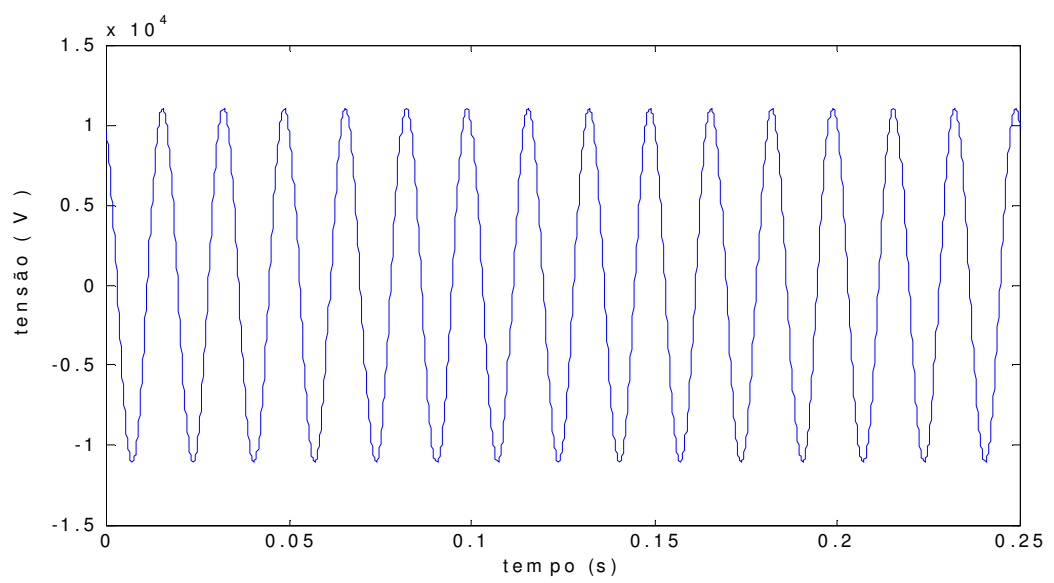


FIGURA 29 - Sinal de tensão em regime permanente.
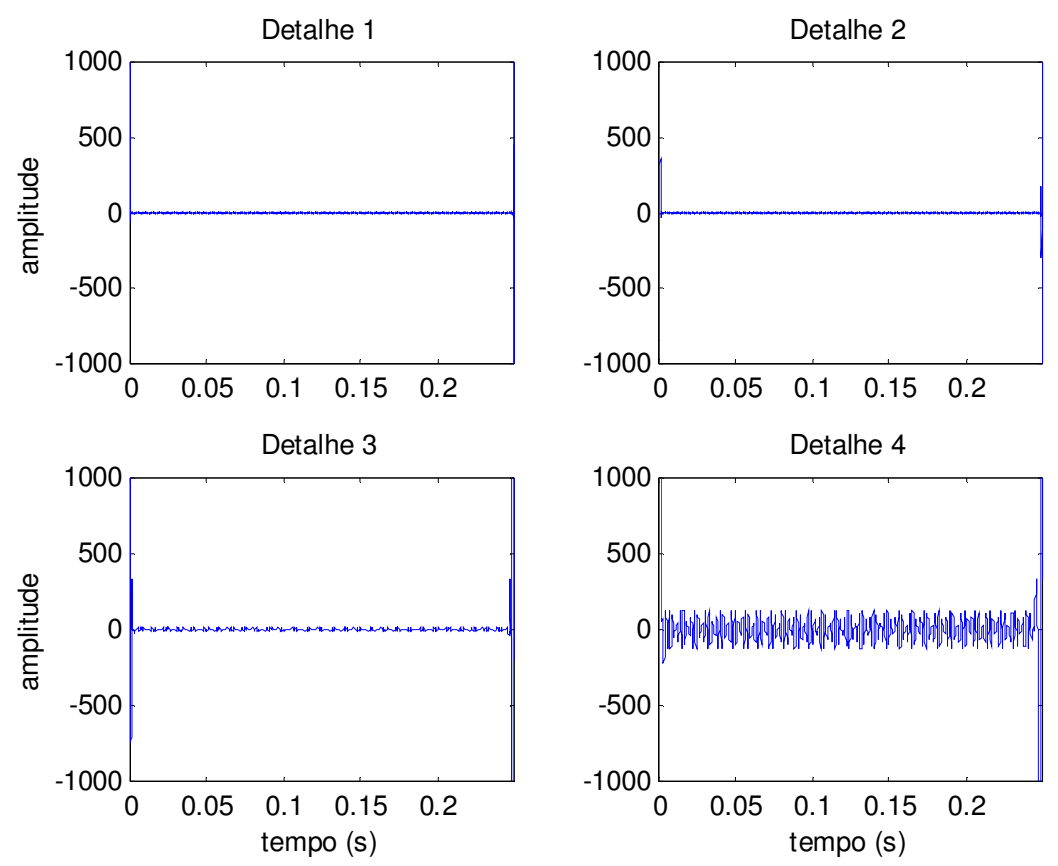

FIGURA 30 - Decomposição em AMR de um sinal em regime permanente.

\subsubsection{AMR aplicada ao Distúrbio Afundamento de Tensão}

Um afundamento de tensão foi detectado próximo a subestação de energia, vide sistema apresentado na Figura 25, como conseqüência de uma falta fase-terra, com duração de 3 ciclos, no transformador T13 a uma distância de aproximadamente 1.400 metros do ponto de medição. O ângulo de inserção da falta considerada foi de $0^{\circ}$ e a resistência de falta de $9 \mathrm{ohms}$. Desta forma, a porcentagem do afundamento de tensão atingiu $10 \%$ como ilustrado na Figura 31. Como dito anteriormente, o distúrbio afundamento de tensão é caracterizado por um decréscimo no valor eficaz da onda, podendo causar o mau funcionamento de equipamentos sensíveis no sistema.

A Figura 32 apresenta os quatro primeiros níveis de decomposição em AMR do sinal com afundamento de tensão. Pode-se observar que a TW apresenta picos nos instantes de inicio e fim do distúrbio nos níveis 1,2 e 3 , tendo sido menos expressivos no nível 1. Este picos, que não aparecem na decomposição do sinal de 
tensão em regime, indicam a presença de freqüências que não estão presentes no sinal senoidal puro. Desta forma, a AMR é capaz de detectar as anomalias no sinal de tensão, indicando a presença do distúrbio afundamento de tensão, detectando-o e localizando-o.

Analisando os níveis 2 e 3 de decomposição apresentados na Figura 32, podese detectar a presença de níveis de freqüências distintas mesmo depois do término do distúrbio afundamento de tensão em estudo.

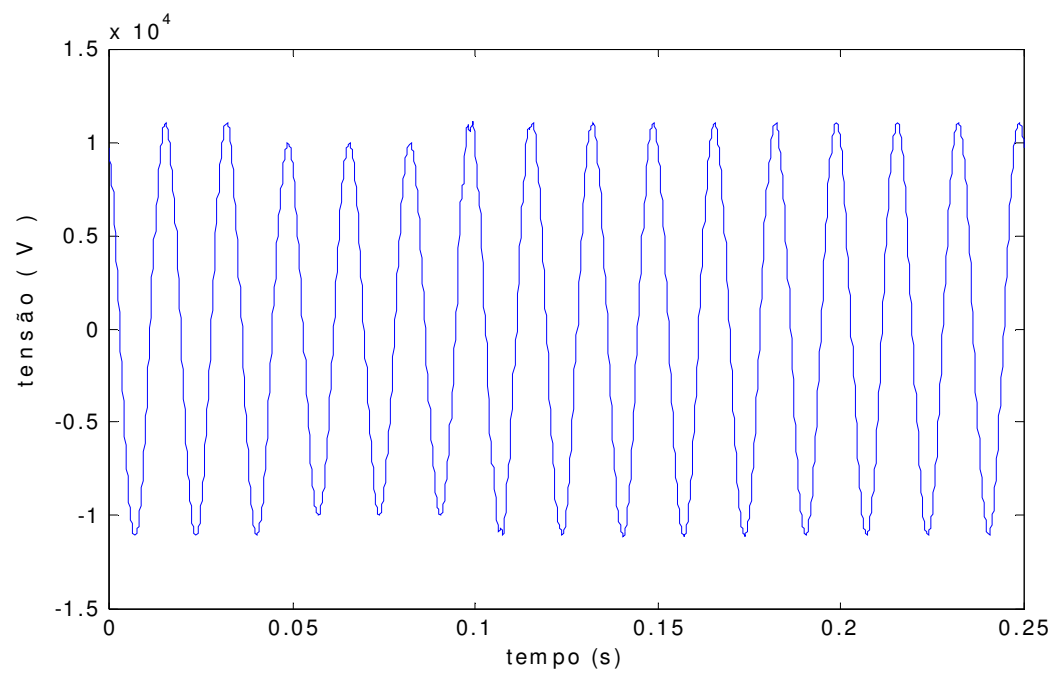

FIGURA 31 - Afundamento de tensão de $10 \%$.
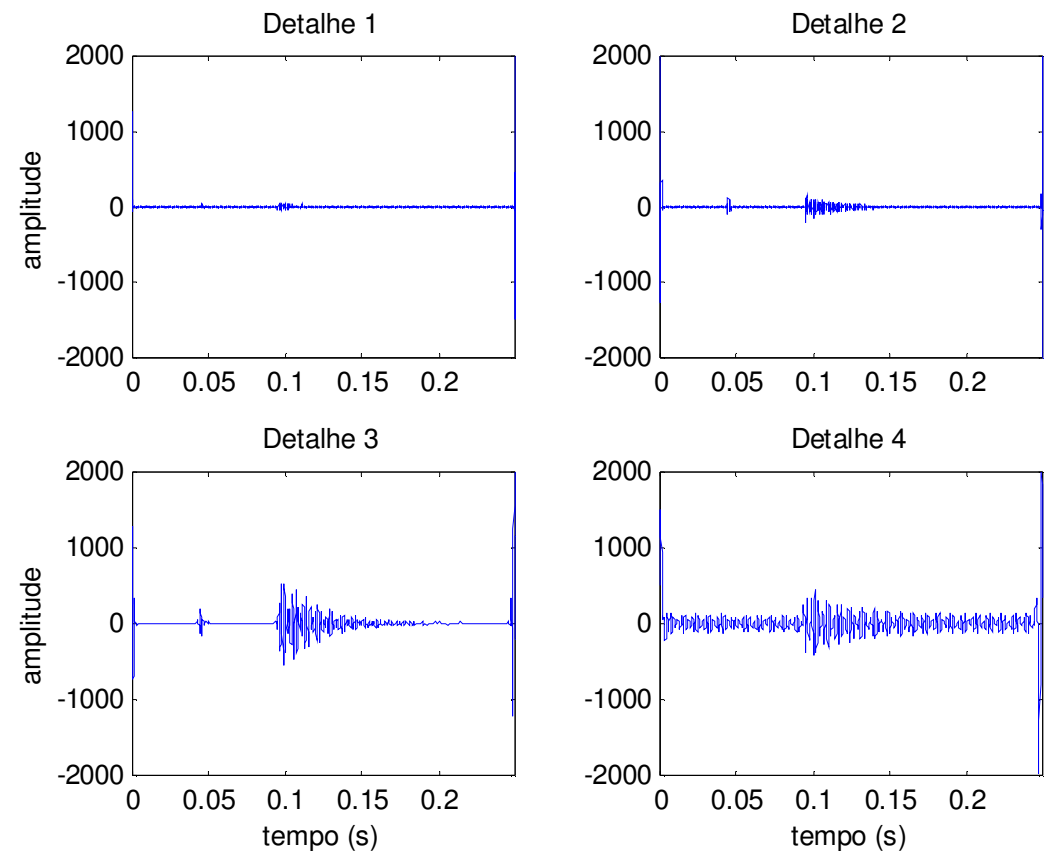
FIGURA 32 - Decomposição em AMR de um afundamento de tensão de 10\%.

\subsubsection{AMR aplicada ao Distúrbio Elevação de Tensão}

Uma falta fase-terra foi simulada com duração de 3 ciclos, no transformador particular 4 (Tp4) a uma distância aproximada de 1800 metros da subestação, com resistência de falta de $1 \mathrm{ohm}$ e ângulo de incidência de falta de $90^{\circ}$.

Decorrente da mesma, uma elevação de tensão com amplitude de $25 \%$ foi caracterizada no ponto de medição (subestação). A Figura 33 apresenta o resultado de tal simulação, onde pode ser observada a elevação da tensão.

Decompondo o sinal apresentado em AMR, obteve-se as formas de onda ilustradas na Figura 34. Nesta, pode-se notar a presença de picos que indicam os instantes de início e fim do distúrbio já no primeiro detalhe de decomposição.

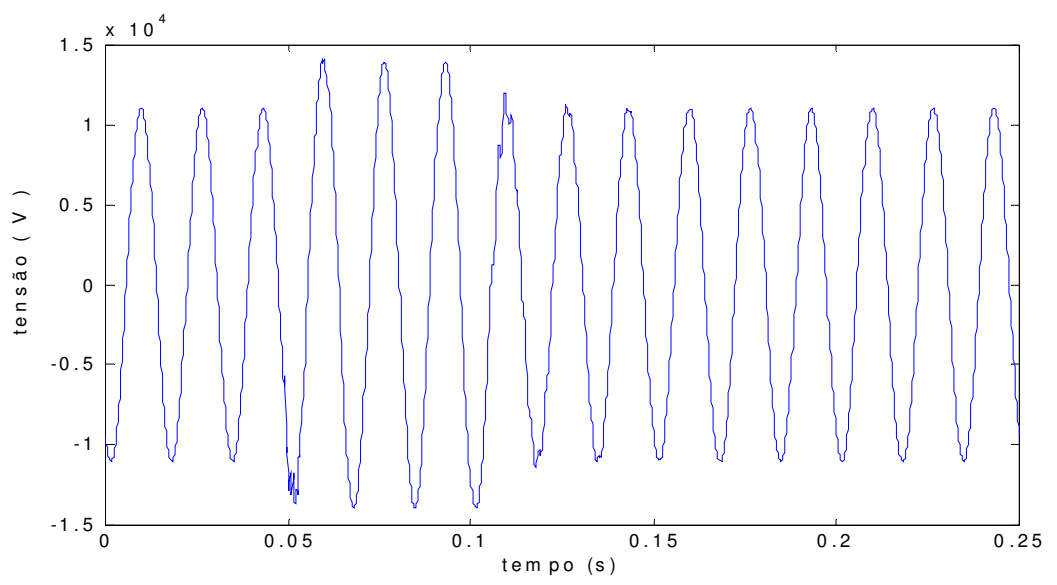

FIGURA 33 - Elevação de tensão de 25\%. 

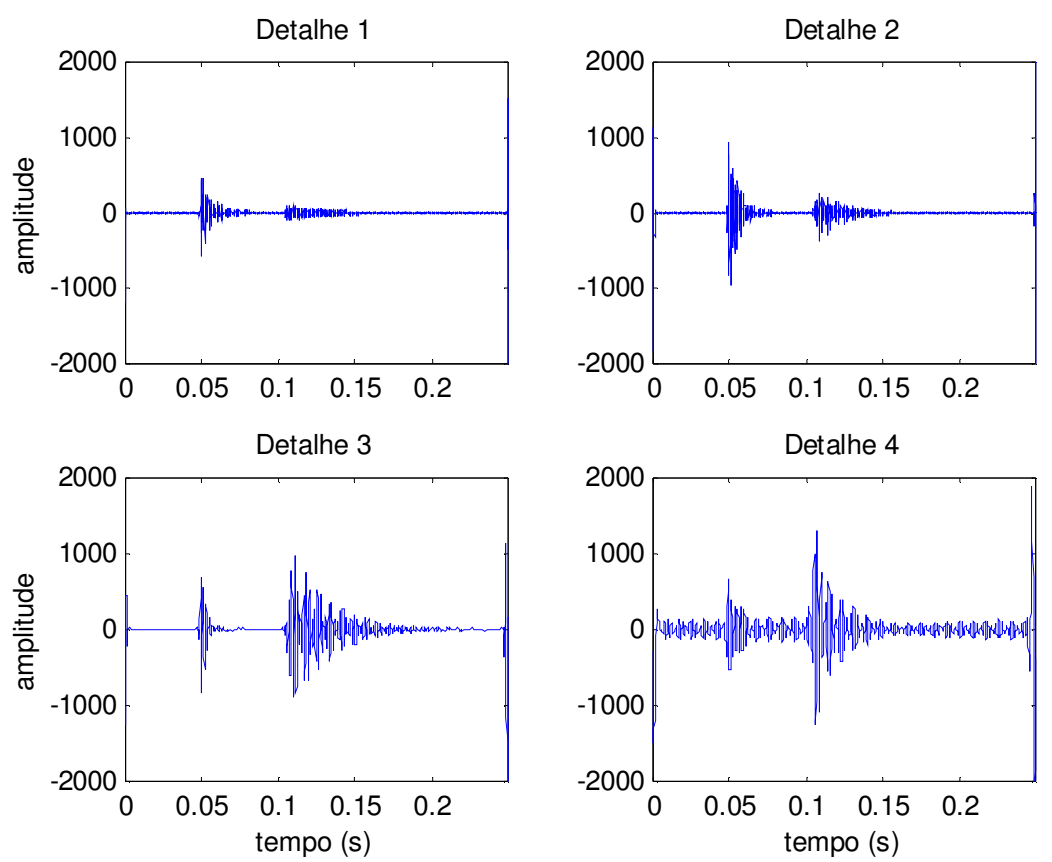

FIGURA 34 - Decomposição em AMR de uma elevação de tensão de $25 \%$.

Uma observação a ser feita provém do comportamento das formas de onda nas decomposições em AMR dos distúrbios afundamento e elevação de tensão, sendo que o mesmo ocorre para interrupção de energia. Analisando as figuras $32 \mathrm{e}$ 34, pode-se notar a semelhança entre as decomposições, dificultando assim a diferenciação entre estes dois distúrbios. Um ponto importante neste estágio de análise é indicar meios de se diferenciar tais distúrbios. A técnica utilizada nesta etapa deste trabalho é fruto do trabalho de GAOUDA et al [11], que consiste em analisar a energia do sinal decomposto que contém o nível de frequência fundamental, tal análise deriva-se do Teorema de Parseval apresentado na seção 4.3.4. No trabalho mencionado foram avaliados os níveis de frequência para cada decomposição do sinal, indicando a energia do sexto e do sétimo detalhe como "região" que contém as informações dos distúrbios com níveis de frequência próxima da frequência do sinal fundamental, ou seja próxima do $60 \mathrm{~Hz}$. A Figura 35, extraída do trabalho de GAOUDA, ilustra a região mencionada, onde o eixo das abscissas indica o número do detalhe e o eixo das ordenadas indica o nível de energia presente no nível de decomposição. Usando-se tal técnica, pode-se diferenciar os distúrbios afundamento de tensão, elevação de tensão e interrupção de energia. 


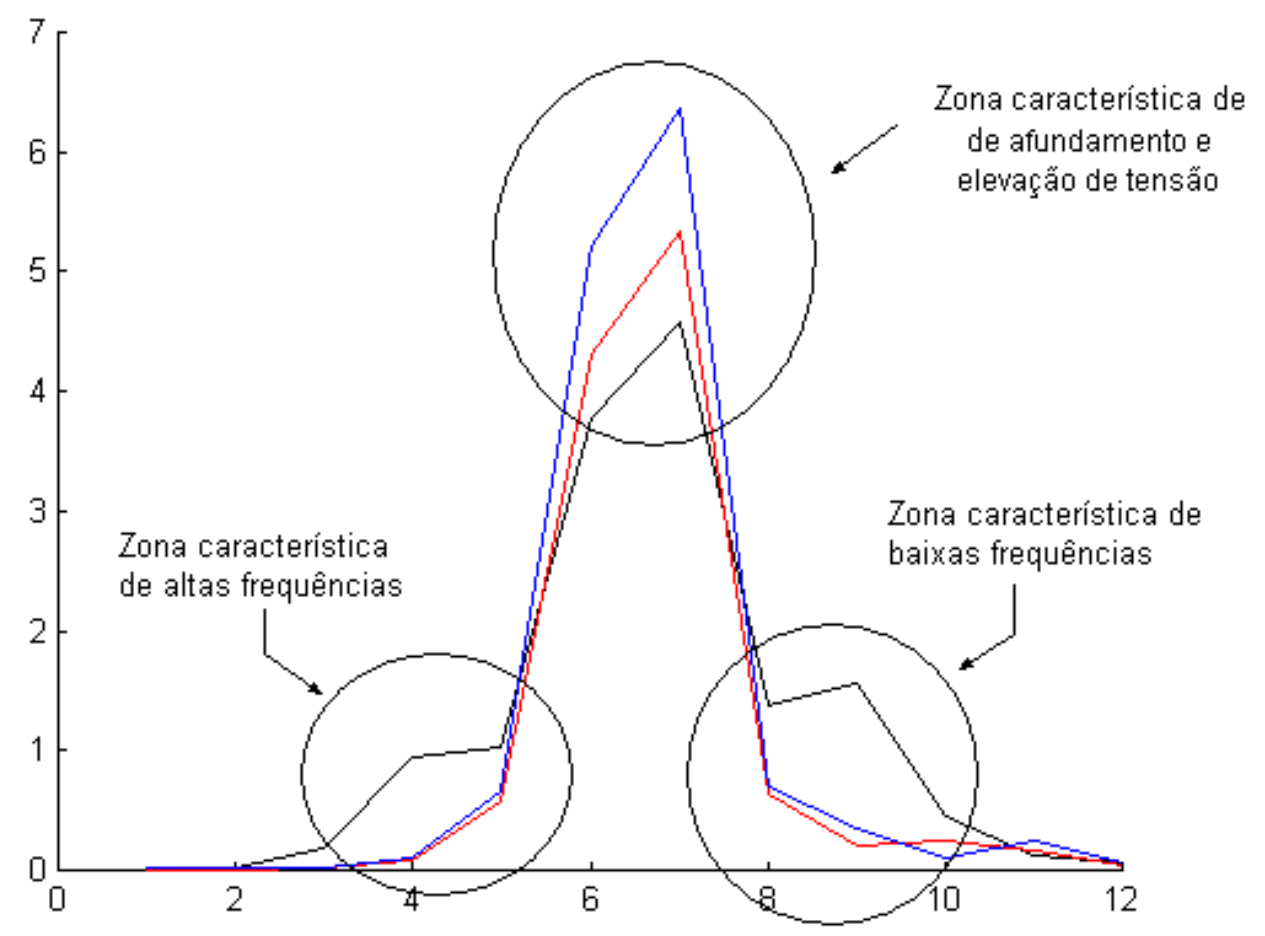

FIGURA 35 - Análise de níveis de frequência para a energia em cada decomposição.

\subsubsection{AMR aplicada ao Distúrbio Oscilação Transitória}

Como mencionado anteriormente no Capítulo 2, os transitórios oscilatórios de baixa freqüência usualmente encontrados são devidos a chaveamento de banco de capacitores. Utilizando-se o sistema elétrico em estudo, foi simulado o chaveamento do banco de capacitores BC3, estando o banco BC2 fixo. A medição desta simulação foi feita próxima ao transformador de distribuição 1 (T1) situado a 338 metros da subestação. O ângulo de inserção do chaveamento foi de $90^{\circ}$ alcançando $1,3 \mathrm{pu} \mathrm{em}$ seu pico máximo. A Figura 36 apresenta a forma de onda simulada. 


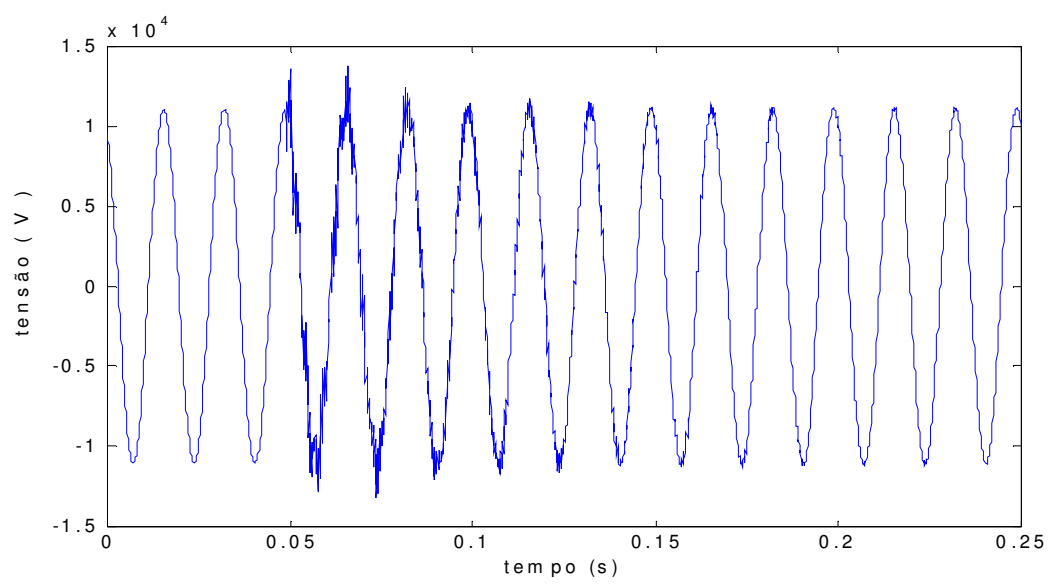

FIGURA 36 - Oscilação transitória proveniente do chaveamento de um banco de capacitores.

As decomposições mostradas na Figura 37 referem-se à oscilação transitória simulada. Nota-se que as formas de onda das decomposições indicam as componentes de frequência do distúrbio, possibilitando a caracterização deste.

Destaca-se nesta etapa, a forma de detecção e localização apresentado pela técnica de AMR para os diferentes distúrbios. Fenômenos tais como afundamento e elevação de tensão são detectados em instantes de tempo, já fenômenos como ruídos e oscilações transitórias estendem-se por todo sinal. Tal diferença na forma de detecção será de fundamental importância no desenvolvimento de técnicas de classificação de distúrbios.

\subsubsection{AMR aplicada a Ruído Incorporado ao Sinal}

Outra análise que merece atenção é para sinal contendo ruído branco incorporado a este (Figura 38). Tal análise é ilustrada na Figuras 39. O ruído incorporado no sinal analisado possui amplitude máxima de $1 \%$, porém, a título de ilustração, a amplitude máxima do ruído mostrado na Figura 38 é de $10 \%$ da amplitude do sinal senoidal fundamental. A presença de picos durante todo o domínio do sinal decomposto (Figura 39), caracteriza o distúrbio ruído. 

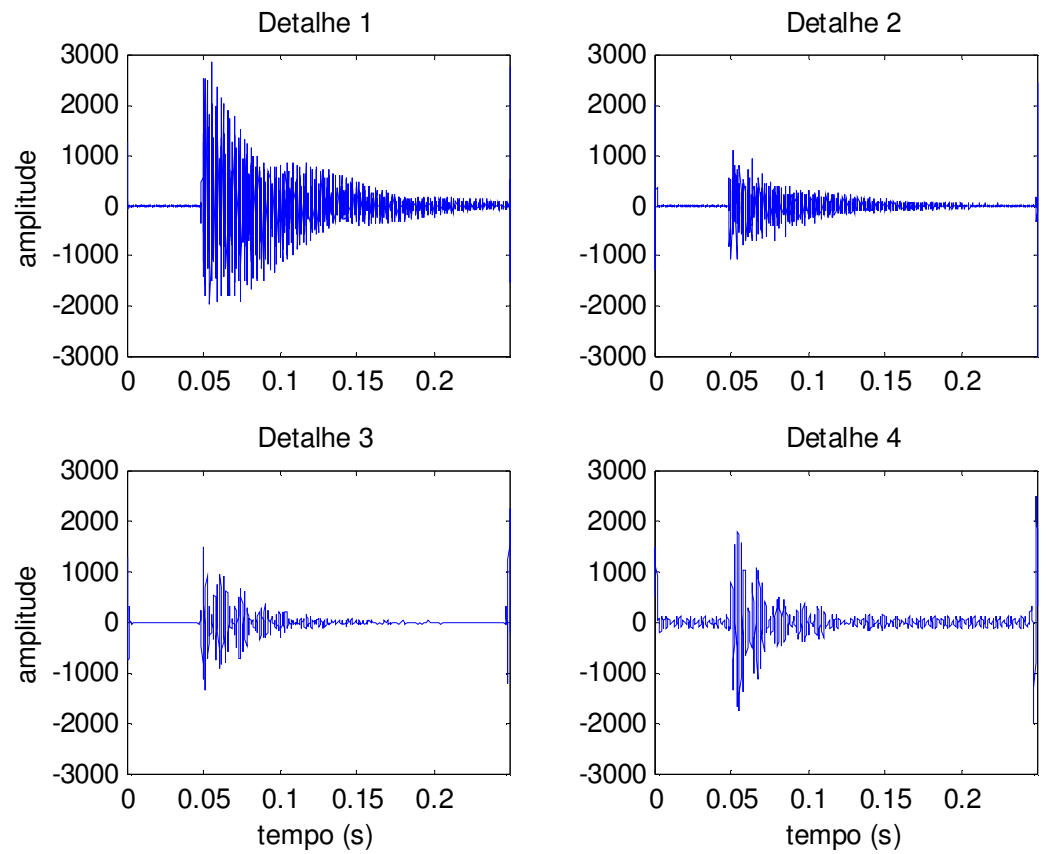

FIGURA 37 - Decomposição em AMR de uma oscilação transitória proveniente do chaveamento de um banco de capacitores.

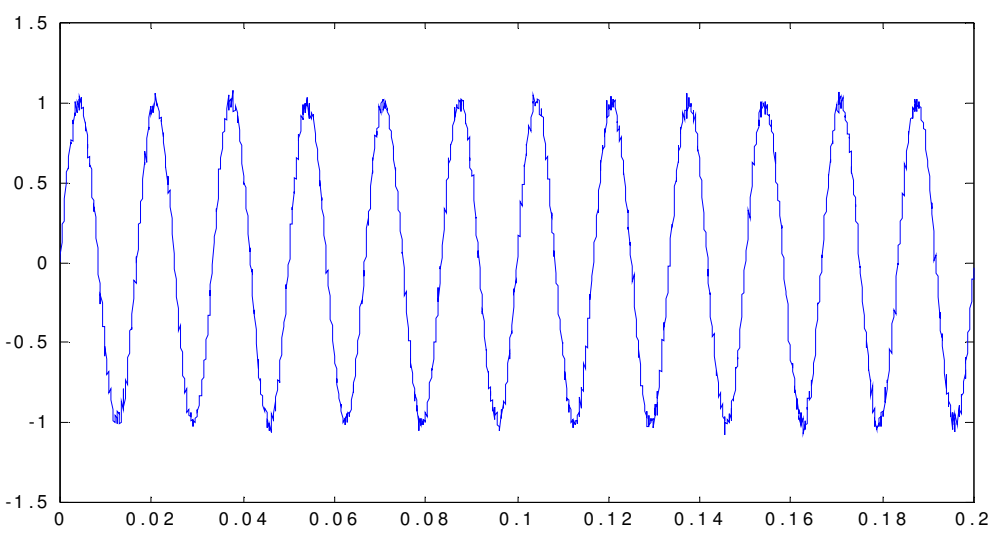

FIGURA 38 - Ruído branco incorporado ao sinal senoidal. 

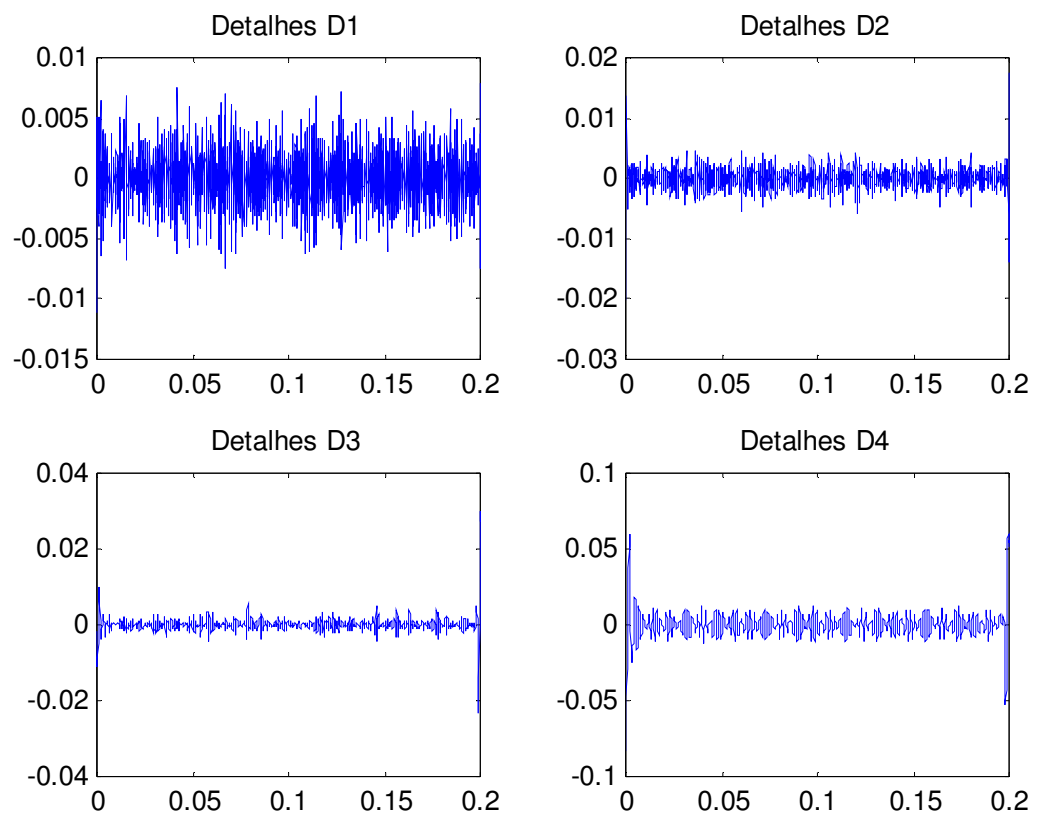

FIGURA 39 - Decomposição em AMR de um sinal contendo ruído branco. 


\section{ANÁLISE AUTOMÁTICA DE DISTÚRBIOS RELACIONADOS COM A QUALIDADE DA ENERGIA}

Uma vez que a AMR se mostrou uma técnica capaz de extrair características dos fenômenos, um passo importante é o desenvolvimento de um algoritmo que os classifique, detecte e localize automaticamente. Este Capítulo busca ilustrar a possibilidade de se desenvolver um algoritmo com tal capacidade.

O método de análise desenvolvido baseia-se na capacidade da ARM em extrair características diferenciadas entre os fenômenos relacionados com a QE. Sendo assim, a diferenciação é caracterizada pela forma como, usualmente, os detalhes obtidos pela ARM comportam-se na decomposição de um dado distúrbio, como apresentado na seção 5.3.

A Figura $40 a, b, c, d$, e e $f$ apresenta a primeira decomposição em ARM para um sinal em regime permanente seguido dos distúrbios de afundamento de tensão, elevação de tensão, ruído e oscilações transitórias, bem como a decomposição de um sinal com interrupção no fornecimento de energia, respectivamente. Pode ser observado que o comportamento do primeiro detalhe de decomposição nitidamente diferencia os fenômenos, exceto para os distúrbios de afundamento e elevação de tensão, sendo que o mesmo ocorre para a interrupção apresentada. Em função das diferenças, pode-se desenvolver um método que diferencie, usando-se os primeiros detalhes de decomposição, os distúrbios ruído e chaveamento de capacitores, bem como o sinal em regime permanente. Já para o caso de diferenciação entre os fenômenos de afundamento de tensão, elevação de tensão e interrupção momentânea, emprega-se o sexto ou o sétimo detalhe de decomposição, como será posteriormente elucidado. 


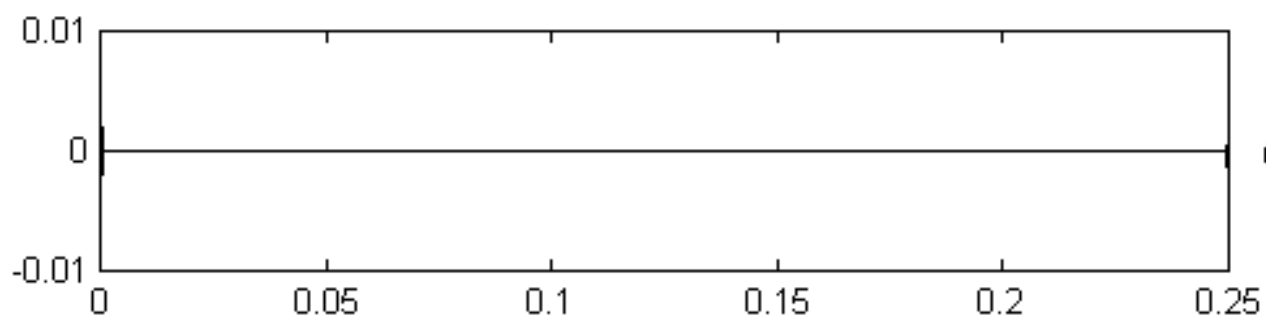

(a)

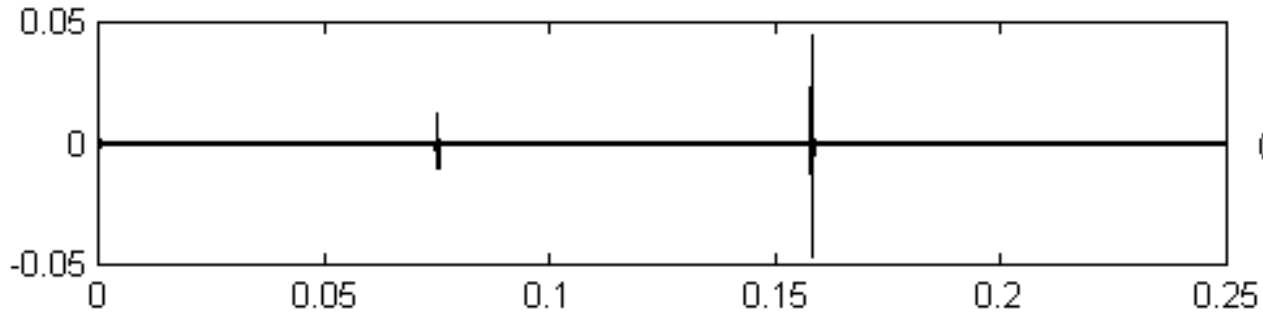

(b)
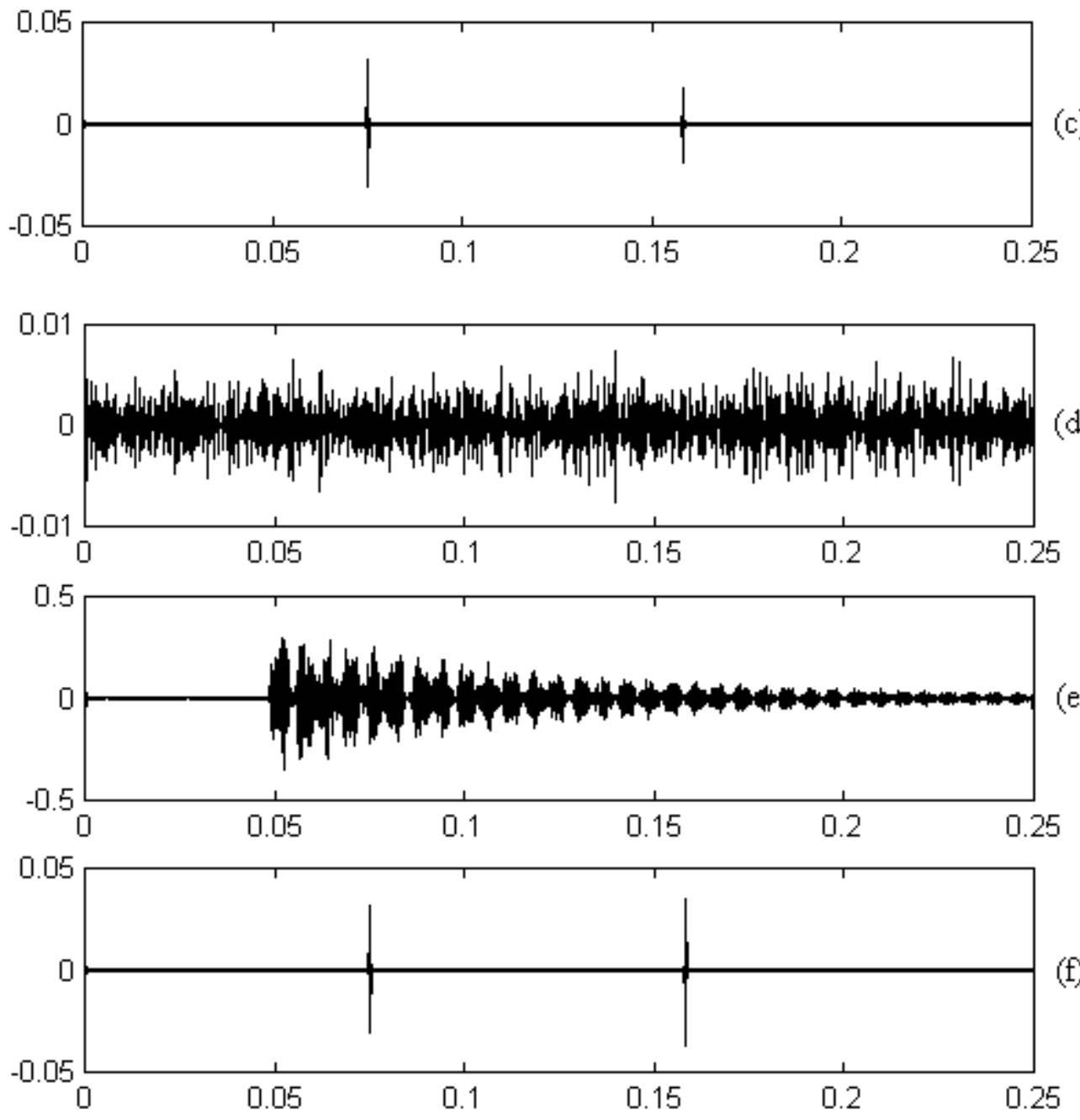

FIGURA 40 - Primeiro detalhe de análise em AMR para: (a) regime permanente, (b) afundamento e (c) elevação de tensão, (d) ruído, (e) oscilações transitórias e (f) interrupção momentânea. 
Como forma de entender melhor o algoritmo implementado, serão tomados como base os passos de desenvolvimento e decisão ilustrado pelo fluxograma apresentado na Figura 41.

\subsection{Descrição dos Sinais de Entrada para Análise}

O sinal de entrada que será submetido ao algoritmo classificador consiste em um "vetor" que compreende os pontos de uma forma de onda simulada no software ATP. Estes sinais, como já mencionado, foram gerados a uma frequência de amostragem de $7,68 \mathrm{kHz}$.

O sinais foram gerados aplicando-se situações de faltas e chaveamento de banco de capacitores em diversos pontos do sistema descrito na seção 5.1, com inserções em 0 e $90^{\circ}$ e diversos valores de resistências de falta, como exemplificado na seção 5.3. Esses dados formaram um grupo de 34 afundamentos de tensão, 26

elevações de tensão, 8 interrupções e 12 oscilações transitórias. Foram também gerados, utilizando-se o software Matlab, 10 casos contendo ruído branco com amplitudes entre 0,1 e $1 \%$ da amplitude do sinal fundamental. Os casos de ruídos foram gerados somando-se ao "vetor" de um sinal senoidal puro, um vetor correspondente ao ruído branco. Sendo assim, formou-se um grupo de 90 casos a serem submetidos a análise de forma a validar o método classificador desenvolvido. 


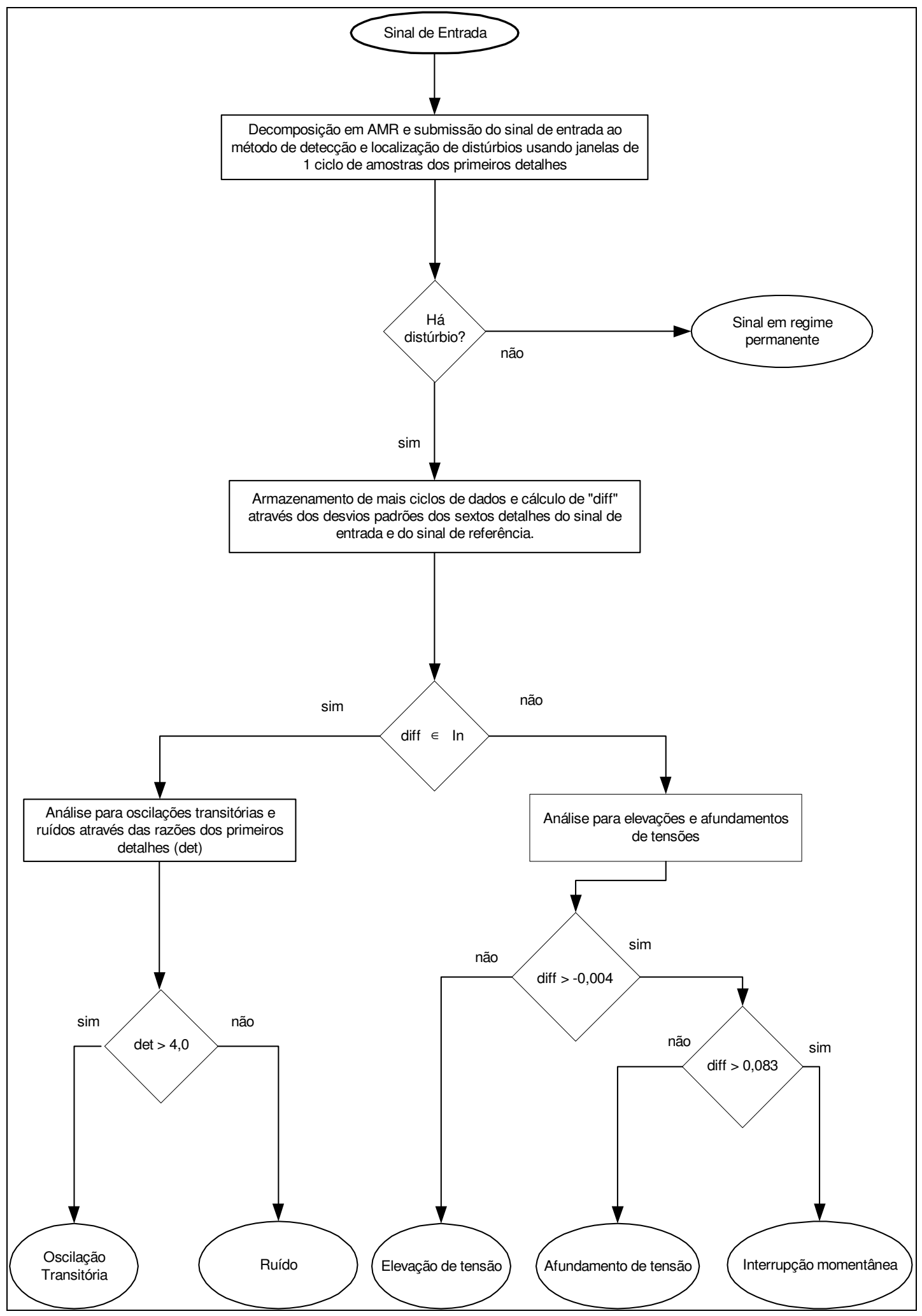

FIGURA 41 - Fluxograma descritivo do método classificador desenvolvido. 


\subsection{Detecção e Localização de Distúrbios}

Para a detecção e localização de distúrbios o algoritmo analisa o sinal de entrada tomando uma janela fixa de um ciclo de dados com passo de meio ciclo, como ilustrado na Figura 42. Tal janela de dados é decomposta em AMR para que seja efetuada a análise dos três primeiros detalhes. Na seção 5.3 pôde ser notado a capacidade de tais sinais (primeiros detalhes) em caracterizar a presença de alguma anomalia no sistema. Os primeiros detalhes do sinal são comparados com os primeiros detalhes de um sinal senoidal que representa o regime permanente do sistema. Sendo assim, diferenças entre estas formas de onda indicam a presença de distúrbios possibilitando a sua detecção. Neste trabalho, a primeira decomposição foi utilizada para detecção dos fenômenos, oferecendo bons resultados, como será evidenciado posteriormente.

As diferenças entre os sinais são mensuradas, avaliando-se a razão entre a média do primeiro detalhe da janela de dados do sinal de entrada e do sinal de referência. Quando o sinal de entrada não apresenta nenhuma variação anormal para o sistema, a razão entre as médias assume valores próximos de um. Por outro lado, quando o primeiro detalhe de decomposição apresenta variações distintas de regime permanente, a razão entre as médias assume valores muito distintos de um. Desta forma, o valor de 1,3 foi tomado como o parâmetro utilizado para detecção de distúrbios tendo oferecido bons resultados como serão exemplificados no Capítulo seguinte.

A Figura 43 ilustra as formas de onda que são utilizadas pelo algoritmo para detecção através da AMR de um sinal. Parte de um sinal caracterizando uma interrupção é ilustrado na Figura $43 a$, e seu primeiro detalhe de decomposição é mostrado na Figura 43b. Pode-se notar pela figura que no instante em que a energia do sistema foi reduzida subitamente, o sinal decomposto indicou a presença de picos que indicam o inicio do distúrbio. Estes picos alteram o valor médio do sinal em regime permitindo a detecção do distúrbio. 


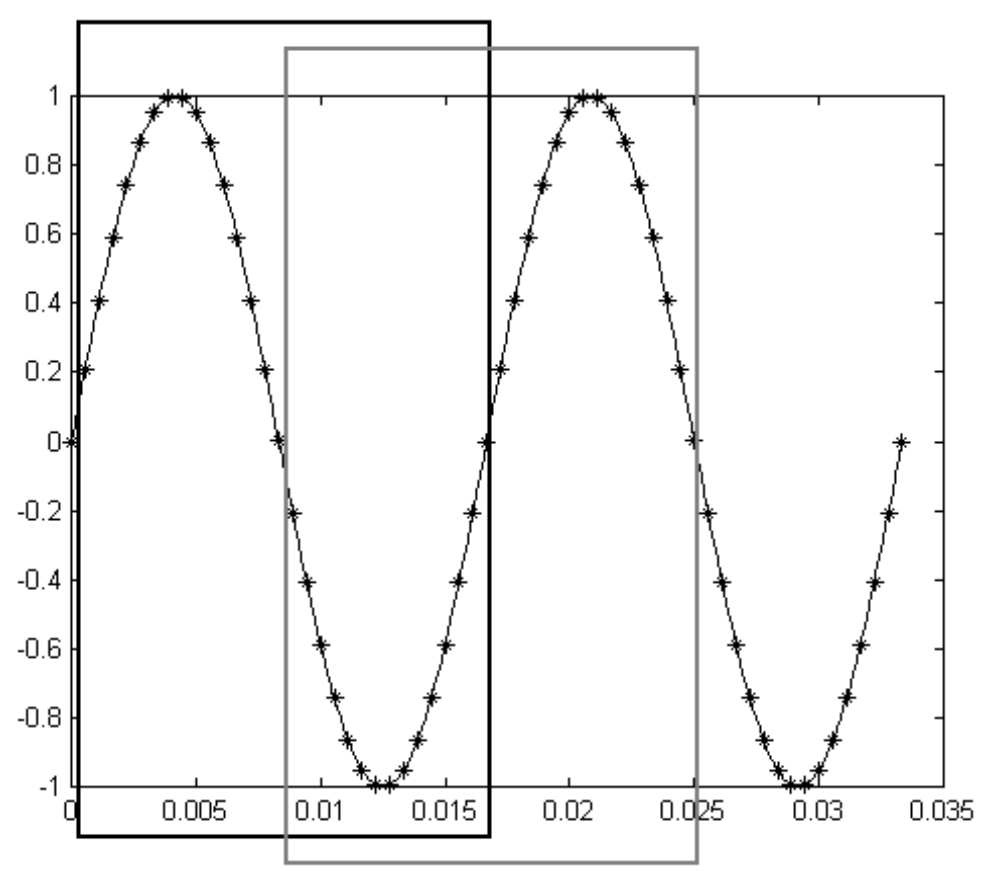

FIGURA 42 - Esquema de janelamento do sinal de entrada para detecção de distúrbios
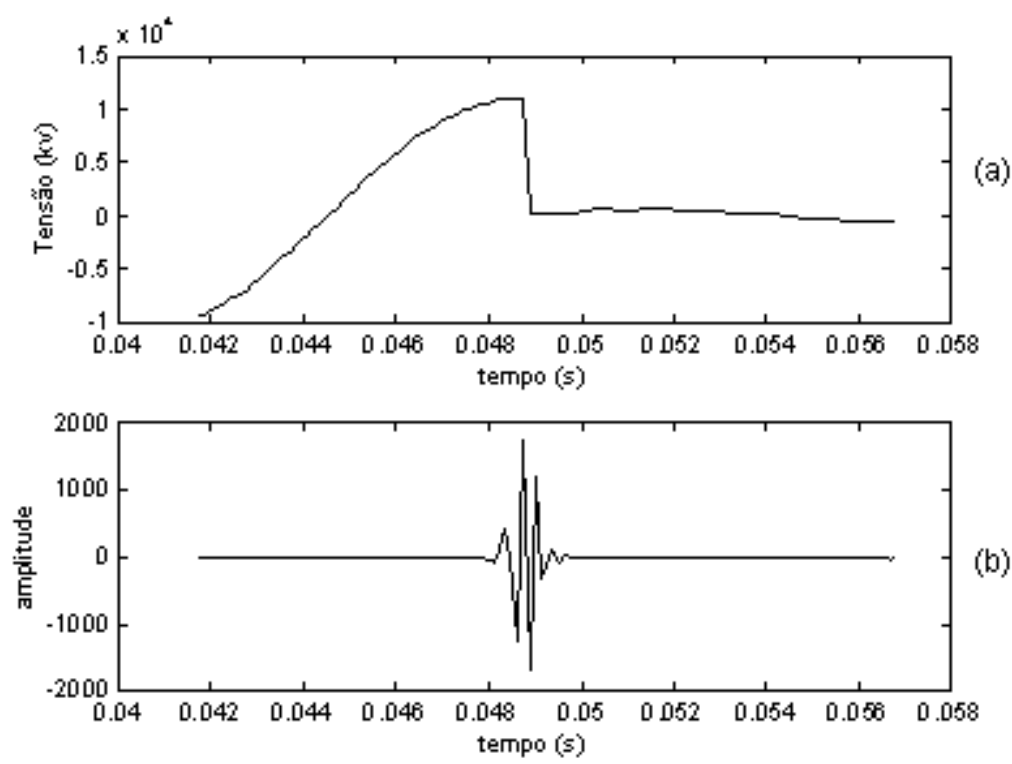

FIGURA 43 - Exemplo de detecção de um distúrbio.

Outra finalidade da análise dos primeiros detalhes está na capacidade da AMR em fornecer diretamente a localização dos distúrbios. A Figura 44 apresenta um distúrbio afundamento de tensão $(a)$, o primeiro $(b)$, o segundo $(c)$ e o terceiro detalhe $(d)$ de decomposição em AMR. Como pode ser observado os detalhes 
indicam corretamente os instantes de início e fim do distúrbio através dos picos ilustrados.

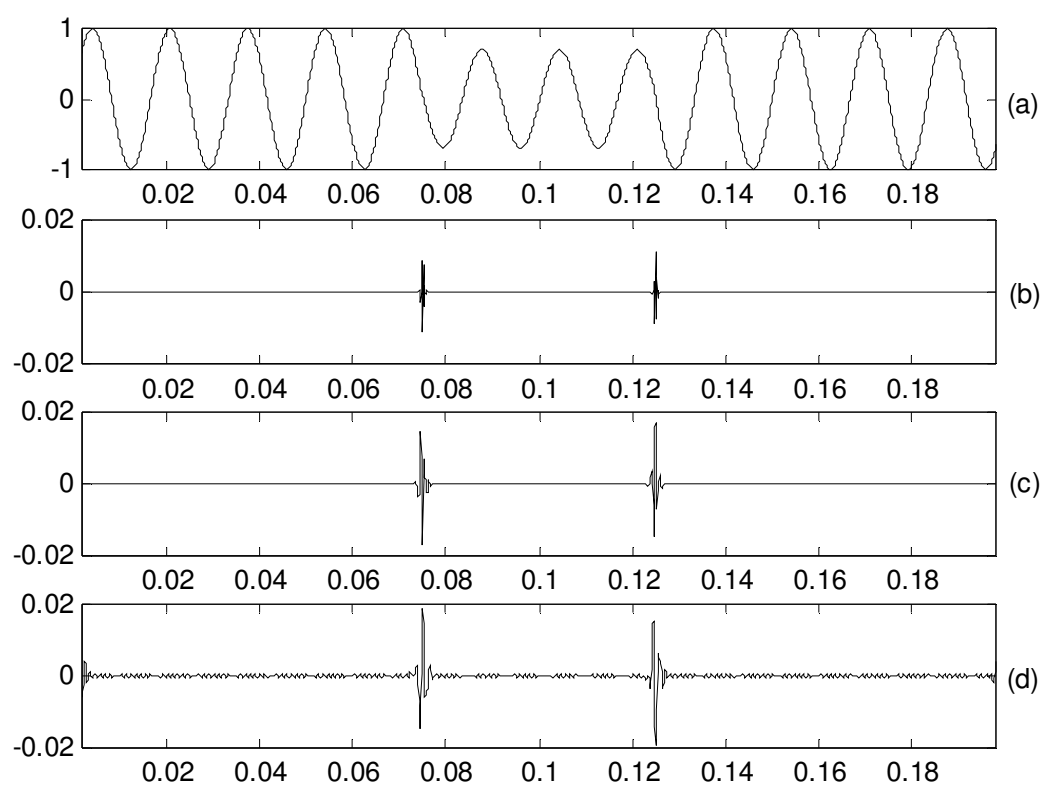

FIGURA 44 - Primeiro (b), segundo (c) e terceiro (d) detalhes de decomposição em AMR de um distúrbio afundamento de tensão (a).

O algoritmo desenvolvido explora esta característica da decomposição de um distúrbio em AMR para localizá-lo. Tal localização é realizada utilizando-se a mesma janela de dados utilizada na detecção do distúrbio. $\mathrm{O}$ algoritmo retém o valor máximo do sinal naquela janela de dados, sendo este o valor indicativo do instante de início do distúrbio.

\subsection{Análise do Sexto Detalhe de Decomposição}

Tendo sido detectada alguma anomalia no sinal de entrada, são colhidos um número maior de ciclos, contendo dados de pré e pós-anomalia. Este sinal é então submetido ao processo de classificação.

O trabalho desenvolvido por GAOUDA et al [11], revela o sexto e o sétimo detalhe de decomposição em AMR, usando-se a função base db4, como indicadores da presença de distúrbios em que o seu nível de frequência se confunde com a 
frequência do sinal fundamental. Sendo assim, o algoritmo desenvolvido analisa tais decomposições como primeiro passo de classificação de distúrbios.

Esta análise se desenvolve com o cálculo da energia do sexto ou sétimo detalhe do sinal de entrada e comparando-a com a energia de um sinal representativo do regime permanente do sistema. Esta comparação é realizada calculando-se a diferença (denominada "diff") entre os valores obtidos para a energia do sinal de entrada e para o sinal em regime. Melhores resultados foram obtidos usando-se o sexto detalhe, pois este indica mais acentuadamente a presença de alguma variação, ou seja este nível de detalhe é mais sensível a variações na frequência $60 \mathrm{~Hz}$.

\subsection{Análise da Diferença entre as Energias no Sexto Detalhe}

Tendo sido calculada a diferença (diff) entre a energia do sinal de entrada e do sinal de referência, o algoritmo avalia os valores obtidos para diff de forma a distinguir a anomalia contida no sinal em dois grupos: distúrbios com frequência similar e distúrbios com frequência superior a frequência do sinal em regime. Valores de diff fora do intervalo $\mathbf{I n}=[-0,0040,004]$ indicam a presença de anomalias com frequência similar à frequência fundamental e valores pertencentes ao intervalo mencionado indicam anomalias com frequência superior à frequência fundamental.

Nesta etapa, a análise é capaz de classificar os distúrbios entre afundamento ou elevação de tensão ou interrupção momentânea, seguindo-se o ramo direito do fluxograma apresentado na Figura 41. Sendo assim, de acordo com os valores de diff obtidos pode-se classificar:

1. Para "diff" menor que $-0,004$, a presença de elevação de tensão é indicada.

2. Valor de "diff" maior que 0,004 é indicada a presença de afundamento de tensão ou interrupção.

3. Valores absolutos de "diff" menores que 0,004 (ou diff pertencente ao intervalo In) não indicam presença de distúrbios com frequência similar à do sistema.

Como apresentado acima, valores de "diff" maiores que 0,004 podem indicar ou afundamento de tensão ou interrupção de energia. Para diferenciar entre estes dois 
tipos de distúrbios, é introduzido um limiar que traduz o limite entre interrupção e afundamento de tensão. Neste trabalho o valor deste limiar foi definido empiricamente igual a 0,083 , oferecendo bons resultados. Através deste, diferenciase os distúrbios afundamento de tensão e interrupção de energia de acordo com as suas definições, isto é: se o valor de "diff" for inferior ao limiar, o distúrbio é caracterizado como afundamento de tensão, caso contrário o distúrbio é caracterizado com interrupção de energia.

Após a caracterização do sinal de entrada como sendo afundamento de tensão, elevação de tensão ou interrupção de energia, o algoritmo utiliza novamente as informações dos primeiros detalhes de decomposição para a estimação da duração do distúrbio e as informações da quinta versão de aproximação para a estimação da amplitude do distúrbio ainda no ramo direito do fluxograma da Figura 41.

\subsection{Análise da Quinta Versão de Aproximação do Sinal Decomposto}

Uma vez realizada a análise do sexto detalhe do sinal e detectado a presença de afundamento de tensão, elevação de tensão ou interrupção de energia, o algoritmo analisa a quinta versão de aproximação do sinal de forma a estimar a amplitude do distúrbio ocorrido. Como já mencionado, tal versão de aproximação é utilizada por conter, por completo, a componente fundamental do sinal, tendo sido extraídas componentes de altas frequiências que poderiam apresentar estimativas errôneas. Os erros que poderiam ocorrer na presença de altas freqüências decorreriam de picos característicos, indicando uma amplitude de sinal que não condiz com a amplitude do distúrbio ocorrido.

Para a estimação da amplitude do distúrbio o algoritmo retém os valores de pico da tensão, na quinta versão de aproximação, antes do distúrbio e durante o distúrbio, uma vez que o instante de inicio do distúrbio foi detectado pelo processo descrito na seção 6.2. A diferença entre estes dois valores indica a variação na amplitude do sinal em regime que caracteriza a amplitude do distúrbio. A Figura 45 apresenta a quinta versão de aproximação de um sinal contendo um afundamento de tensão como exemplo de cálculo da amplitude do distúrbio. Neste exemplo o valor 
de pico antes do distúrbio assumiu um valor igual a 1,0076 e o valor durante o distúrbio igual a 0,6318, correspondendo a uma amplitude de distúrbio de 37,58\%.

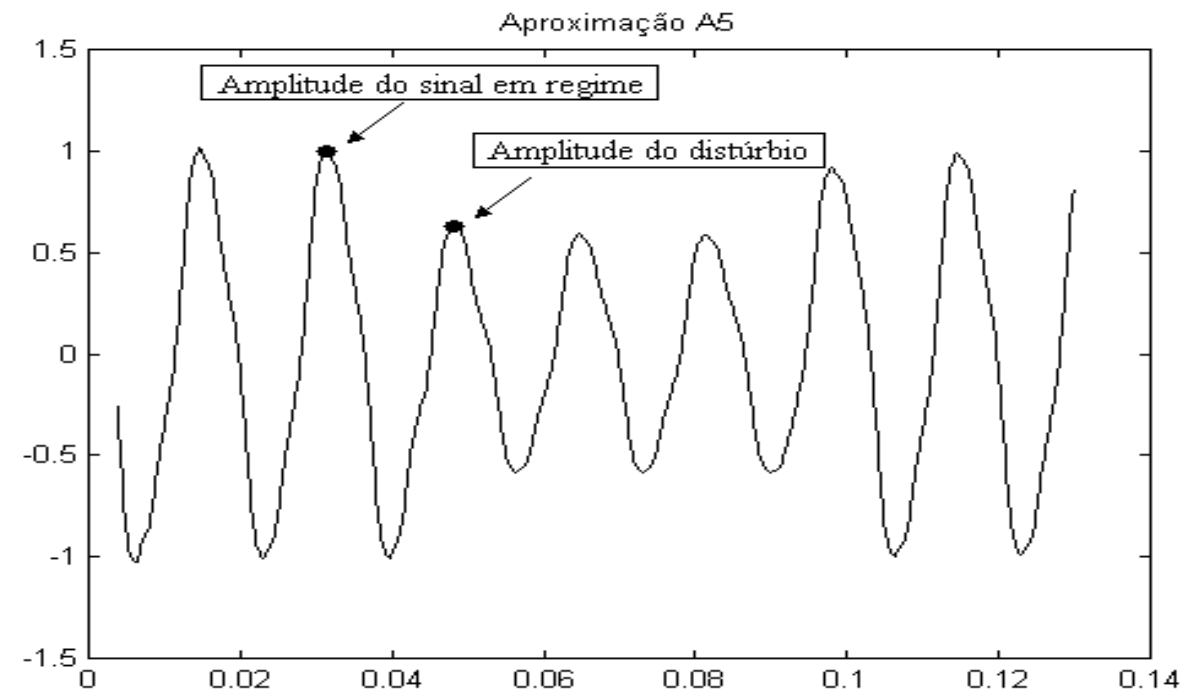

FIGURA 45 - Exemplo de estimação da amplitude de um afundamento de tensão.

\subsection{Análise dos Três Primeiros Niveis de Decomposição}

Ainda analisando o ramo direito do fluxograma apresentado na Figura 41, os primeiros detalhes de decomposição são utilizados para a estimar a duração do distúrbio. Pôde ser percebido que as formas de ondas dos 3 primeiros detalhes são bastante similares, em se tratando dos distúrbios em estudo, como exemplificado na seção 5.3. Através das análises realizadas neste trabalho, o terceiro detalhe foi utilizado e ofereceu os melhores resultados.

Tendo-se como exemplo o terceiro detalhe de decomposição apresentado na Figura 44, esta etapa do algoritmo tem como objetivo reter os picos que caracterizam os instantes de início e fim do distúrbio. Para isso foi utilizada uma janela fixa de 20 amostras para percorrer o sinal com passo do tamanho da própria janela (passo igual a 20 amostras). Desta forma, foi efetuado o calculo da média (det1) de cada janela até que uma variação em det1 indique a janela que contém o instante de início do distúrbio. Tendo sido detectada tal janela, o algoritmo retém o instante de tempo relativo ao maior pico existente nesta. Este tempo refere-se ao instante de início do distúrbio. Para a detecção descrita, somente variações superiores a 3,5 vezes a média da primeira janela, são tomadas para a indicação da presença de uma anomalia. 
Após a detecção do tempo de inicio, a janela utilizada para o cálculo de det1 será iniciada após 64 amostras (que corresponde a meio ciclo do sinal) do instante de início do distúrbio. Tal "salto" da janela é realizado para que variações em instantes inferiores ao tempo mínimo de definição dos fenômenos em estudo não sejam detectadas. Em seguida o algoritmo detectará, através de variações em det1, a janela de dados que contém o instante de término do distúrbio e o reterá através de um processo similar ao realizado para o instante de início do distúrbio.

\subsubsection{Análise para Oscilações Transitórias e Ruídos}

Retornando ao ponto de distinção dos distúrbios quanto ao nível de frequência, valores de diff pertencentes ao intervalo In, indicam a presença de distúrbio cuja frequência é superior à frequência fundamental. Desta forma o sinal é novamente submetido a análise dos primeiros detalhes de decomposição.

A diferenciação entre os distúrbios oscilação transitória e ruído é realizada explorando as respostas típicas que estes oferecem em AMR. Usualmente a resposta oferecida por oscilações transitórias apresenta picos superiores aos oferecidos pela resposta em AMR dos ruídos. Desta forma a idéia inicial foi estipular um limiar que diferenciasse estes distúrbios. Contudo um método que ofereceu melhores resultados foi utilizar uma janela de dados de vinte amostras e percorrer todo o sinal, similarmente ao descrito anteriormente, calculando a razão (denominada "Det") entre a média de uma janela com a média da janela anterior. As razões calculadas são então comparadas a um limiar que diferencia oscilações transitórias de ruído. Desta forma os distúrbios em estudo puderam ser diferenciados com maior precisão. $\mathrm{O}$ número de vinte amostras para a janela foi escolhido empiricamente adequando aos estudos desenvolvidos.

Uma vez que para as maiores amplitudes de ruídos simuladas, que representam valores típicos existentes em sistemas elétricos, o valor de det não superou 2,4 e para os casos de oscilações transitórias que apresentaram menor impacto no sistema, os valores de det não foram inferiores a 7, tomou-se o limiar de diferenciação entre estes distúrbios com o valor 4,0. Este valor de det atendeu perfeitamente às necessidades para classificação. 
O algoritmo desenvolvido (Analisador de Distúrbios Relacionados com a QE, aqui denominado ANADIQE) pode ser encontrado no Apêndice II, onde o software utilizado para a implementação foi o Matlab.

O Capítulo que segue irá apresentar resultados obtidos da simulação do conjunto de casos gerados para testes usando-se o algoritmo desenvolvido. 


\section{RESULTADOS OBTIDOS UTILIZANDO O MÉTODO DE ANÁLISE (ANADIQE) DESENVOLVIDO.}

Seguindo a metodologia apresentada no Capítulo 6, efetuou-se de forma automatizada a localização, detecção e classificação dos distúrbios pertencentes ao conjunto de testes formado pelas 90 situações diferentes apresentadas. Destas, 34 situações referem-se a afundamentos de tensão de 0,1 a 0,9 pu, 26 a elevações de tensão de 0,1 a 0,8 pu, 8 a interrupções de energia, 10 a ruídos e 12 a oscilações transitórias devido ao chaveamento de bancos de capacitores. Os fenômenos, com exceção dos ruídos, foram caracterizados tomando-se como ângulos de incidência os valores 0 e $90^{\circ}$.

Com o intuito de quantificarmos a eficiência do ANADIQE, serão apresentados os resultados obtidos quando da submissão dos casos gerados ao algoritmo. Buscando uma melhor apresentação do método, serão apresentados alguns resultados parciais no processo de classificação de alguns distúrbios.

\subsection{Detecção e Localização do Distúrbio}

Como ilustração da detecção e localização de um distúrbio inserido como sinal de entrada ao ANADIQE, será mostrado detalhadamente a evolução de um sinal contendo um afundamento de tensão causado por uma falta fase-terra. A falta simulada, mostrada na Figura 46, foi iniciada aproximadamente após 2,5 ciclos de simulação e aplicada próxima ao transformador de distribuição 13 (T13 Figura 25), com resistência de falta de $1 \mathrm{ohm}$.

Uma comparação entre o sinal de entrada e um sinal de referência é o meio utilizado pelo método para a detecção do distúrbio, vide seção 6.2. A comparação é 
realizada calculando-se a média de uma janela de um ciclo do sinal de entrada e do sinal de referência.

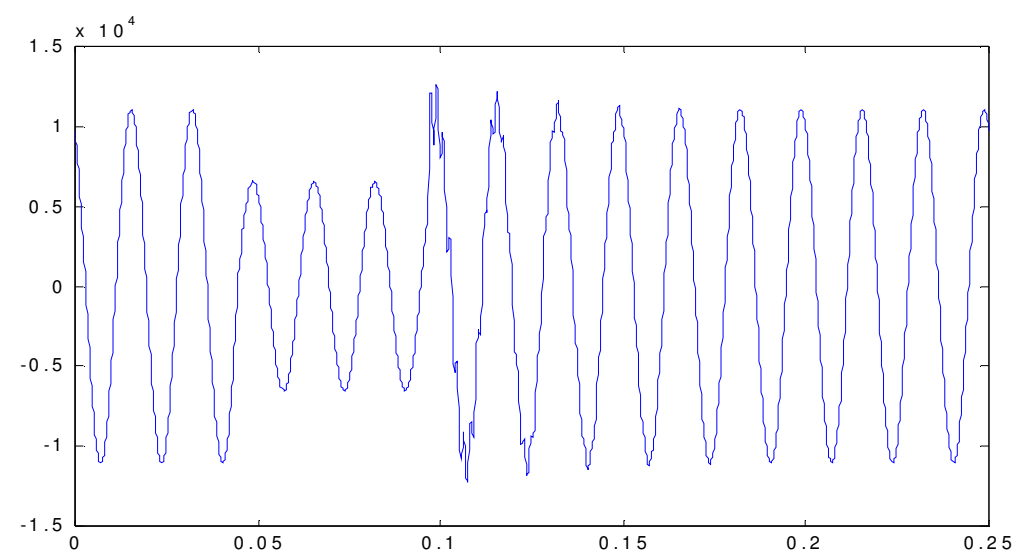

FIGURA 46 - Afundamento de tensão analisado passo a passo.

TABELA 9 - Detecção de um afundamento de tensão.

\begin{tabular}{c|c|c|c}
\hline $\begin{array}{c}\text { Número da Janela } \\
\text { de detecção }\end{array}$ & $\begin{array}{c}\text { Média do sinal de } \\
\text { referência }\end{array}$ & $\begin{array}{c}\text { Média do sinal de } \\
\text { entrada }\end{array}$ & $\begin{array}{c}\text { Razão entre as } \\
\text { médias dos sinais }\end{array}$ \\
\hline 1 & 6,2078 & 6,2078 & 1 \\
\hline 2 & 6,0056 & 6,0056 & 1 \\
\hline 3 & 5,9353 & 5,9353 & 1 \\
\hline 4 & 5,6275 & 5,6275 & 1,7942 \\
\hline 5 & 7,7273 & 13,8643 & \\
\hline
\end{tabular}

Tendo submetido o afundamento de tensão mencionado à análise, foram obtidos os dados apresentados na Tabela 9, onde a primeira coluna refere-se ao número da janela utilizada para detecção, ou seja o número de passos realizados pelo algoritmo para a detecção do evento. A segunda e a terceira coluna apresentam a média obtida na janela do sinal de entrada e do sinal de referência, respectivamente, considerando-se os valores absolutos dos sinais. A razão entre estes dois sinais é apresentada na quarta coluna da Tabela 9.

Como esperado, a razão entre o sinal de entrada e o sinal de referência manteve-se próximo de 1 para os períodos que precedem o distúrbio. No entanto, quando a janela de análise englobou parte do distúrbio, variações ocorreram na média do sinal de entrada, indicando a presença do distúrbio, uma vez que superou o 
valor 1,3 utilizado para diferenciação de regime permanente e sinal com alguma anomalia.

A Figura 47 mostra as decomposições dos sinais de entrada e referência no instante de detecção do distúrbio em análise, considerando a quinta janela de detecção. Nesta figura, pode-se observar o instante em que a decomposição do sinal de entrada (em cor azul) apresentou variações que diferem do regime permanente do sinal (em cor preta).

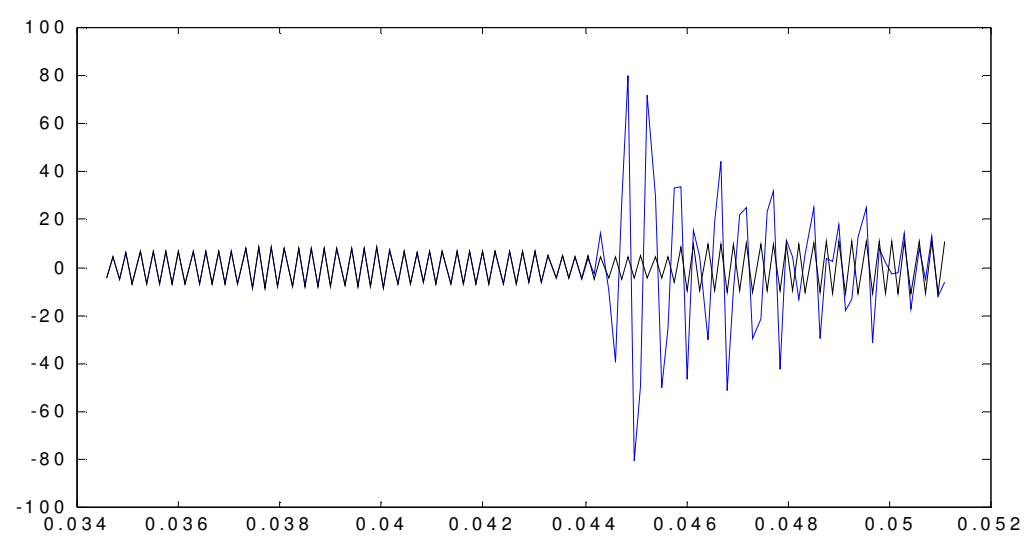

FIGURA 47 - Janela de decomposição em AMR para detecção de um distúrbio.

Através da Figura 47, pode-se estimar a clareza quanto a localização deste distúrbio, uma vez que o instante de detecção é o instante de tempo em que o distúrbio ocorreu. Para o afundamento de tensão em análise o tempo de localização retornado pelo algoritmo foi de 44,3 ms.

Através do procedimento ilustrado para um afundamento de tensão, o ANADIQE detectou todos os 90 distúrbios simulados, possibilitando análises posteriores de classificação.

\subsection{Classificação de Distúrbios}

Dando prosseguimento à análise do distúrbio afundamento de tensão detectado na seção anterior, neste estágio a janela completa contendo o distúrbio é analisada. O primeiro passo de análise refere-se ao cálculo da diferença (diff) entre a energia do sinal de entrada (sinal contendo o afundamento de tensão) e a energia do sinal de 
referência. Alguns valores de diff são apresentados na Tabela 10 para diferentes tipos de distúrbios. Pode-se verificar que através destes valores é possível identificar os distúrbios afundamento de tensão e elevação de tensão, sendo que o mesmo ocorre para interrupção de energia.

TABELA 10 - Valores de diff para diferentes distúrbios.

\begin{tabular}{c|c|c}
\hline Distúrbio em Análise & Energia do sinal de entrada & Diff \\
\hline Sinal em Regime Permanente & 0,6720 & 0 \\
\hline Afundamento de $15 \%$ a $0^{\circ}$ & 0,6564 & 0,0156 \\
\hline Afundamento de $15 \%$ a $90^{\circ}$ & 0,6545 & 0,0175 \\
\hline Afundamento de $70 \%$ a $0^{\circ}$ & 0,5984 & 0,0736 \\
\hline Interrupção de Energia de 99\% & 0,5696 & 0,1024 \\
\hline Elevação de $20 \%$ a $0^{\circ}$ & 0,9932 & $-0,3212$ \\
\hline Elevação de $20 \%$ a $90^{\circ}$ & 0,9919 & $-0,3199$ \\
\hline Elevação de 35\% a 90 & 1,3641 & $-0,6921$ \\
\hline Ruído com amplitude máxima de $0,8 \%$ & 0,6725 & $-0,00047$ \\
\hline Ruído com amplitude máxima de $1 \%$ & 0,6726 & $-0,00061$ \\
\hline Oscilação transitória com inserção a $90^{\circ}$ & 0,6734 & $-0,0014$ \\
\hline Oscilação transitória com inserção a $0^{\circ}$ & 0,6734 & $-0,0014$ \\
\hline
\end{tabular}

Utilizando o cálculo de diff, foi possível classificar todos os casos simulados nos grupos de altas freqüências e frequência similar a frequência do sinal em regime. Desta forma, a classificação entre afundamento de tensão, elevação de tensão e interrupção de energia tornou-se um algoritmo independente do procedimento de classificação de distúrbios entre oscilação transitória em ruído.

\subsubsection{Classificação de Distúrbios com Frequência Similar à do Sinal em Regime}

A classificação entre afundamento de tensão e elevação de tensão ocorre diretamente do cálculo da diferença diff, uma vez que o sinal de diff é o diferenciador entre afundamento ou elevação da tensão. Como já mencionado, a Tabela 10 apresenta alguns valores de diff para os distúrbios mencionados, sendo o valor de diff superior a 0,004 para os afundamentos de tensão e inferior a $-0,004$ para as elevações de tensão. 
Em se tratando da diferenciação entre afundamento de tensão em interrupção de energia, necessitou-se estipular um limiar que caracterizasse estes distúrbios. Uma vez que interrupções de energia são definidas como um decréscimo no valor eficaz da tensão superior a 90\%, o limiar de diferenciação foi estipulado empiricamente (limiar igual a 0,083) de forma a se adequar ao estudo. Tendo em vista os casos simulados, o algoritmo acertou 63 dos 68 casos, que consistem em 34 afundamentos de tensão (Afund.), 26 elevações de tensão (Elev.) e 8 interrupções de energia (Inter.). A região onde o algoritmo apresentou maior dificuldade para a classificação, situa-se próximo ao limiar de diferenciação entre afundamento de tensão e interrupção momentânea. As Tabelas 11 e 12 apresentam a análise de 34 casos com inserção a $0^{\circ}$ e 34 casos com inserção a $90^{\circ}$, respectivamente, compreendendo os 68 casos mencionados. Nestas, pode ser observado, na sétima coluna que apresenta a resposta oferecida pelo ANADIQE, os erros cometidos pelo algoritmo (células em cinza), onde os distúrbios pertencem à região de maior dificuldade de classificação. Justifica-se tal comportamento do algoritmo através da não-linearidade do parâmetro diff.

\subsubsection{Estimação da Duração e da Amplitude do Distúrbio}

Ainda analisando os distúrbios cujo conteúdo de frequência é similar à frequência do sinal em regime, o trabalho desenvolvido propõe um método para a estimação do tempo de duração do distúrbio, bem como a amplitude em que este distúrbio ocorre.

Tendo sido submetido os 68 casos mencionados na seção anterior à análise, o método apresentou resultados animadores, tendo sido capaz de estimar a amplitude de todos os distúrbios com erro médio de 2,3\%. Em se tratando da estimação da duração dos distúrbios em análise, o algoritmo foi capaz de estimar com erro médio de $3,33 \%$ a duração de 55, sendo que a duração dos 13 casos restantes foram estimadas com erros superiores a 10\% (ilustrados através de células em cor cinza na quinta coluna das Tabelas 11 e 12). As Tabelas 11 e 12 apresentam também, a estimação da duração (ED) dos 68 casos simulados, bem como o erro cometido (EC) na estimação destes. Salienta-se que a duração esperada de todos os distúrbios (DED), de acordo com as simulações efetuadas, é de $50 \mathrm{~ms}$, o que corresponde a 3 
ciclos. Nas Tabelas mencionadas, os distúrbios estão caracterizados de acordo com as Tabelas 5, 6 e 7 .

Como ilustração, a Figura 48 apresenta um caso analisado para estimação da duração em que o resultado foi superior a 10\% (caso 20 apresentado na Tabela 11). Pode ser percebido, através da Figura 48b, a dificuldade para o algoritmo em detectar os instantes de inicio e fim do distúrbio, uma vez que picos característicos de oscilações transitórias aparecem durante e depois do distúrbio com duração superior a meio ciclo (tempo mínimo de duração dos distúrbios afundamento de tensão, elevação de tensão e interrupção de energia, vide Capítulo 2).

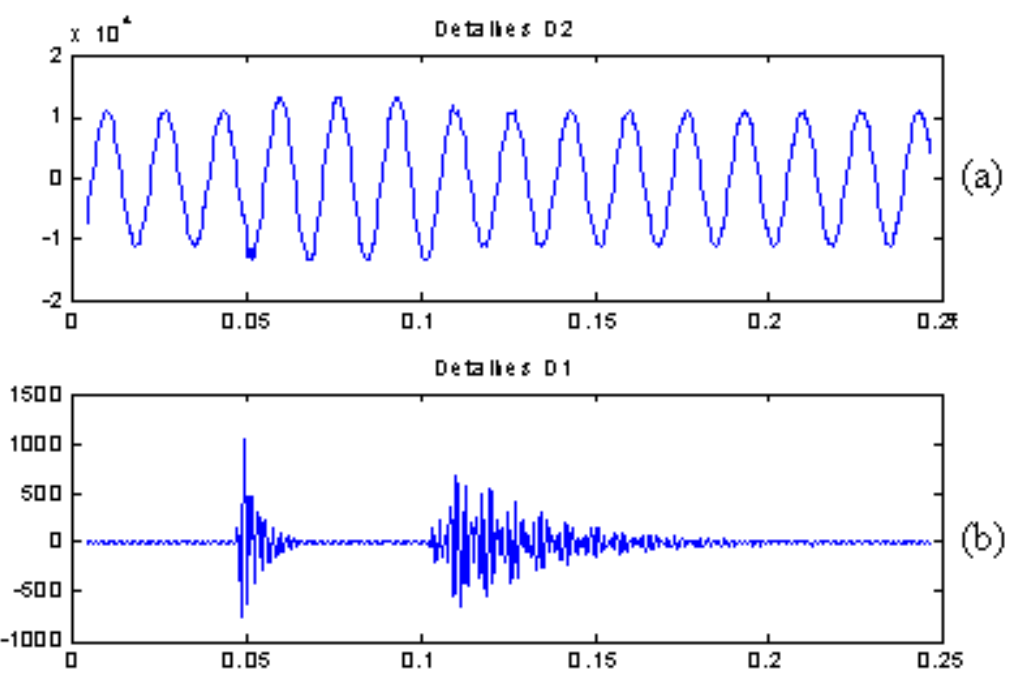

FIGURA 48 - Elevação de tensão (a) submetida a análise para estimação da duração e seu terceiro detalhe de decomposição em AMR (b). 
TABELA 11 - Análise de distúrbios de frequência similar à do sinal fundamental com inserção a $0^{\circ}$ para classificação e estimação da duração.

\begin{tabular}{|c|c|c|c|c|c|c|}
\hline № & DISTÚRBIO & $\begin{array}{l}\mathrm{DD} \\
(\mathrm{ms})\end{array}$ & ED (ms) & EC (\%) & Valor de Diff & $\begin{array}{l}\text { Classificação } \\
\text { do ANADIQE }\end{array}$ \\
\hline 1 & Afund. $10 \%$ a $0^{\circ}$ & 50 & 41,60 & 16,8 & 0.0142 & Afund. \\
\hline 2 & Afund. $15 \%$ a $0^{\circ}$ & 50 & 44,20 & 11,6 & 0.0202 & Afund. \\
\hline 3 & Afund. $20 \%$ a $0^{\circ}$ & 50 & 48,88 & 2,24 & 0.0274 & Afund. \\
\hline 4 & Afund. $25 \%$ a $0^{\circ}$ & 50 & 48,88 & 2,24 & 0.0330 & Afund. \\
\hline 5 & Afund. $30 \%$ a $0^{\circ}$ & 50 & 48,88 & 2,24 & 0.0392 & Afund. \\
\hline 6 & Afund. $35 \%$ a $0^{\circ}$ & 50 & 44,20 & 11,6 & 0.0459 & Afund. \\
\hline 7 & Afund. $40 \%$ a $0^{\circ}$ & 50 & 48,88 & 2,24 & 0.0489 & Afund. \\
\hline 8 & Afund. $45 \%$ a $0^{\circ}$ & 50 & 48,88 & 2,24 & 0.0544 & Afund. \\
\hline 9 & Afund. $50 \%$ a $0^{\circ}$ & 50 & 49,27 & 1,46 & 0.0582 & Afund. \\
\hline 10 & Afund. $55 \%$ a $0^{\circ}$ & 50 & 48,88 & 2,24 & 0.0617 & Afund. \\
\hline 11 & Afund. $60 \%$ a $0^{\circ}$ & 50 & 48,88 & 2,24 & 0.0655 & Afund. \\
\hline 12 & Afund. $65 \%$ a $0^{\circ}$ & 50 & 49,27 & 1,46 & 0.0713 & Afund. \\
\hline 13 & Afund. $70 \%$ a $0^{\circ}$ & 50 & 49,27 & 1,46 & 0.0735 & Afund. \\
\hline 14 & Afund. $75 \%$ a $0^{\circ}$ & 50 & 49,27 & 1,46 & 0.0758 & Afund. \\
\hline 15 & Afund. $80 \%$ a $0^{\circ}$ & 50 & 44,20 & 11,6 & 0.0781 & Afund. \\
\hline 16 & Afund. $85 \%$ a $0^{\circ}$ & 50 & 44,20 & 11,6 & 0.0801 & Afund. \\
\hline 17 & Afund. $90 \%$ a $0^{\circ}$ & 50 & 49,27 & 1,46 & 0.0820 & Afund. \\
\hline 18 & Elev. $10 \% 0^{\circ}$ & 50 & 46,41 & 7,18 & -0.0236 & Elev. \\
\hline 19 & Elev. 15\% 0음 & 50 & 49,27 & 1,46 & -0.0236 & Elev. \\
\hline 20 & Elev. $20 \% 0^{\circ}$ & 50 & 54,08 & 8,16 & -0.0271 & Elev. \\
\hline 21 & Elev. 25\% 0음 & 50 & 49,27 & 1,46 & -0.0298 & Elev. \\
\hline 22 & Elev. $30 \% 0^{\circ}$ & 50 & 49,27 & 1,46 & -0.0297 & Elev. \\
\hline 23 & Elev. 35\% 0음 & 50 & 54,60 & 9,20 & -0.0546 & Elev. \\
\hline 24 & Elev. $40 \% 0^{\circ}$ & 50 & 54,47 & 8,94 & -0.0592 & Elev. \\
\hline 25 & Elev. $45 \% 0^{\circ}$ & 50 & 49,27 & 1,46 & -0.0620 & Elev. \\
\hline 26 & Elev. $50 \% 0^{\circ}$ & 50 & 51,22 & 2,44 & -0.0842 & Elev. \\
\hline 27 & Elev. 55\% 0음 & 50 & 51,48 & 2,96 & -0.0877 & Elev. \\
\hline 28 & Elev. $60 \% 0^{\circ}$ & 50 & 49,27 & 1,46 & -0.0650 & Elev. \\
\hline 29 & Elev. $65 \% 0^{\circ}$ & 50 & 49,27 & 1,46 & -0.0972 & Elev. \\
\hline 30 & Elev. $70 \% 0^{\circ}$ & 50 & 49,27 & 1,46 & -0.0987 & Elev. \\
\hline 31 & Inter. 92\% a $0^{\circ}$ & 50 & 49,27 & 1,46 & 0.0820 & Afund. \\
\hline 32 & Inter. $94 \%$ a $0^{\circ}$ & 50 & 44,20 & 11,6 & 0.0824 & Afund. \\
\hline 33 & Inter. $96 \%$ a $0^{\circ}$ & 50 & 49,27 & 1,46 & 0.0828 & Afund. \\
\hline 34 & Inter. $99 \%$ a $0^{\circ}$ & 50 & 49,27 & 1,46 & 0.0834 & Inter. \\
\hline
\end{tabular}


TABELA 12 - Análise de distúrbios de frequência similar à do sinal fundamental com inserção a $90^{\circ}$ para classificação e estimação da duração.

\begin{tabular}{|c|c|c|c|c|c|c|}
\hline № & DISTÚRBIO & $\begin{array}{l}\mathrm{DD} \\
(\mathrm{ms})\end{array}$ & $\mathrm{ED}(\mathrm{ms})$ & EC (\%) & Valor de Diff & $\begin{array}{l}\text { Classificação } \\
\text { do ANADIQE }\end{array}$ \\
\hline 35 & Afund. $10 \%$ a $90^{\circ}$ & 50 & 51,61 & 3,22 & 0.0156 & Afund. \\
\hline 36 & Afund. $15 \%$ a $90^{\circ}$ & 50 & 51,61 & 3,22 & 0.0221 & Afund. \\
\hline 37 & Afund. $20 \%$ a $90^{\circ}$ & 50 & 51,61 & 3,22 & 0.0298 & Afund. \\
\hline 38 & Afund. $25 \%$ a $90^{\circ}$ & 50 & 51,61 & 3,22 & 0.0358 & Afund. \\
\hline 39 & Afund. $30 \%$ a $90^{\circ}$ & 50 & 51,61 & 3,22 & 0.0421 & Afund. \\
\hline 40 & Afund. $35 \%$ a $90^{\circ}$ & 50 & 46,93 & 6,14 & 0.0500 & Afund. \\
\hline 41 & Afund. $40 \%$ a $90^{\circ}$ & 50 & 51,61 & 3,22 & 0.0520 & Afund. \\
\hline 42 & Afund. $45 \%$ a $90^{\circ}$ & 50 & 51,61 & 3,22 & 0.0573 & Afund. \\
\hline 43 & Afund. $50 \%$ a $90^{\circ}$ & 50 & 51,61 & 3,22 & 0.0622 & Afund. \\
\hline 44 & Afund. $55 \%$ a $90^{\circ}$ & 50 & 51,61 & 3,22 & 0.0658 & Afund. \\
\hline 45 & Afund. $60 \%$ a $90^{\circ}$ & 50 & 51,61 & 3,22 & 0.0695 & Afund. \\
\hline 46 & Afund. $65 \%$ a $90^{\circ}$ & 50 & 51,61 & 3,22 & 0.0759 & Afund. \\
\hline 47 & Afund. $70 \%$ a $90^{\circ}$ & 50 & 51,61 & 3,22 & 0.0781 & Afund. \\
\hline 48 & Afund. $75 \%$ a $90^{\circ}$ & 50 & 51,61 & 3,22 & 0.0803 & Afund. \\
\hline 49 & Afund. $80 \%$ a $90^{\circ}$ & 50 & 51,61 & 3,22 & 0.0823 & Afund. \\
\hline 50 & Afund. $85 \%$ a $90^{\circ}$ & 50 & 51,61 & 3,22 & 0.0841 & Inter. \\
\hline 51 & Afund. $90 \%$ a $90^{\circ}$ & 50 & 51,61 & 3,22 & 0.0856 & Inter. \\
\hline 52 & Elev. $10 \% 90^{\circ}$ & 50 & 53,04 & 6,08 & 0.0249 & Elev. \\
\hline 53 & Elev. $15 \% 90^{\circ}$ & 50 & 53,04 & 6,08 & 0.0244 & Elev. \\
\hline 54 & Elev. $20 \% 90^{\circ}$ & 50 & 60,32 & 20,6 & 0.0277 & Elev. \\
\hline 55 & Elev. $25 \% 90^{\circ}$ & 50 & 53,04 & 6,08 & 0.0301 & Elev. \\
\hline 56 & Elev. $30 \% 90^{\circ}$ & 50 & 53,04 & 6,08 & 0.0296 & Elev. \\
\hline 57 & Elev. 35\% 90응 & 50 & 60,32 & 20,6 & 0.0565 & Elev. \\
\hline 58 & Elev. 40\% 90응 & 50 & 53,04 & 6,08 & 0.0609 & Elev. \\
\hline 59 & Elev. 45\% 90응 & 50 & 53,04 & 6,08 & 0.0635 & Elev. \\
\hline 60 & Elev. $50 \% 90^{\circ}$ & 50 & 32,24 & 35,5 & 0.0874 & Elev. \\
\hline 61 & Elev. 55\% 90은 & 50 & 32,24 & 35,5 & 0.0908 & Elev. \\
\hline 62 & Elev. $60 \% 90^{\circ}$ & 50 & 32,24 & 35,5 & 0.0654 & Elev. \\
\hline 63 & Elev. $65 \% 90^{\circ}$ & 50 & 31,20 & 37,6 & 0.0998 & Elev. \\
\hline 64 & Elev. $70 \% 90^{\circ}$ & 50 & 31,72 & 36,5 & 0.1011 & Elev. \\
\hline 65 & Inter. $92 \%$ a $90^{\circ}$ & 50 & 51,61 & 3,22 & 0.0856 & Inter. \\
\hline 66 & Inter. $94 \%$ a $90^{\circ}$ & 50 & 51,61 & 3,22 & 0.0859 & Inter. \\
\hline 67 & Inter. $96 \%$ a $90^{\circ}$ & 50 & 51,61 & 3,22 & 0.0862 & Inter. \\
\hline 68 & Inter. $99 \%$ a $90^{\circ}$ & 50 & 51,61 & 3,22 & 0.0866 & Inter. \\
\hline
\end{tabular}




\subsubsection{Classificação entre Oscilações Transitórias em Ruídos}

O outro ramo de análise do algoritmo consiste na diferenciação entre ruídos e oscilações transitórias (OscTrans). Para tanto, como já descrito no Capitulo anterior, é utilizado o terceiro detalhe de decomposição, calculando-se a razão (det) entre as médias do sinal de entrada e do sinal de referência compreendidos em uma janela contendo 20 amostras.

A Tabela 13 apresenta a análise realizada para os distúrbios mencionados, apresentando na segunda coluna o caso em análise, na terceira coluna e na quarta coluna os valores de Diff e de det obtidos para os casos simulados. Ressalta-se que os casos apresentados na Tabela que segue compreendem os mesmos apresentados na seção 5.1.1. Pode-se perceber que os valores de det obtidos permitem diferenciar os ruídos das oscilações transitórias, já que os valores de Diff são capazes de diferenciar estes fenômenos daqueles cujo conteúdo de frequência é similar ao sinal fundamental. A quinta coluna da tabela apresenta a resposta do ANADIQE para os casos em estudo.

O algoritmo classificador, utilizando a análise descrita, foi capaz de classificar todos os casos simulados onde foi necessário estipular um limiar (det) que diferenciasse os distúrbios em análise. Como já elucidado no Capítulo anterior este limiar assumiu o valor 4,0. Este valor de det atendeu perfeitamente às necessidades para classificação. 
TABELA 13 - Análise de distúrbios de frequência superior à do sinal fundamental para a classificação..

\begin{tabular}{|c|c|c|c|c|}
\hline № & Distúrbio & Diff & $\operatorname{det}$ & Classificação do ANADIQE \\
\hline 69 & OscTrans a $0^{\circ}$ medido no TP4 & -0.0014 & 7,1919 & OscTrans \\
\hline 70 & OscTrans a $0^{\circ}$ medido no T8 & -0.0016 & 13,277 & OscTrans \\
\hline 71 & OscTrans a $0^{\circ}$ medido no T3 & -0.0020 & 38,963 & OscTrans \\
\hline 72 & OscTrans a $0^{\circ}$ medido no T13 & -0.0023 & 13,292 & OscTrans \\
\hline 73 & OscTrans a $0^{\circ}$ medido no T1 & -0.0019 & 18,373 & OscTrans \\
\hline 74 & OscTrans a $0^{\circ}$ medido na Sub. & -0.0022 & 31,577 & OscTrans \\
\hline 75 & OscTrans a $90^{\circ}$ medido no TP4 & -0.0014 & 40,491 & OscTrans \\
\hline 76 & OscTrans a $90^{\circ}$ medido no T8 & -0.0016 & 78,328 & OscTrans \\
\hline 77 & OscTrans a 90ํm medido no T3 & -0.0020 & 66,738 & OscTrans \\
\hline 78 & OscTrans a $90^{\circ}$ medido no T13 & -0.0022 & 44,857 & OscTrans \\
\hline 79 & OscTrans a $90^{\circ}$ medido no T1 & -0.0019 & 37,787 & OscTrans \\
\hline 80 & OscTrans a $90^{\circ}$ medido na Sub. & -0.0022 & 83,942 & OscTrans \\
\hline 81 & Ruído de $0.1 \%$ & $1.0045 e-4$ & 2,0176 & Ruído \\
\hline 82 & Ruído de $0.2 \%$ & $2.3332 \mathrm{e}-4$ & 2,2078 & Ruído \\
\hline 83 & Ruído de $0.3 \%$ & $1.4156 \mathrm{e}-4$ & 2,1098 & Ruído \\
\hline 84 & Ruído de $0.4 \%$ & $4.7649 \mathrm{e}-4$ & 2,1567 & Ruído \\
\hline 85 & Ruído de $0.5 \%$ & $5.4156 \mathrm{e}-4$ & 2,3720 & Ruído \\
\hline 86 & Ruído de $0.6 \%$ & $4.2498 \mathrm{e}-4$ & 2,3198 & Ruído \\
\hline 87 & Ruído de $0.7 \%$ & $1.0298 \mathrm{e}-4$ & 2,2643 & Ruído \\
\hline 88 & Ruído de $0.8 \%$ & $5.2171 \mathrm{e}-4$ & 2,1220 & Ruído \\
\hline 89 & Ruído de $0.9 \%$ & $2.4104 \mathrm{e}-4$ & 1,8077 & Ruído \\
\hline 90 & Ruído de $1 \%$ & $4.4462 \mathrm{e}-4$ & 2,3989 & Ruído \\
\hline
\end{tabular}

Procurou-se apresentar neste Capítulo os resultados obtidos quando da submissão dos casos simulados, utilizando o sistema elétrico apresentado na seção 5.1 do Capítulo 5, ao algoritmo (ANADIQE) descrito no Capítulo 6. Pode ser verificado a eficiência do método uma vez que os casos simulados compreendem as mais variadas formas dos distúrbios em estudo.

Tendo sido submetido 90 casos ao ANADIQE para análise, sendo estes 34 de afundamentos de tensão, 26 de elevações de tensão, 8 de interrupções de energia, 12 de oscilações transitórias e 10 de ruídos, o algoritmo foi capaz de detectar todos os distúrbios e classificar 85 compreendendo um índice de acertos de 94\%. Quanto à estimação da amplitude e do tempo de duração dos distúrbios o ANADIQE apresentou erro médio de $2,3 \%$ e $3,33 \%$, respectivamente. Tais índices ilustram a 
eficiência do algoritmo desenvolvido e indica a possibilidade de se desenvolver um método automático de análise de distúrbios utilizando-se a Transformada Wavelet.

O Capítulo seguinte busca apresentar alguns comentários com respeito às facilidades e dificuldades encontradas durante o desenvolvimento do ANADIQE, no que diz respeito aos ajustes de parâmetros utilizados nas fases de detecção, localização e classificação de distúrbios. 


\section{COMENTÁRIOS E CONCLUSÕES FINAIS}

O aumento do número de equipamentos eletrônicos tem aumentado significativamente o interesse pela qualidade da energia fornecida pelas concessionárias, uma vez que pequenos distúrbios que ocorrem nos sistemas, podem provocar inúmeras interferências indesejáveis como: acionamento indevido de relés, mau funcionamento de equipamentos sensíveis, distorções em equipamentos de medição, podendo chegar até mesmo à interrupção do fornecimento de energia. $\mathrm{O}$ efeito econômico causado por tais distúrbios pode ser significativo tanto para as concessionárias quanto para os consumidores.

Procurou-se no desenvolver deste trabalho conhecer os problemas que envolvem o conceito da Qualidade da Energia viabilizando a tomada de medidas que diminuam, ou mesmo eliminam, o efeito de fenômenos relacionados com o tema.

Para uma melhor análise dos distúrbios em estudo, faz-se necessário a utilização de alguma ferramenta extra que permita visualizar o comportamento de cada distúrbio. Desta forma, cabe o estudo de ferramentas que proporcionem os resultados esperados.

A ferramenta mais conhecida e utilizada para a análise de sinais é a Transformada de Fourier, que decompõe um sinal em ondas senoidais de diferentes freqüências. Uma outra forma de se pensar sobre a Transformada de Fourier é como uma técnica matemática de mudança de base, que transforma um sinal de uma base de tempo para uma base de freqüência. Similarmente à Análise de Fourier, a Análise Wavelet também é uma técnica matemática de mudança de base, onde se pode obter simultaneamente, informações tanto no domínio do tempo quanto no domínio da freqüência do sinal a ser analisado, mostrando-se um conjunto de técnicas e ferramentas de grande importância para análise de sinais. 
A eficiência da TW para análise de sinais está diretamente relacionada com o comportamento das funções bases Wavelets. A Wavelet mãe utilizada no decorrer deste trabalho foi a db4, descrito por Ingrid Daubechies e já consagrada em aplicações por apresentar bons resultados, alguns dos quais ilustrados neste trabalho.

A TW, tendo sido explorada na técnica de AMR, foi utilizada com sucesso, uma vez que esta oferece, diretamente, bons resultados na análise (detecção e localização) de distúrbios transitórios no sistema de potência. A técnica de AMR foi explorada também na sua capacidade de extrair características únicas para os diferentes distúrbios (distinguindo o conteúdo de frequência existente em cada distúrbio analisado), possibilitando o desenvolvimento de um algoritmo que detecte, localize e classifique automaticamente diferentes distúrbios.

O algoritmo de análise desenvolvido (ANADIQE) mostrou-se bastante eficiente para análise dos distúrbios simulados. Considerando-se a diferenciação entre os 90 distúrbios analisados, o ANADIQE acertou 85 casos consistindo em um índice superior a $94 \%$ de acertos. Neste aspecto, ressalta-se a dificuldade de se estipular um limiar que diferencie afundamento de tensão de interrupção de energia, uma vez que sua variação entre as diferentes porcentagens de afundamento ocorre de forma não linear. Desta forma, pode ser proposto como um trabalho futuro a busca de um método que supere em eficiência o algoritmo desenvolvido neste trabalho quanto a diferenciação entre os distúrbios afundamento de tensão e interrupção de energia.

O trabalho desenvolvido apresenta um método de estimação da amplitude de distúrbios, onde a eficiência do método desenvolvido apresentou erro médio de $2,3 \%$.

Em se tratando da estimação da duração dos distúrbios afundamento de tensão, elevação de tensão e interrupção momentânea, o ANADIQE explora, com eficiência, a capacidade da TW em extrair características dos distúrbios. Este estima com erro médio de 3,33\% a duração de 55 casos de um total de 68 casos simulados referentes aos distúrbios utilizados nesta análise. Para os 13 casos restantes, a duração estimada assumiu valores entre 10 e $36 \%$.

Tendo em vista os desenvolvimentos realizados no decorrer deste trabalho de mestrado, foi possível conhecer os problemas existentes no que se refere ao 
desenvolvimento de um método classificador dos diferentes distúrbios existentes. Neste contexto, ressalta-se o alcance obtido pelo algoritmo desenvolvido, onde este indica um caminho promissor para o desenvolvimento de um algoritmo global de classificação, abrangendo outros distúrbios existentes nos SEPs.

Como consequiência da realização deste trabalho alguns artigos foram publicados e apresentados em congressos nacionais. A referência [32] compreende um estudo sobre a escolha de funções Wavelet mães para aplicações em QE, tal trabalho, como citado na seção 5.2, foi publicado no Congresso Brasileiro de Automática no ano de 2002. A referência [33] consiste em estudos realizados sobre transitórios decorrentes de chaveamento de bancos de capacitores realizados no sistema apresentado na seção 5.1. Este trabalho foi exposto no XV Seminário Nacional de Distribuição de Energia Elétrica - SENDI, realizado em Novembro de 2002. Ainda deste trabalho, a referência [34] consiste em um artigo submetido e aceito em primeira análise ao $17^{\circ}$ Seminário Nacional de Produção e Transmissão de Energia Elétrica - SNPTEE, a ser realizado em Outubro deste ano. 


\section{REFERÊNCIAS BIBLIOGRÁFICAS}

[1] DUGAN, R. C., MCGRANAGHAN, M. F. and BEATY, H. W. Electrical power systems quality. New York: McGraw-Hill, xv, 265 p. 1996.

[2] ANEEL. AGÊNCIA NACIONAL DE ENERGIA ELÉTRICA: Resolução No 24. 15 p. 27 de Janeiro de 2000.

[3] ANEEL. AGÊNCIA NACIONAL DE ENERGIA ELÉTRICA: Resolução No 505. 11 p. 26 de Novembro de 2001.

[4] SANTOSO, S., GRADY, W. M., POWERS, E. J., LAMOREE, J. and BHATT, S. C. Characterization of Distribution Power Quality Events with Fourier and Wavelet Transforms. IEEE Transactions on Power Delivery, 15, 1, 247-254, January, 2000.

[5] OLIVEIRA, J. C. D. Projeto SIDAQEE - Capítulo II Qualidade da Energia Elétrica: Definição e Análise dos Itens de Qualidade. Uberlândia: Universidade Federal de Uberlândia, p.

[6] IEEE. Recommended Practice for Monitoring Electric Power Quality. IEEE, vi, 70 p. 1995.

[7] BOLLEN, M. H. J. Understanding power quality problems : voltage sags and interruptions. New York: IEEE Press, xvii, 543 p. 1999.

[8] SANTOSO, S., POWERS, E. J., GRADY, W. M. and HOFMANN, P. Power Quality Assessment Via Wavelet Transform Analysis. IEEE Transactions on Power Delivery, 11, 2, 924-930, April, 1996.

[9] ANGRisAni, L., DAPONTE, P., D'APUZZO, M. and TESTA, A. A Measurement Method Based on the Wavelet Transform for Power Quality 
Analysis. IEEE Transactions on Power Delivery, 13, 4, 990-998, October, 1998.

[10] HUANG, S.-J., HSIEH, C.-T. and HUANG, C.-L. Application of wavelets to classify power system disturbances. Electric Power Systems Research, 47, 8793, March, 1998.

[11] GAOUDA, A. M., SALAMA, M. M. A., R.SULTAN, M. and CHIKHANI, A. Y. Power Quality Detection and Classification Using Wavelet-Multiresolution Signal Decomposition. IEEE Transactions on Power Delivery, 14, 4, 14691476, October, 1999.

[12] POISSON, O., RIOUAL, P. and MEUNIER, M. New Signal Processing Tools Applied to Power Quality Analysis. IEEE Transactions on Power Delivery, 14, 2, 561-566, April, 1999.

[13] ZHENG, T., MAKRAM, E. B. and GIRGIS, A. A. Power System Transient and Harmonic Studies Using Wavelet Transform. IEEE Transactions on Power Delivery, 14, 4, 1461-1467, October, 1999.

[14] POISSON, O., RIOUAL, P. and MEUNIER, M. Detection and Measurement of Power Quality Disturbances Using Wavelet Transform. IEEE Transactions on Power Delivery, 15, 3, 1039-1044, July, 2000.

[15] HUANG, J., NEGNEVITSKY, M. and NGUYEN, D. T. A Neural-Fuzzy Classifier for Recognition of Power Quality Disturbances. IEEE Transactions on Power Delivery, 17, 2, 609-616, April, 2002.

[16] SANTOSO, S., POWERS, E. J., GRADY, W. M. and PARSONS, A. C. Power Quality Disturbance Waveform Recognition Using Wavelet-Based Neural Classifier - Partl: Theoretical Foundation. IEEE Transactions on Power Delivery, 15, 1, 222-228, January, 2000.

[17] SANTOSO, S., POWERS, E. J., GRADY, W. M. and PARSONS, A. C. Power Quality Disturbance Waveform Recognition Using Wavelet-Based Neural Classifier - Part 2: Application. IEEE Transactions on Power Delivery, 15, 1, 229-235, January, 2000. 
[18] YANG, H.-T. and LIAO, C.-C. A De-Noising Scheme for Enhancing WaveletBased Power Quality Monitoring System. IEEE Transactions on Power Delivery, 16, 3, 353-360, July, 2001.

[19] KEZUNOVIC, M. and LIAO, Y. A Novel Software Implementation Concept for Power Quality Study. IEEE Transactions on Power Delivery, 17, 2, 544549, April, 2002.

[20] DAUBECHIES, I. Where Do Wavelets Come From? - A Personal Point of View. Proceedings of the IEEE, 84, 4, 510-513, April, 1996.

[21] LIMA, P. C. Wavelets: Teoria, Algorítmos e Aplicações. Belo Horizonte: Departamento de Matemática - ICEX - UFMG, p. 2002.

[22] UFC. Universidade Federal do Ceará: O Movimento Browniano. www.fisica.ufc.br/brown/brown.htm, Novembro 2001.

[23] DAUBECHIES, I. Ten lectures on wavelets. Philadelphia, Pa.: Society for Industrial and Applied Mathematics, xix, 357 p. 1992.

[24] KIM, C. H. and AGGARWAL, R. Wavelet transforms in power systems: Part 1 General introduction to the wavelet transforms. Power Engineering Journal, 14, 2, 81-87, April, 2000.

[25] CHUI, C. K. An introduction to wavelets. Boston: Academic Press, x, 264 p. 1992.

[26] KAISER, G. A friendly guide to wavelets. Boston: Birkhäuser, xiv, 300 p. 1994.

[27] MISITI, M., MISITI, Y., OPPENHEIM, G. and POGGI, J.-M. Wavelet Toolbox: User`s Guide. Natick, MA: The MathWorks, 626 p. 1997.

[28] GOMES, J., VELHO, L. and GOLDEnStein, S. $21^{\circ}$ Colóquio Brasileiro de Matemática - Wavelets: Teoria, Software e Aplicações. IMPA Rio de Janeiro, Brazil: Impa, iv-216 p. 1997.

[29] BURRUS, C. S., GOPINATH, R. A. and GUO, H. Introduction to wavelets and wavelet transforms : a primer. Upper Saddle River, NJ: Prentice Hall, xiv, 268 p. 1998. 
[30] PSCAD/EMTDC. Electro-Magnetic Transients in DC systems. 3.0. Winnipeg: Manitoba HVDC Research Centre, viii-73 p. 1994.

[31] SANTOS, C. J. Transitórios originados pelo chaveamento de bancos de capacitores da concessionária em um sistema elétrico de distribuição. São Carlos, 2000. 106p. Dissertação (Mestrado) - Escola de Engenharia de São Carlos, Universidade de São Paulo.

[32] ARRUDA, E. F. D., FILHO, O. D., COURY, D. V. and CARNEIRO, A. A. F. M. Um Estudo das Famílias Wavelets Aplicadas à Qualidade da Energia Elétrica. CBA2002, 6 p, Natal, RN 2002.

[33] SANTOS, C. J. , OLESKOVIKZ, M. , COURY, D. V., ARRUDA, E. F. Transitórios Devido ao Restabelecimento de Alimentadores num Sistema Elétrico de Distribuição na Presença de Bancos de Capacitores fixos. XV Seminário Nacional de Distribuição de Energia Elétrica - SENDI, Salvador. BA. Novembro, 2002.

[34] OleskOVIKZ, M., ARRUdA, E. F., FILHO, O. D., COURY, D. V. and CARNEIRO, A. A. F. M. Análise da Qualidade da Energia Elétrica Utilizando Transformadas Wavelet Combinadas às Redes Neurais Artificiais. Aceito em primeira análise no $17^{\circ}$ Seminário Nacional de Produção e Transmissão de Energia Elétrica - SNPTEE, Uberlândia, MG, Outubro 2003. 


\section{APÊNDICE I}

Este Apêndice apresenta o arquivo utilizado como entrada de dados para o software ATP. Tal arquivo consta de todos os dados do sistema elétrico simulado.

Para a obtenção dos casos, foram efetuados chaveamentos nos pontos em coloração vermelha onde os tempos referentes às durações dos fenômenos simulados, também são definidos. Em coloração azul no arquivo de dados que segue é apresentado o ponto de configuração do valor das resistências de falta utilizadas nas simulações.

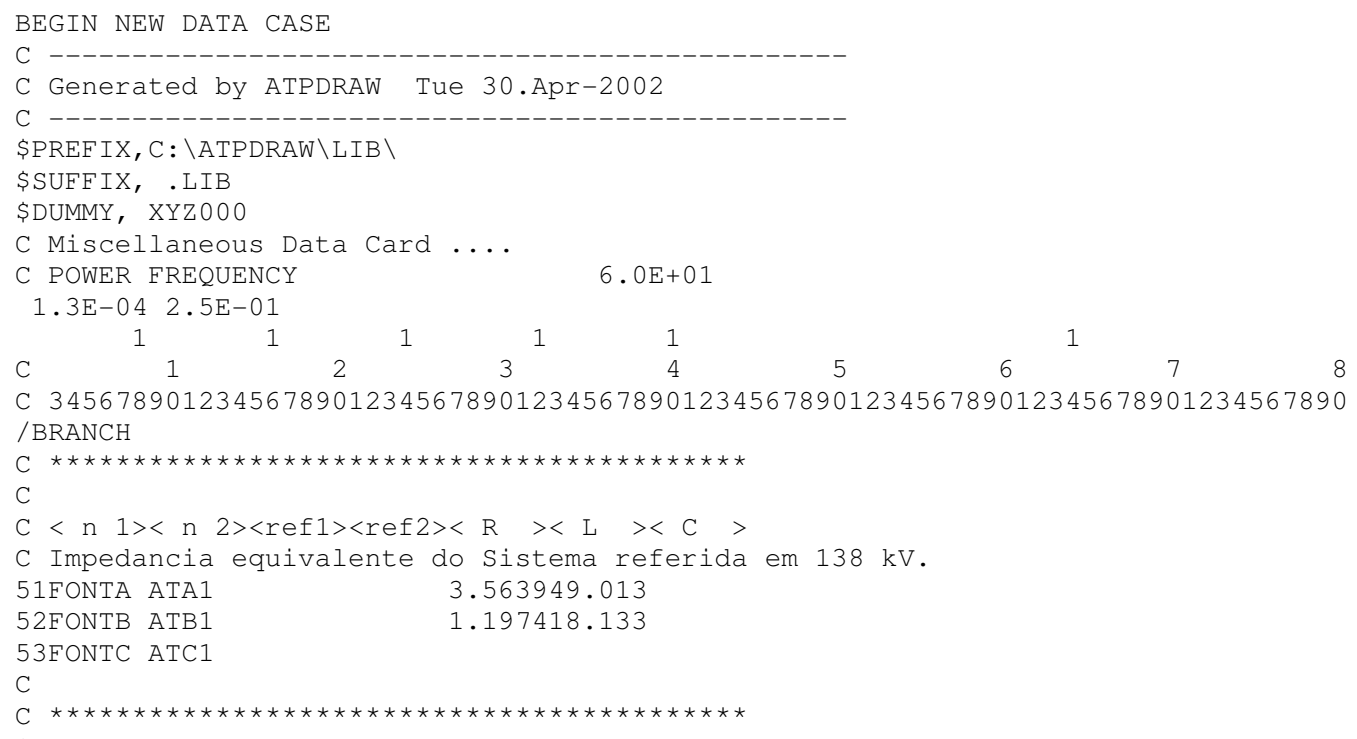




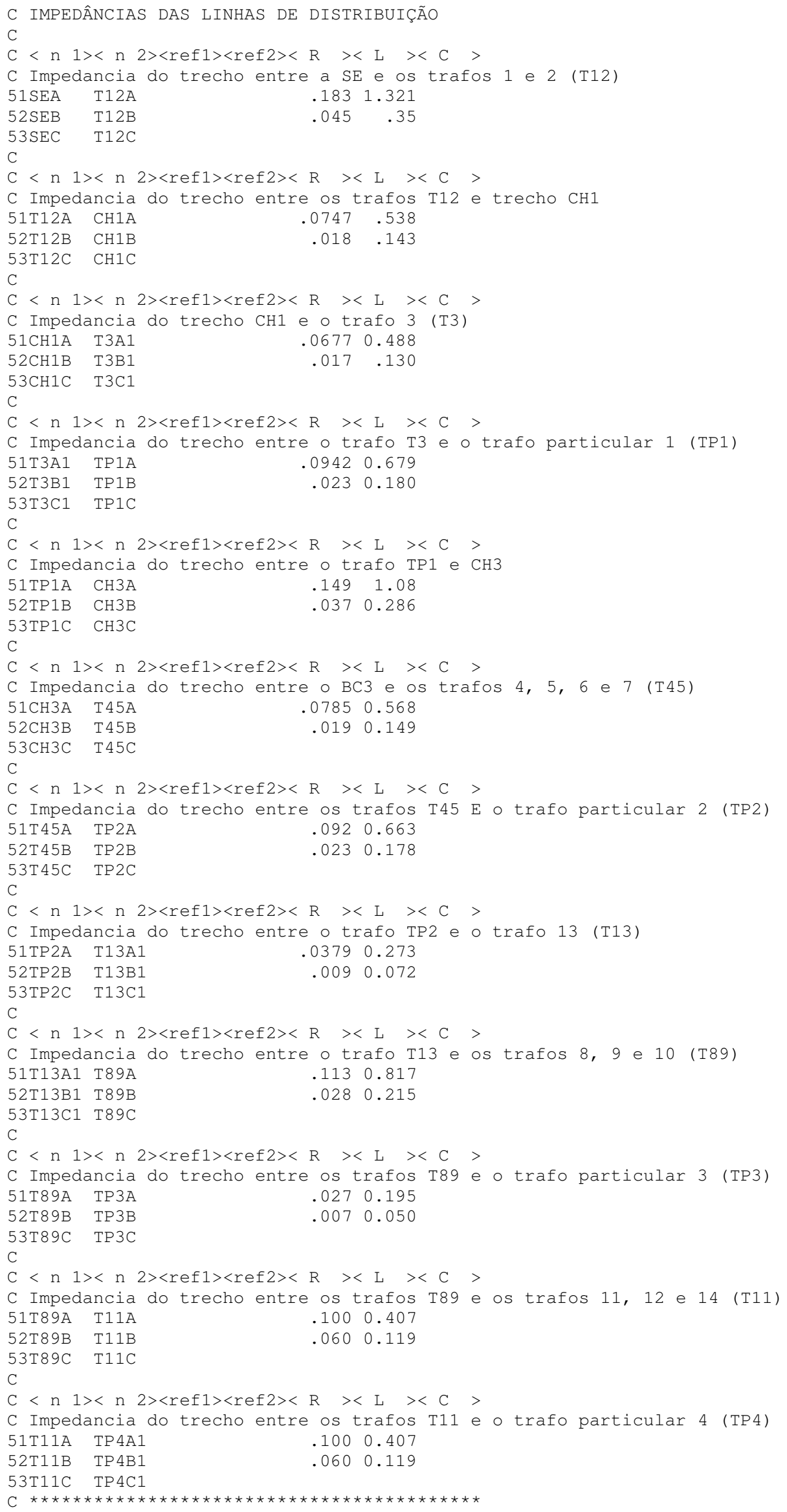




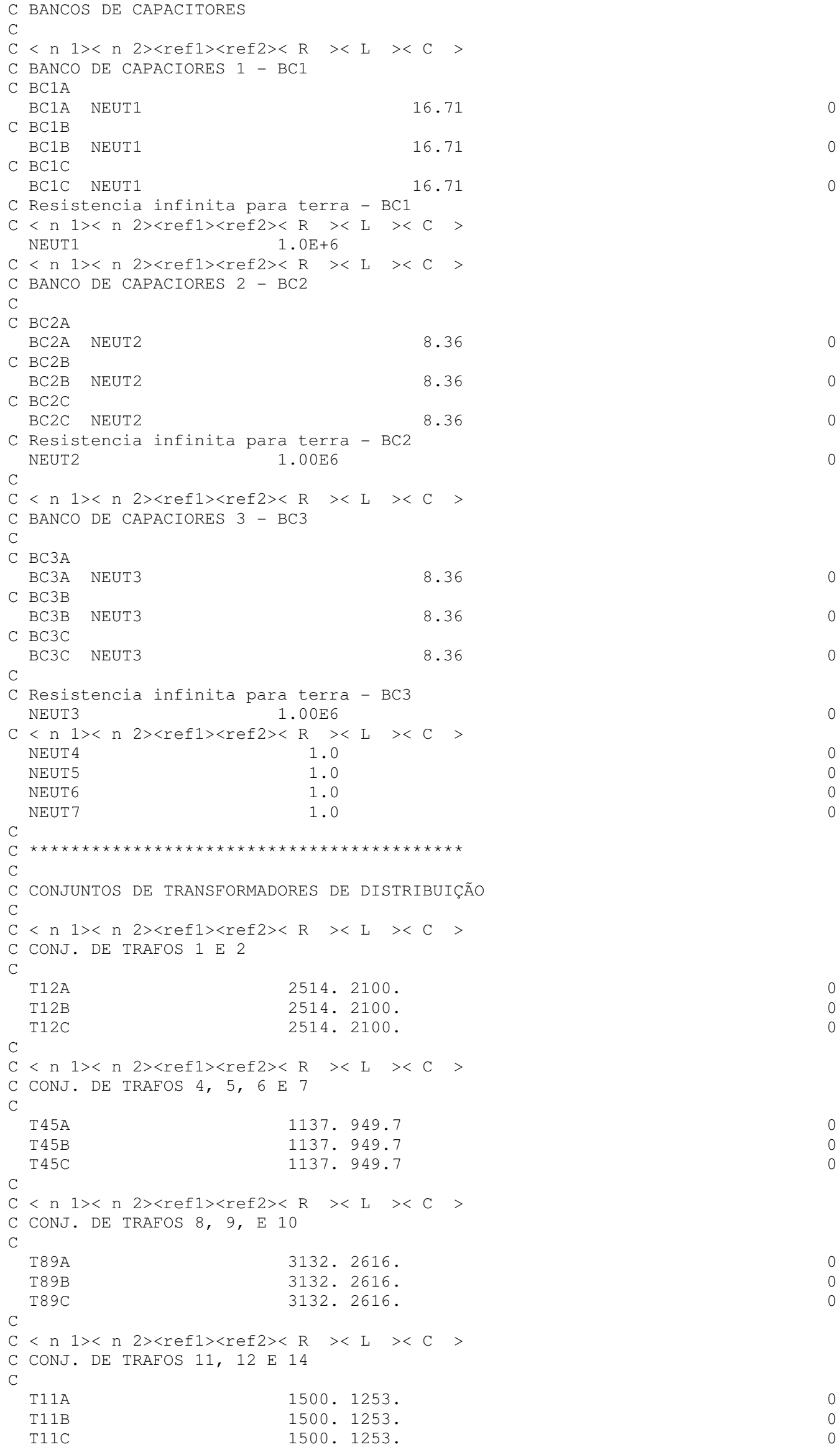


C CARGAS NOS SECUNDÁRIOS DOS TRAFOS MODELADOS

$\mathrm{C}$

$\mathrm{C}<\mathrm{n} 1><\mathrm{n} 2><\operatorname{ref} 1><\operatorname{ref} 2><\mathrm{R} \quad><\mathrm{L} \quad><\mathrm{C}>$

C CARGA NO SECUNDÁRIO DO TRAFO DE DISTRIBUIÇÃO 3 (AMARELO)

$\begin{array}{ll}\text { T3A2 } & 1.44261 .2050 \\ \text { T3B2 } & 1.44261 .2050 \\ \text { T3C2 } & 1.44261 .2050\end{array}$

C CARGA NO SECUNDÁRIO DO TRAFO DE DISTRIBUIÇÃO 13 (AMARELO)

$\begin{array}{ll}\text { T13A2 } & 2.42972 .0310 \\ \text { T13B2 } & 2.42972 .0310 \\ \text { T13C2 } & 2.42972 .0310\end{array}$

C CARGA NO SECUNDÁRIO DO TRAFO PARTICULAR DE DISTRIBUIÇÃO 4 (VERDE) $\begin{array}{ll}\text { TP } 4 A 2 & 0.15900 .1800\end{array}$

TP4B2 0.15900 .1800

TP4C2 0.15900 .1800

TP 4A2 3343

TP 4B2 3343

TP 4C2 3343

$\mathrm{C}<\mathrm{n} 1><\mathrm{n} 2><\operatorname{ref} 1><\operatorname{ref} 2><\mathrm{R} \quad><\mathrm{L} \quad><\mathrm{C} \quad>$

C RESISTÊNCIA DE FALTA SEA/B/C1 E TERRA

$\begin{array}{ll}\text { SEA1 } & 0.01 \\ \text { SEB1 } & 0.01\end{array}$

$\begin{array}{ll}\text { SEB1 } & 0.01 \\ \text { SEC1 } & 0.01\end{array}$

$\mathrm{C}<\mathrm{n} 1><\mathrm{n} 2><\operatorname{ref} 1>\langle\operatorname{ref} 2><\mathrm{R} \quad><\mathrm{L} \quad><\mathrm{C} \quad>$

C RESISTÊNCIA DE FALTA CH1A/B/C1 E TERRA
$\mathrm{CH} 1 \mathrm{~A} 1$
0.01
$\mathrm{CH} 1 \mathrm{~B}$
0.01

0.01

C

$\mathrm{C}<\mathrm{n} 1><\mathrm{n} 2><\operatorname{ref} 1><\operatorname{ref} 2><\mathrm{R} \quad><\mathrm{L} \quad><\mathrm{C} \quad>$

C RESISTÊNCIA DE FALTA CH3A/B/C1 E TERRA
CH3A1
0.01
$\mathrm{CH} 3 \mathrm{~B} 1$
0.01
$\mathrm{CH} 3 \mathrm{C} 1$
0.01

$\mathrm{C}$

C CONJUNTOS DE TRANSFORMADORES DE DISTRIBUIÇÃO PARTICULARES

$\mathrm{C}<\mathrm{n} 1><\mathrm{n} 2><\operatorname{ref} 1><\operatorname{ref} 2><\mathrm{R} \quad><\mathrm{L} \quad><\mathrm{C} \quad>$

C TRAFO PARTICULAR 1 (03 trafos)

45.81107 .2

TP1B 45.81107 .2

TP1C $\quad 45.81107 .2$

TP1A 15.00

TP1B 15.00

TP1C 15.00

$\mathrm{C}<\mathrm{n} 1><\mathrm{n} 2><\operatorname{ref} 1><\operatorname{ref} 2><\mathrm{R} \quad><\mathrm{L} \quad><\mathrm{C} \quad>$

C TRAFO PARTICULAR 2 (04 trafos)

TP2A

TP2B

71.58167 .4

71.58167 .4

TP2C 71.58167 .4

$\begin{array}{ll}\text { TP2A } & 10.00\end{array}$

TP2B 10.00

10.00

$\mathrm{C}<\mathrm{n} 1><\mathrm{n} 2><\operatorname{ref} 1><\operatorname{ref} 2><\mathrm{R} \quad><\mathrm{L} \quad><\mathrm{C}>$

C TRAFO PARTICULAR 3 (02 trafos)

TP3A

TP3B 251.2 587.5

251.2587 .5

TP3A 3.00

TP3B $\quad 3.00$

$\mathrm{C}$

3.00 


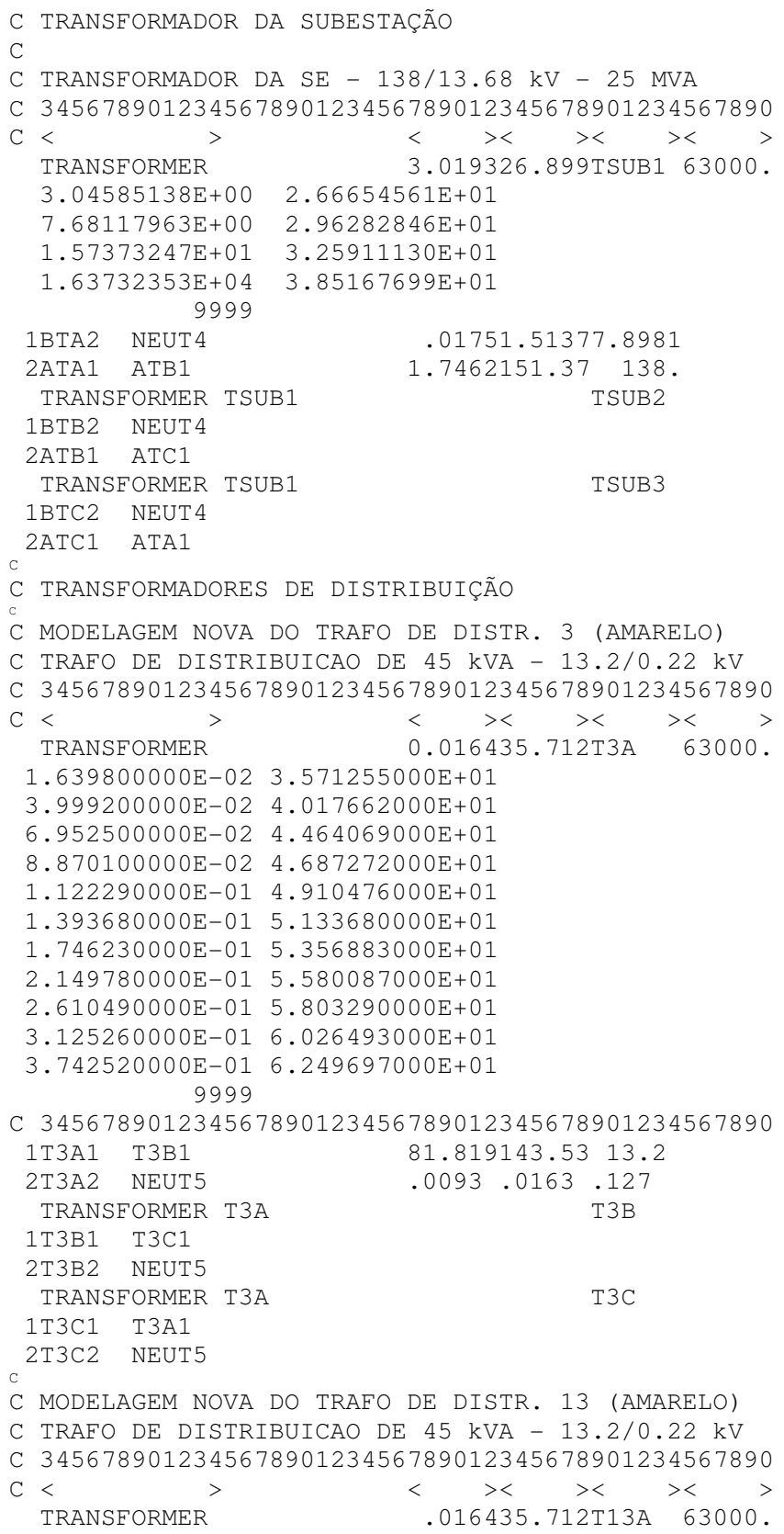

C 3456789012345678901234567890123456789012345678901234567890

$1.639800000 \mathrm{E}-02 \quad 3.571255000 \mathrm{E}+01$

$3.999200000 \mathrm{E}-02 \quad 4.017662000 \mathrm{E}+01$

$6.952500000 \mathrm{E}-02 \quad 4.464069000 \mathrm{E}+01$

$8.870100000 \mathrm{E}-02 \quad 4.687272000 \mathrm{E}+01$

$1.122290000 \mathrm{E}-01 \quad 4.910476000 \mathrm{E}+01$

$1.393680000 \mathrm{E}-015.133680000 \mathrm{E}+01$

$1.746230000 \mathrm{E}-015.356883000 \mathrm{E}+01$

$2.149780000 \mathrm{E}-015.580087000 \mathrm{E}+01$

$2.610490000 \mathrm{E}-015.803290000 \mathrm{E}+01$

$3.125260000 \mathrm{E}-016.026493000 \mathrm{E}+01$

$3.742520000 \mathrm{E}-01 \quad 6.249697000 \mathrm{E}+01$ 9999

1T13A1 T13B1

2T13A2 NEUT6

$$
\begin{gathered}
81.819143 .53 \quad 13.2 \\
.0093 .0163 \quad .127 \\
\mathrm{~T} 13 \mathrm{~B}
\end{gathered}
$$

TRANSFORMER T13A

IT13B1 T13C1

2T13B2 NEUT6

TRANSFORMER T13A T13C

1T13C1 T13A1

$2 \mathrm{~T} 13 \mathrm{C} 2 \mathrm{NEUT} 6$ 
C MODELAGEM NOVA DO TRAFO DE DISTR. 4 (VERDE)

C TRAFO DE DISTRIBUICAO DE $45 \mathrm{kVA}-13.2 / 0.22 \mathrm{kV}$

C 345678901234567890123456789012345678901234567890

$\mathrm{C}<$ TRANSFORMER $\quad .016435 .712 \mathrm{~T} 4 \mathrm{~A} \quad 63000$.

C 3456789012345678901234567890123456789012345678901234567890

$1.639800000 \mathrm{E}-02 \quad 3.571255000 \mathrm{E}+01$

$3.999200000 \mathrm{E}-02 \quad 4.017662000 \mathrm{E}+01$

$6.952500000 \mathrm{E}-02 \quad 4.464069000 \mathrm{E}+01$

$8.870100000 \mathrm{E}-02 \quad 4.687272000 \mathrm{E}+01$

$1.122290000 \mathrm{E}-01 \quad 4.910476000 \mathrm{E}+01$

$1.393680000 \mathrm{E}-015.133680000 \mathrm{E}+01$

$1.746230000 \mathrm{E}-015.356883000 \mathrm{E}+01$

$2.149780000 \mathrm{E}-015.580087000 \mathrm{E}+01$

$2.610490000 \mathrm{E}-01 \quad 5.803290000 \mathrm{E}+01$

$3.125260000 \mathrm{E}-01 \quad 6.026493000 \mathrm{E}+01$

$3.742520000 \mathrm{E}-016.249697000 \mathrm{E}+01$ 9999

$1 \mathrm{TP} 4 \mathrm{~A} 1 \mathrm{TP} 4 \mathrm{~B} 1$

2TP 4A2 NEUT7

TRANSFORMER T4A

$81.819143 .53 \quad 13.2$

$.0093 \quad .0163 \quad .127$

$1 \mathrm{TP} 4 \mathrm{~B} 1$ TP4C1

2TP4B2 NEUT7

TRANSFORMER T4A T4C

$1 \mathrm{TP} 4 \mathrm{C} 1 \mathrm{TP} 4 \mathrm{~A} 1$

2 TP 4C2 NEUT7

$\mathrm{C}$

SWITCH

$\mathrm{C}$

C CHAVES (DISJUNTORES) DO ALIMENTADOR

$\mathrm{C}$

$\mathrm{C}<\mathrm{n} 1><\mathrm{n} 2><$ Tclose $><$ Top/Tde $><$ Ie $><$ Vf $/$ CLOP $><$ type $>$

BTA2 SEA $-1.00 \mathrm{E}+00 \quad 1.000 \mathrm{E}+01 \quad 0.000 \mathrm{E}+00$

BTB2 SEB $-1.00 \mathrm{E}+001.000 \mathrm{E}+01 \quad 0.000 \mathrm{E}+00$

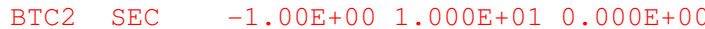

$\mathrm{C}$

C CHAVES DE COMANDO DOS BANCOS DE CAPACITORES

C CHAVE DE COMANDO BC1

$\mathrm{C}<\mathrm{n} 1><\mathrm{n} 2><$ Tclose $><$ Top $/$ Tde $><$ Ie $\quad><$ Vf $/$ CLOP $><$ type $>$

CH1A BC1A $1.000 \mathrm{E}+01 \quad 1.000 \mathrm{E}+01 \quad 0.000 \mathrm{E}+00$

CH1B BC1B $1.000 \mathrm{E}+01 \quad 1.000 \mathrm{E}+01 \quad 0.000 \mathrm{E}+00$

$\mathrm{CH} 1 \mathrm{C} \quad \mathrm{BC} 1 \mathrm{C} \quad 1.000 \mathrm{E}+01 \quad 1.000 \mathrm{E}+01 \quad 0.000 \mathrm{E}+00$

$\mathrm{C}$

$\mathrm{C}<\mathrm{n} 1><\mathrm{n} 2><$ Tclose $><$ Top $/$ Tde $><$ Ie $\quad><$ Vf $/$ CLOP $><$ type $>$

C CHAVE DE COMANDO BC2

$\begin{array}{lllll}\mathrm{CH} 1 \mathrm{~A} & \mathrm{BC} 2 \mathrm{~A} & 1.000 \mathrm{E}+01 & 1.000 \mathrm{E}+01 & 0.000 \mathrm{E}+00\end{array}$

CH1B BC2B 1.000E+01 1.000E+01 $0.000 \mathrm{E}+00$

$\mathrm{CH} 1 \mathrm{C} \quad \mathrm{BC} 2 \mathrm{C} \quad 1.000 \mathrm{E}+01 \quad 1.000 \mathrm{E}+01 \quad 0.000 \mathrm{E}+00$

$\mathrm{C}$

$\mathrm{C}<\mathrm{n} 1><\mathrm{n} 2><$ Tclose $><\mathrm{Top} / \mathrm{Tde}><$ Ie $\quad><\mathrm{Vf} / \mathrm{CLOP} \quad><$ type $>$

C CHAVE DE COMANDO BC3

$\begin{array}{lllllllll}\text { CH3A BC3A } & 1.000 \mathrm{E}+01 & 1.000 \mathrm{E}+01 & 0.000 \mathrm{E}+00\end{array}$

$\begin{array}{llllll}\mathrm{CH} 3 \mathrm{~B} & \mathrm{BC} 3 \mathrm{~B} & 1.000 \mathrm{E}+01 & 1.000 \mathrm{E}+01 & 0.000 \mathrm{E}+00\end{array}$

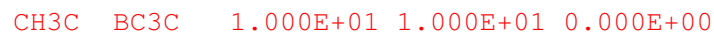

$\mathrm{C}<\mathrm{n} 1><\mathrm{n} 2><$ Tclose $><\mathrm{Top} / \mathrm{Tde}><$ Ie $\quad><\mathrm{Vf} / \mathrm{CLOP}><$ type $>$

C CHAVE DE FALTA SEA - SEA1

SEA SEA1 4.450E-02 9.450E-02 0.000E+00

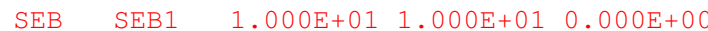

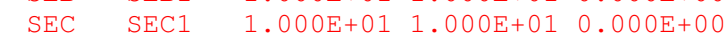

$\mathrm{C}<\mathrm{n} 1><\mathrm{n} 2><$ Tclose $><$ Top $/$ Tde $><$ Ie $\quad><$ Vf $/$ CLOP $><$ type $>$

C CHAVE DE FALTA CH1A - CH1A 1

$\begin{array}{lllll}\text { CH1A CH1A1 } & 1.000 \mathrm{E}+01 & 1.000 \mathrm{E}+01 & 0.000 \mathrm{E}+00\end{array}$

CH1B CH1B1 1.000E+01 1.000E+01 $0.000 \mathrm{E}+00$

CH1C CH1C1 1.000E+01 1.000E+01 $0.000 \mathrm{E}+00$ 
$\mathrm{C}$

$\mathrm{C}<\mathrm{n} 1><\mathrm{n} 2><$ Tclose $><$ Top $/$ Tde $><$ Ie $><$ Vf $/$ CLOP $><$ type $>$

C CHAVE DE FALTA CH3A - CH3A1

$\begin{array}{lllll}\text { CH3A CH3A1 1.000E+01 } 1.000 \mathrm{E}+01 & 0.000 \mathrm{E}+00\end{array}$

CH3B CH3B1 1.000E+01 1.000E+01 0.000E+00

$\begin{array}{llllll}\mathrm{CH} 3 \mathrm{C} & \mathrm{CH} 3 \mathrm{C} 1 & 1.000 \mathrm{E}+01 & 1.000 \mathrm{E}+01 & 0.000 \mathrm{E}+00\end{array}$

$\mathrm{C}$

/SOURCE

C FONTE EQUIVALENTE DO SISTEMA de $138 \mathrm{kV}$.

$\mathrm{C}<\mathrm{n} 1><><$ Ampl. $\quad>$ Freq. $\quad><$ Phase $/ \mathrm{T} 0><$

$14 \mathrm{FONTA} \quad 0 \quad 112676.53$

60 .

$14 \mathrm{FONTB} 0112676.53 \quad 60 . \quad-120$.

$14 \mathrm{FONTC} \quad 0 \quad 112676.53$

$60 . \quad 120$

A1 $><$ T1 $><$ TSTART $><$ TSTOP

-1 . 2 .

BLANK BRANCH

BLANK SWITCH

BLANK SOURCE

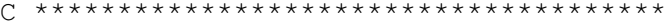

$\mathrm{C}<\quad><\quad><\quad><\quad><\quad><\quad>$

SEA SEB SEC

BLANK OUTPUT

BLANK PLOT

BEGIN NEW DATA CASE

BLANK 


\section{APÊNDICE II}

O algoritmo ANADIQE desenvolvido foi subdividido em módulos de análise de forma a se detectar, localizar e classificar os diferentes distúrbios em análise. Este Apêndice apresenta o ANADIQE em seus diferentes módulos.

O primeiro módulo apresentado consiste no arquivo principal do algoritmo. Este gerencia todo o desenvolvimento de análise acionando os outro módulos quando necessário.

O módulo de detecção apresentado em seguida é acionado após as definições dos dados a serem analisados. Uma vez detectado um distúrbio o algoritmo principal aciona o módulo de decomposição que armazena as decomposições utilizadas nas análises posteriores. Nesta etapa, a diferença Diff é calculada e comparada aos limiares de diferenciação pelo módulo principal, acionando o módulo de análise de distúrbios com freqüências similares ou superiores à frequência do sinal fundamental.

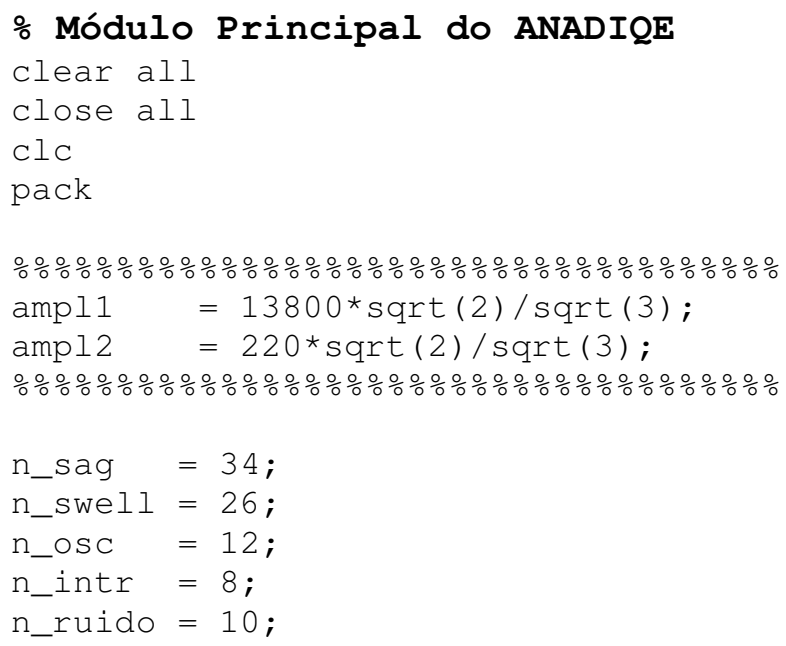




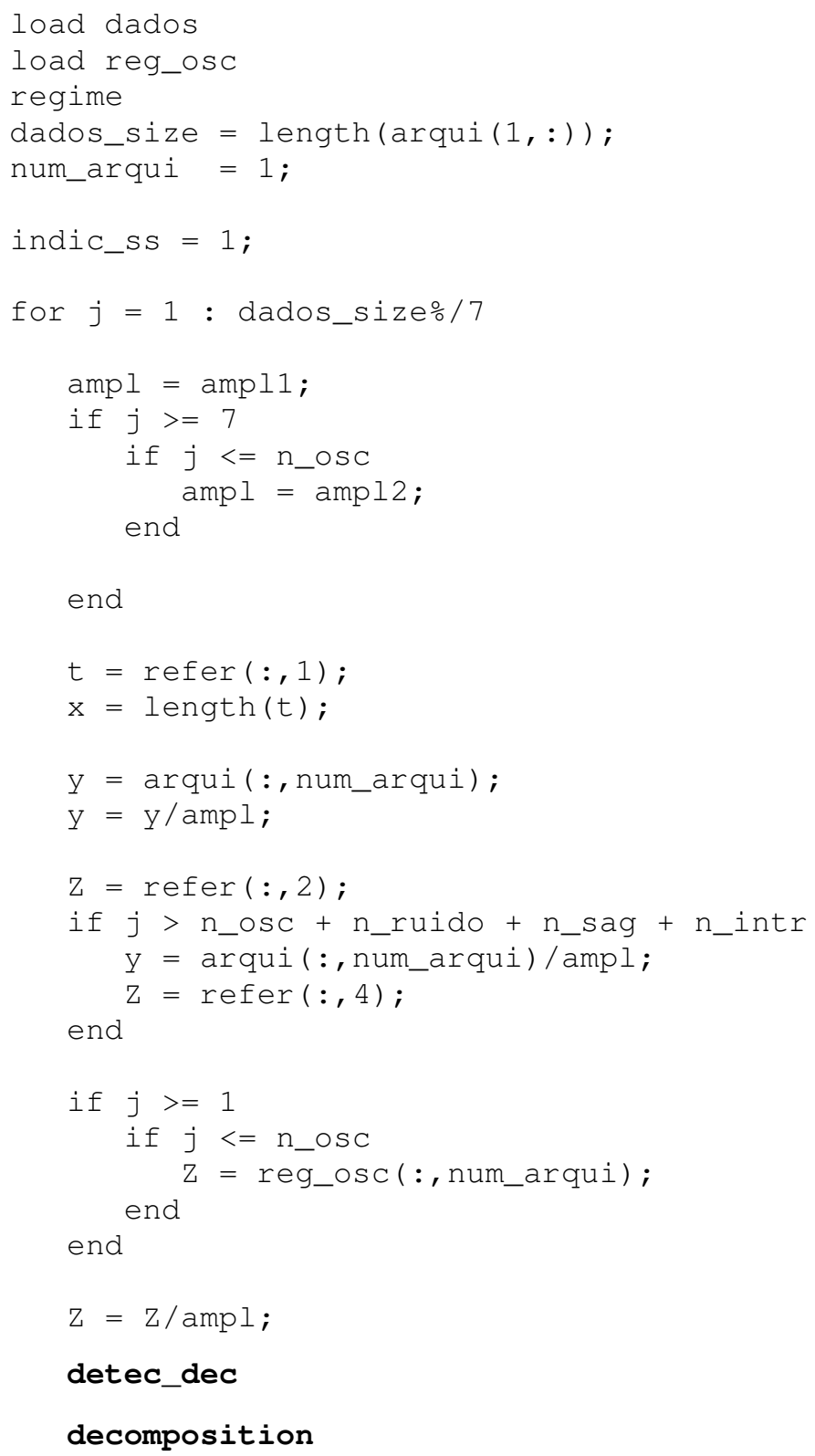




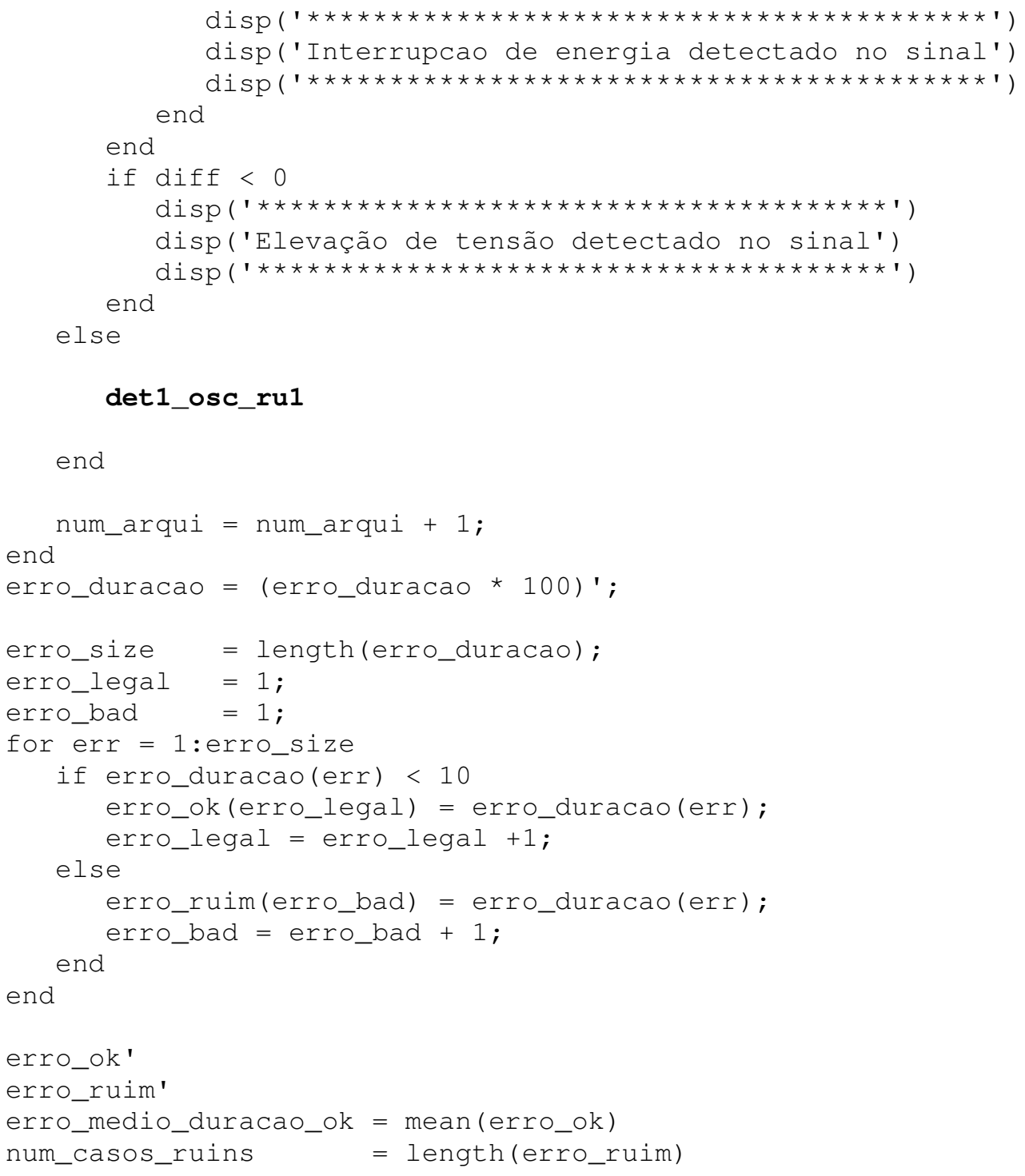

\section{ঃDetecção de distúrbios com janelamento de 1 ciclo}

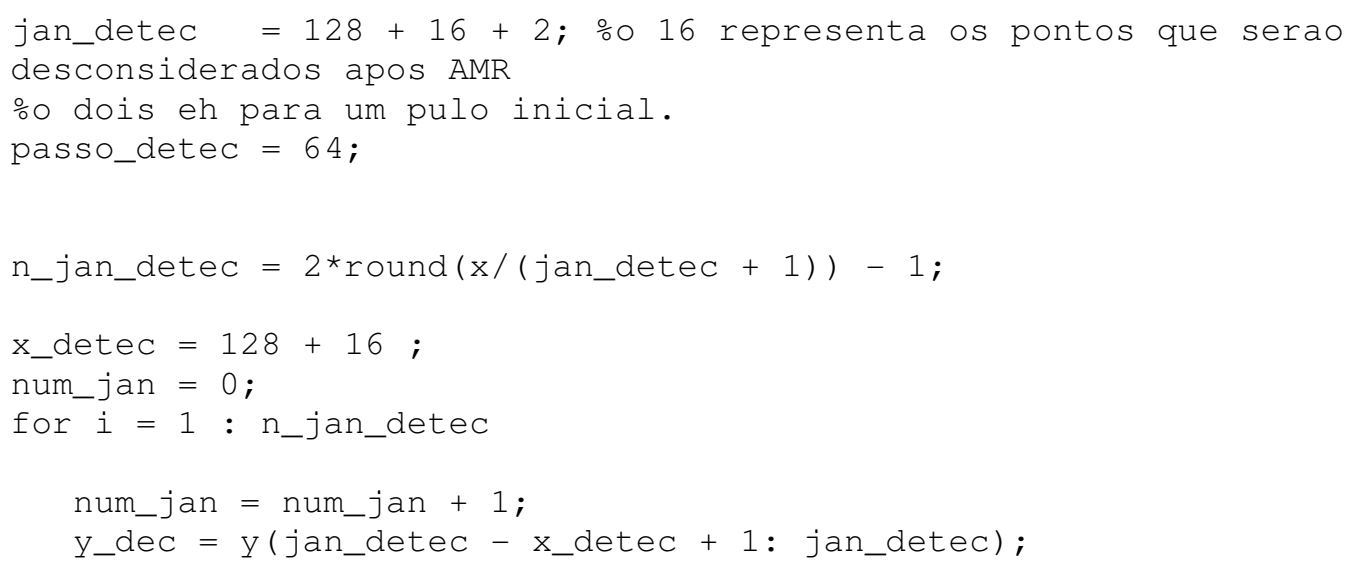




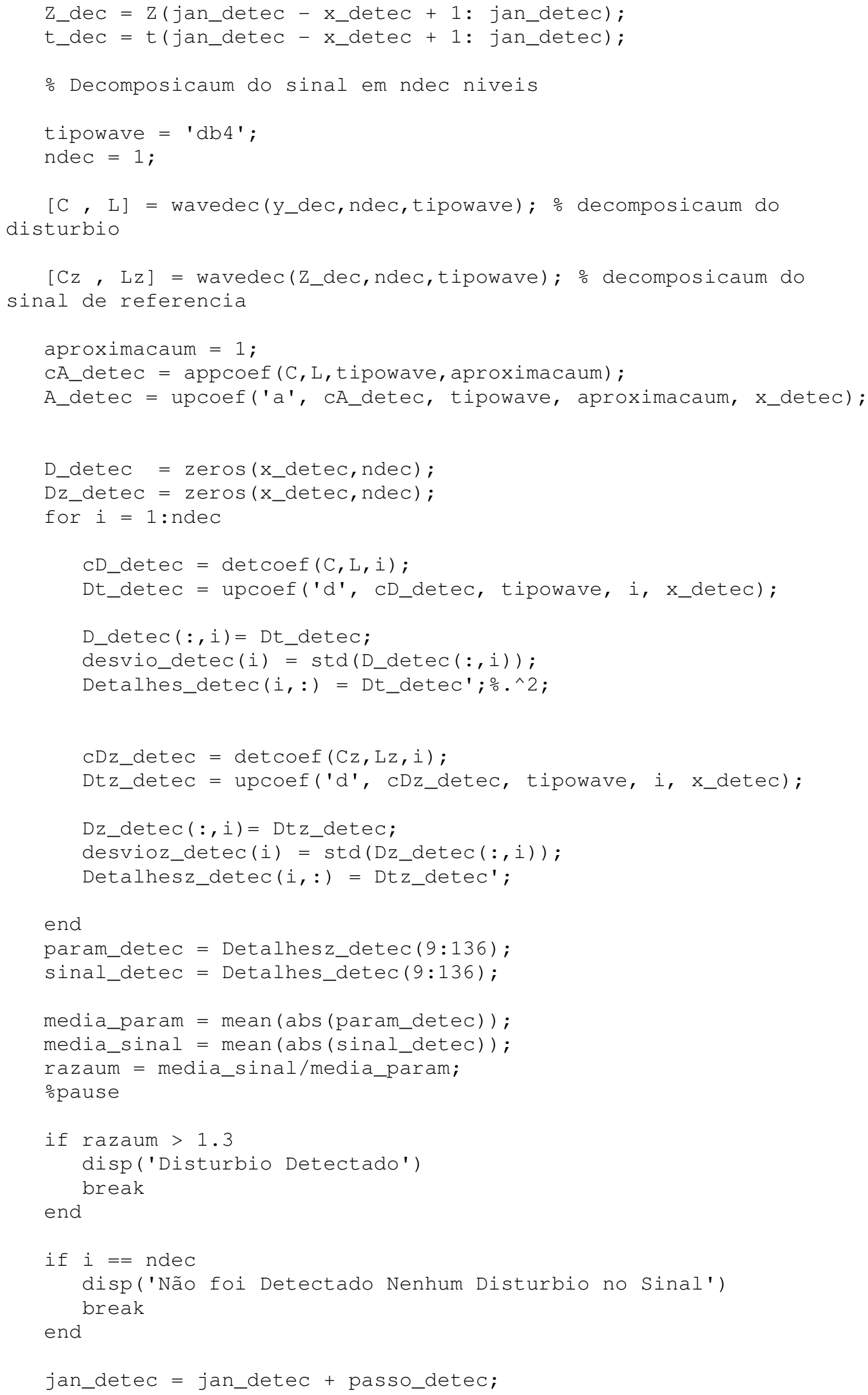




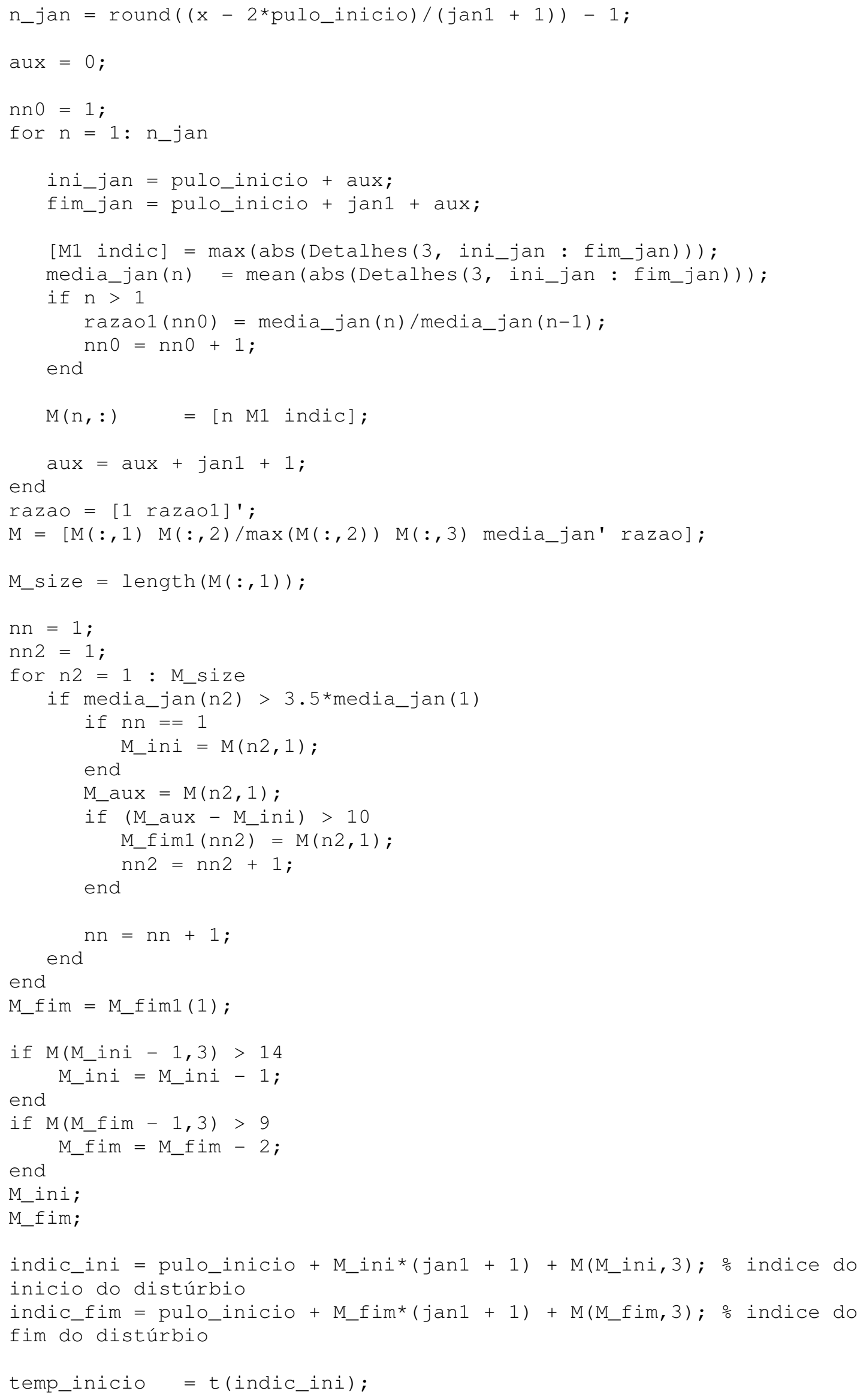




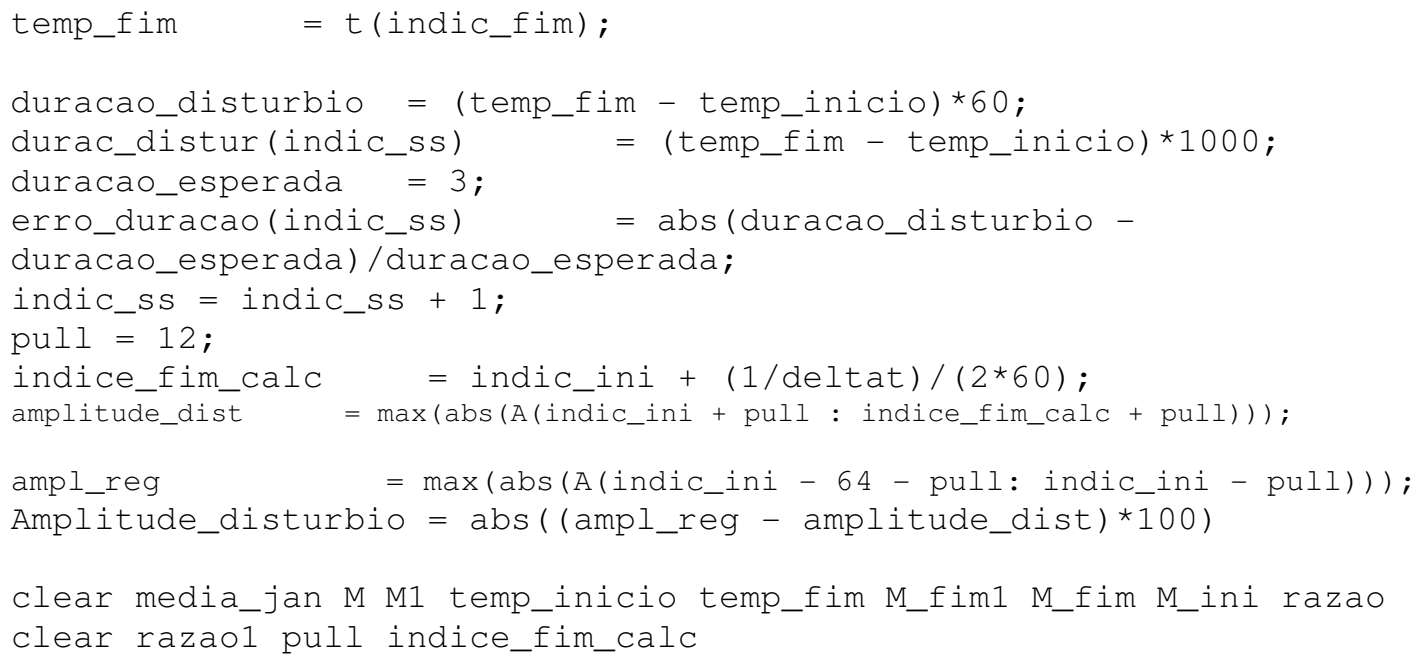

\section{\% Analise do terceito detalhe para frequências superiores}

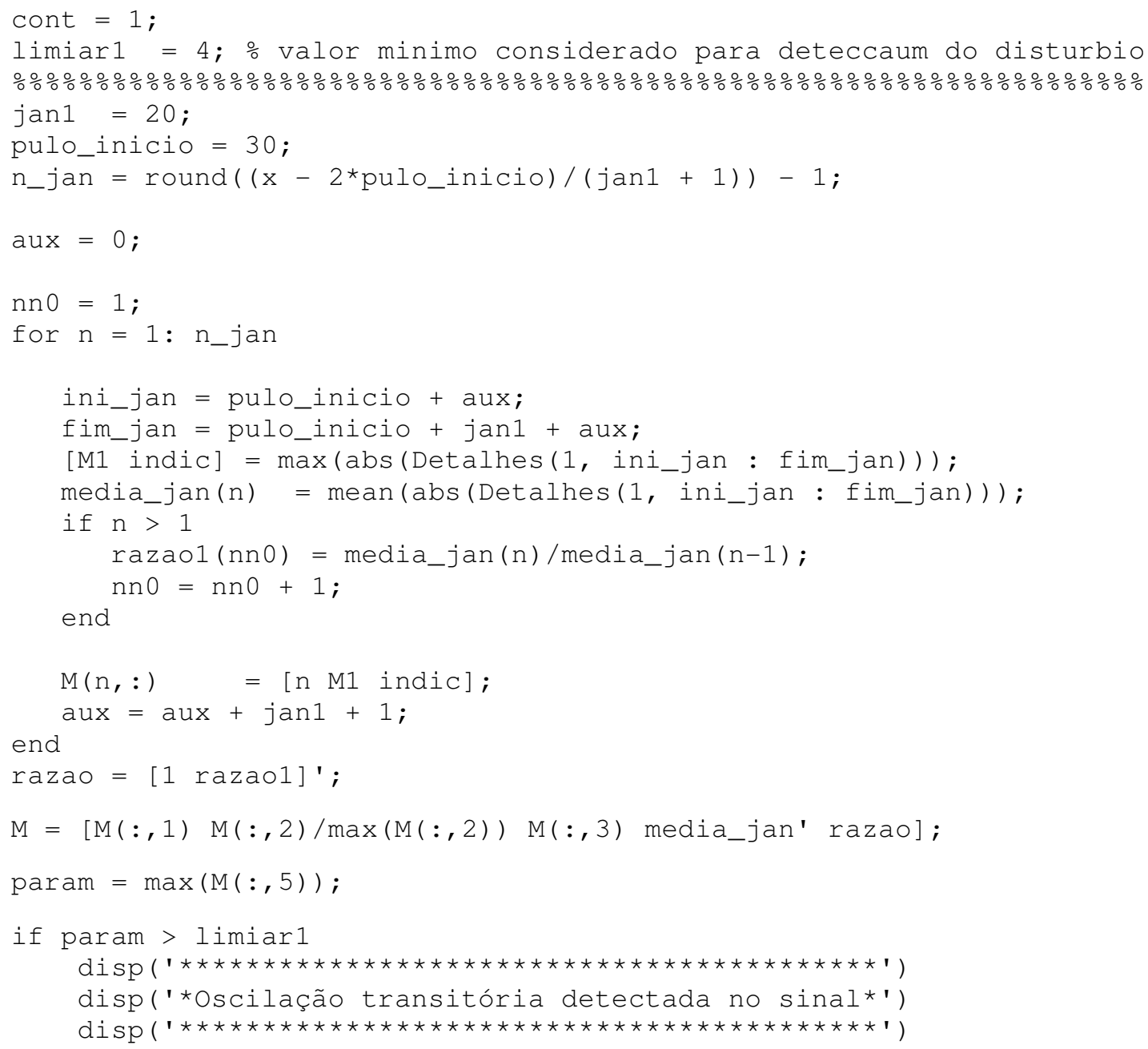




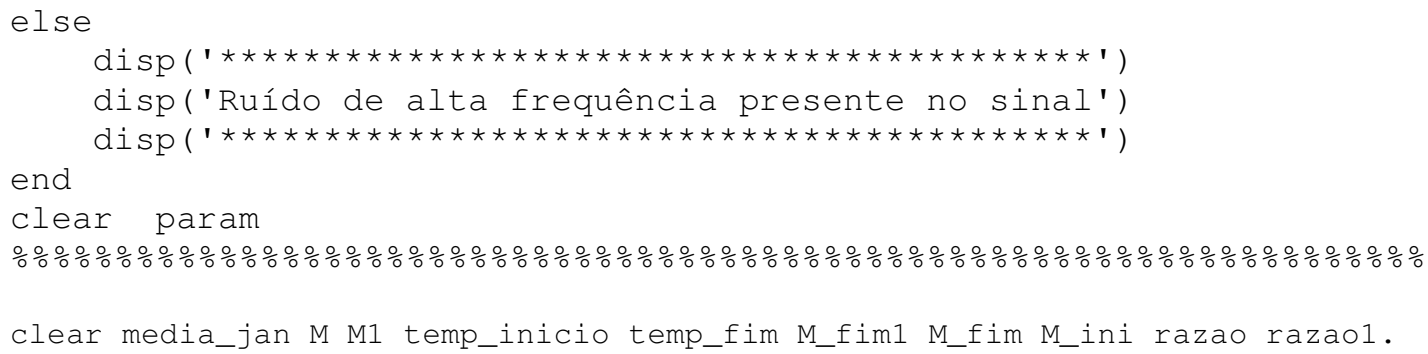




\title{
APÊNDICE III
}

\section{UM ESTUDO DAS FAMÍLIAS WAVELETS APLICADAS À QUALIDADE DA ENERGIA ELÉTRICA}

\author{
ELCIO F. DE ARRUDA, ODILON D. FILHO, DENIS V. COURY, ADRIANO A. F. M. CARNEIRO \\ Depto. De Engenharia Elétrica, Escola de Eng. de São Carlos, Universidade de São Paulo. \\ P.O.Box 359, CEP 13566-590, São Carlos, SP, Brasil, +55-16-273 9366 \\ E-mails:\{franklin, delmont, coury, adriano\}@esel.eesc.sc.usp.br
}

\begin{abstract}
Resumo- Este trabalho apresenta um estudo de famílias de bases Wavelets ortogonais aplicadas à Qualidade da Energia Elétrica. Variações nas formas de ondas dos sinais de tensão e corrente como sag, swell, distorções harmônicas e ruídos, tem se tornado freqüentes nos atuais sistemas elétricos, atraindo a atenção para a qualidade da energia elétrica fornecida pelas concessionárias. A análise de tais fenômenos, que normalmente é descrita no domínio do tempo (resolução de equação diferencial) ou no domínio da freqüência (através da Transformada de Fourier), pode agora ser analisada simultaneamente em ambos os domínios do tempo e da freqüência, dispondo-se da Transformada Wavelet. Neste contexto, é apresentada uma avaliação de tais fenômenos através da Análise de Resoluções Múltiplas, com base nas diversas Wavelets ortogonais. Dos estudos efetuados, conclui-se pelo emprego de algumas funções bases como mais adequadas para análise dos fenômenos acima referenciados.
\end{abstract}

\begin{abstract}
This paper presents a study for orthogonal bases of wavelets families applied to Power Quality. Variations in voltage and current waveforms as sag, swell, harmonic distortions and noise have became frequent in the electric systems, attracting the attention for the power quality supplied. The analysis of such phenomena that is usually described in the time domain (differential equation resolution) or in the frequency domain (Fourier Transform), now can be analyzed simultaneously in both domains; time and frequency, by the Wavelet Transform. In this context, an evaluation of such phenomena by Multiresolution Analysis, based on several orthogonal wavelets, is presented. This study shows which base functions are more appropriate for the analysis of the phenomena above mentioned.
\end{abstract}

Keywords_- Wavelet Transform, Power Quality, Orthogonal Wavelet Family, Multiresolution Analysis.

\section{Introdução:}

As situações transitórias em sistemas de potência são comuns e, na prática, podem ser ocasionadas por descargas atmosféricas, correntes de magnetização de transformadores, faltas sustentadas, correntes de partida de grandes motores, ou ainda pelos efeitos de chaveamentos de capacitores em linhas de transmissão.

Estes distúrbios que ocorrem nos sistemas, podem provocar inúmeras interferências indesejáveis como acionamento indevido de relés, mau funcionamento de equipamentos sensíveis, distorções em equipamentos de medição, podendo chegar até a interromper o fornecimento de energia. Tudo isto acaba tendo um efeito econômico não desprezível acarretando prejuízos tanto às concessionárias como aos consumidores. Atualmente, com a proliferação de equipamentos sofisticados, exige-se cada vez mais uma melhor qualidade no sinal entregue pela concessionária.

A análise e o entendimento destes transitórios associados às condições anormais têm sempre auxiliado na explicação e retificação dos mesmos. Sendo assim, a identificação em tempo real de tais transitórios, com um processamento rápido e preciso dos sinais medidos de tensão e corrente, aplicações de controle on-line em transmissão e distribuição e o armazenamento/compressão de dados são interesses particulares de muitos engenheiros da área de sistema de potência.

Uma etapa importante desta questão é definir o que seria então um problema de QE. Entre muitos apontamentos da literatura (Dugan et al., 1996), pode-se classificar o assunto como qualquer problema manifestado na tensão, corrente ou desvio de freqüência, que resulte em falha ou má operação dos equipamentos de consumidores. 
Atualmente, a QE é avaliada pela concessionária e órgãos governamentais através de equipamentos que medem índices específicos, como DEC (Duração Equivalente de Interrupção por Unidade Consumidora) e FEC (Frequiência Equivalente de Interrupção por Unidade Consumidora), cujas definições se encontram na Resolução № 24 da Agência Nacional de Energia Elétrica - ANEEL (ANEEL, 2000). No entanto, estes índices estão relacionados somente com o intervalo de tempo em que o sistema permanece desligado e a freqüência de tais desligamentos. Sendo assim, estes não detectam certas alterações nas formas de onda e na frequiência que são, na maioria das vezes, causadas por ruídos, distorções harmônicas, certas condições de falta e chaveamento de capacitores que podem causar problemas operacionais em equipamentos.

Cabe ressaltar, que todos os fenômenos relacionados à $\mathrm{QE}$ devem ser detectados, localizados e classificados. Ferramentas como a Transformada de Fourier (TF), Redes Neurais Artificiais (RNA) e Transformada Wavelet (TW) tem sido usadas para análise de distúrbios em Sistemas Elétricos de Potência (SEP) ligados à QE (Aggarwal e Kim, 2000; Huang et al., 1998).

Dentre estas, a TW se destaca por sua aplicabilidade sendo uma técnica matemática similar a TF. A TW decompõe um dado sinal em diferentes níveis de frequiência, preservando ainda as informações pertinentes ao domínio do tempo, fornecendo assim informações nos dois domínios, simultaneamente. Desta forma, é possível localizar distúrbios no domínio do tempo e dizer qual o seu nível de frequiência (Daubechies, 1992).

Para se obter informações aceitáveis no estudo de fenômenos ligados à QE, é necessário que as funções bases utilizadas na TW forneçam resoluções capazes de diferenciar variações nos domínios considerados (tempo e freqüência), indicando ou não a presença de distúrbios.

Desta forma, o artigo apresenta um estudo com análise de comportamento de diversas famílias de bases Wavelets ortogonais, aplicadas à $\mathrm{QE}$, com o objetivo de identificar quais destas bases melhor se adequam ao estudo em questão.

\section{A Transformada Wavelet}

A análise de dados de acordo com escalas variáveis no domínio do tempo e da frequiência é a idéia básica da utilização da teoria Wavelet. O termo "Wavelet" foi originariamente introduzido por J. Morlet, tendo a base matemática de suas idéias sido formalizada pelo físico teórico Alex Grossmann (Daubechies, 1996).

A Transformada Wavelet (TW) é uma ferramenta matemática para análise de sinais similar à Transformada de Fourier (TF). A TW decompõe o sinal em diferentes escalas, com diferentes níveis de resolução, a partir de uma única função. Diferentemente da TF que fornece uma representação global do sinal, a TW apresenta representações locais no domínio do tempo e da frequêencia de um dado sinal (Santoso et al., 1996).

Seja $f(t)$ uma função definida no espaço $L^{2}(\Re)$. Tal sinal satisfaz

$$
\int_{-\infty}^{\infty}|f(t)|^{2} d t<\infty .
$$

A Transformada Wavelet Contínua (TWC) de $f$ é dada pela equação:

$$
(T W C)(a, b)=\int f(t) \overline{\psi_{a, b}(t)} d t
$$

Nesta equação, os parâmetros $a$ e $b$ variam continuamente em $\mathrm{R}$, sendo as funções $\psi_{a, b}$ denominadas Wavelets e definidas de acordo com a Eq. (2):

$$
\psi_{a, b}(t)=\frac{1}{\sqrt{a}} \psi\left(\frac{t-b}{a}\right) .
$$

Analisando a Eq. (1) pode-se perceber que a Transformada Wavelet depende de dois parâmetros, $a$ e $b$, que correspondem, respectivamente, às informações da escala, ou dilatação, e translação, ou tempo. Tal equação decompõe $f$ em uma superposição de Wavelets $\psi_{a, b}$, sendo os coeficientes nesta superposição obtidos pela transformada Wavelet de $f$. É possível reconstruir $f$ representando-a como uma soma de coeficientes da TW, da forma apresentada na Eq. (3) indicada a seguir (Daubechies, 1992):

$$
f(t)=\frac{1}{C_{\psi}} \iint\left\langle f, \psi_{a, b}(t)\right\rangle \psi_{a, b}(t) \frac{d a d b}{a^{2}} .
$$

\subsection{A Transformada "Wavelet" Discreta}

$\mathrm{Na}$ Transformada Wavelet Discreta (TWD) o parâmetro de dilatação $a$ e $\quad$ o de translação $b$, utilizados na Eq. (1), assumem somente valores discretos. forma:

Sendo assim a TWD pode ser escrita da seguinte

$$
(T W D)(m, n):=\left.\left|a_{0}\right|^{m}\right|^{\frac{-1}{2}} \sum_{n} f(n) \psi\left(\frac{x-n b_{0} a_{0}{ }^{m}}{a_{0}{ }^{m}}\right) .
$$

onde $\psi$ é a Wavelet mãe e os parâmetros $a$ e $b$ tornam-se funções dos parâmetros inteiros $m$ e $n$, isto é, $a=a_{0}{ }^{m}$ e $b=n b_{0} a_{0}{ }^{m}$, fato que pode ser observado comparando as Eq. (1) e (4) (Kim e Aggarwal, 2000).

\subsection{Análise de Resoluções Múltiplas}

A técnica de Análise de Resoluções Múltiplas (ARM) decompõe um dado sinal em diferentes níveis de resolução, de modo a fornecer informações importantes no domínio do tempo e da freqüência. 
O sinal a ser analisado é decomposto em dois outros sinais, uma versão detalhada e outra atenuada, através de filtros passa alta $\left(h_{1}\right)$ e passa baixa $\left(h_{0}\right)$ que são representados matematicamente por funções Wavelets e funções escala, respectivamente.

Como o sinal atenuado - proveniente do filtro passa baixa - é novamente decomposto, resultando em dois novos sinais detalhados e atenuados em níveis de freqüência diferentes, estes fornecem informações diretas, relativas ao sinal original, no domínio da frequiência e do tempo (Gomes e Velho, 1998).

As Fig.1 e Fig.2 ilustram a técnica descrita, sendo a Fig. 1 a representação do processo de filtragem acompanhado também de um operador downsampling o qual reduz a quantidade de informações a ser processada. A Fig. 2 ilustra a decomposição de um sinal. A Fig.2a representa a versão aproximada do sinal (A3) sendo que os detalhes da decomposição do mesmo (D1, D2 e D3) são apresentados nas Fig. 2b, c e d respectivamente.

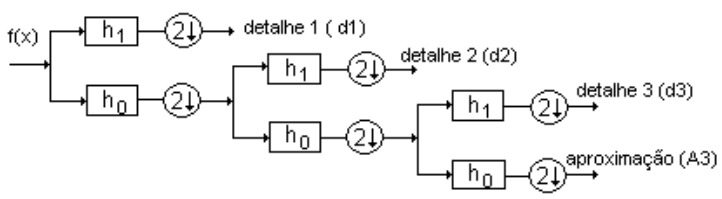

Figura 1. Processo de decomposição de um sinal através de filtragem.

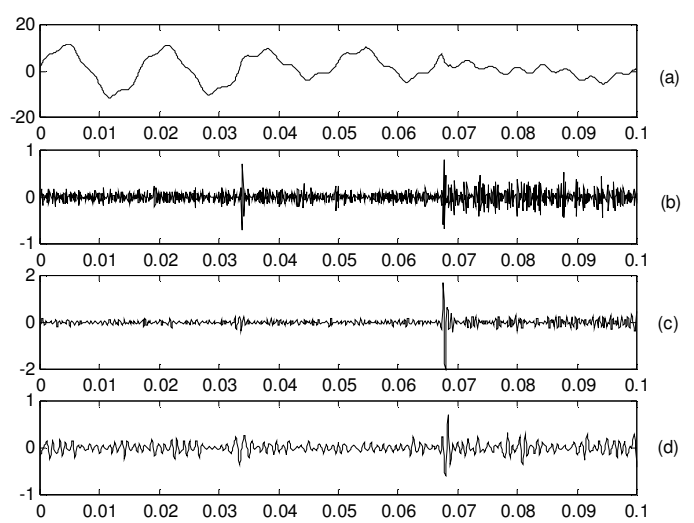

Figura 2. Representação de um sinal sob ARM. Aproximação A3 (a), detalhe 1 (b), detalhe 2 (c) e detalhe 3 (d).

\section{Aplicação das famílias Wavelets ortogonais na Qualidade da Energia Elétrica}

Após diversos testes realizados com várias funções bases Wavelets para a análise da qualidade da energia elétrica, foram obtidos resultados que indicam algumas funções base como mais adequadas em certas análises. Geralmente, Wavelets mais suaves indicam melhor resolução em frequiência que Wavelets que possuem variações bruscas como a Wavelet de Haar, Fig.3a; o oposto é aplicado para resolução no domínio do tempo. As funções: Haar, Daubechies $(\mathrm{db} N, N=2,3, \ldots, 8)$, Symlets $(\operatorname{sym} M, M=$
$1,2, \ldots 8)$ e Coiflets (coif $P, P=1,2, \ldots, 5$ ), formam o grupo de vinte e uma bases ortogonais submetidas, neste artigo, a testes com o objetivo de detectar e localizar distúrbios relacionados com a QE. Note-se que $N, M$ e $P$ representam a ordem de tais funções, sendo algumas destas exemplificadas na Fig. 3.

A técnica de ARM foi utilizada para análise dos fenômenos sag, swell, distorções harmônicas e ruídos, com a utilização das vinte e uma bases ortogonais mencionadas acima, tendo sido utilizadas todas as bases na análise de cada distúrbio mencionado.

A escolha de uma base para a análise dos distúrbios em estudo considerará sua capacidade de distinção entre os níveis de freqüência do sinal original e dos distúrbios. Uma base que se molde em tal premissa pode ser utilizada, também, para a classificação de distúrbios através de diferentes técnicas, sendo uma delas ilustrada no trabalho de (Santoso et al, 1996).

A seguir são apresentados os distúrbios analisados, tendo sido amostrados a uma taxa de 9,6 $\mathrm{kHz}$, bem como resultados da utilização de apenas algumas das funções bases utilizadas para análise.
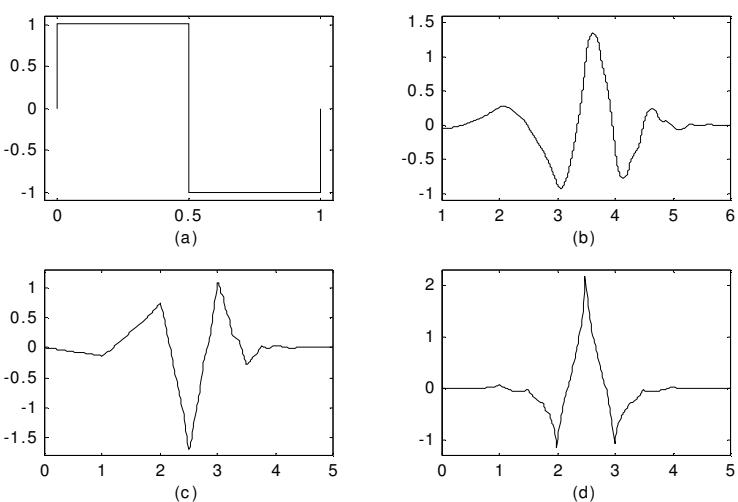

Figura 3. Funções da base Wavelets: Haar (a), db 4 (b), sym 3 (c) e coif 1 (d).

\subsection{Sag}

Dependendo da localização da falta e das condições do sistema, a falta pode causar um decréscimo temporário de $10-90 \%$ da tensão do sistema (efeito referenciado como sag) com duração entre meio ciclo e 1 min. O mesmo pode ser causado por uma corrente de falta, por chaveamento de cargas pesadas ou pela partida de grandes motores. Quedas de tensão com períodos inferiores a $10 \mathrm{~ms}$ e abaixo de $10 \%$ não são levadas em consideração. Isto se explica pelo fato de os distúrbios com período de duração abaixo de $10 \mathrm{~ms}$ serem considerados como transitórios e quedas de tensão menores que $10 \%$ serem toleradas pela maioria dos equipamentos elétricos (Dugan, 1996). A Fig. 4 ilustra um sag típico que pode ter como provável causa uma falta fase-terra.

Dentre as vinte e uma bases utilizadas, são ilustrados nas Fig.5 e Fig.6 os resultados obtidos com as bases de Haar e db4. A função base Haar, assim 
como as bases sym1 e coif1, não se adequam a este tipo de análise, uma vez que tal aplicação exige melhor resolução em frequiência. Por outro lado, a $\mathrm{db} 4$, que possui comportamento mais suave, oferece respostas de decomposição em Resoluções Múltiplas que indicam claramente a localização do distúrbio, bem como a detecção do mesmo. Salienta-se que as bases ' $\mathrm{db} N$ ' $(N=5,6,7$ e 8$)$, 'sym $M$ ' $(M=4,5, \ldots, 8)$ e 'coif $P$ ' $(P=3,4$ e5) se enquadram ao mesmo perfil de análise para o distúrbio sag obtido com a db4. Já as bases $\mathrm{db} 2$ e 3 , sym2 e 3 e coif2 apresentam resultados que podem indicar erros em um processo de detecção de distúrbios, apontando a presença de frequiências inexistentes no sinal original.

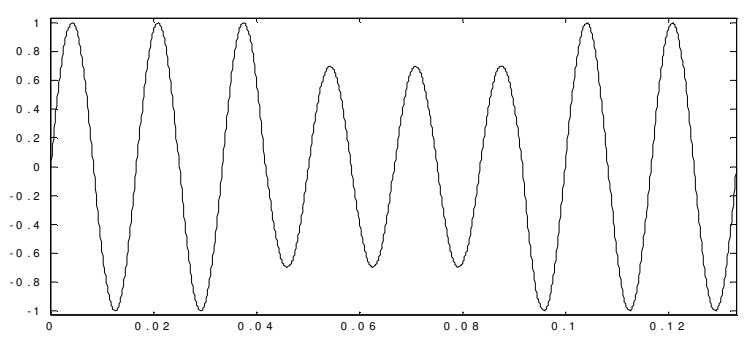

Figura 4. Distúrbio Sag típico de 30\%.
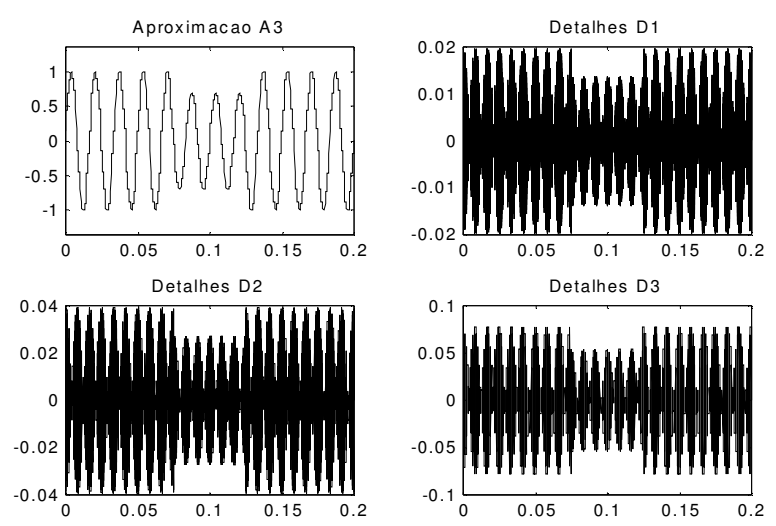

Figura 5. Decomposição de um sag de 30\% em ARM utilizando a função base de Haar
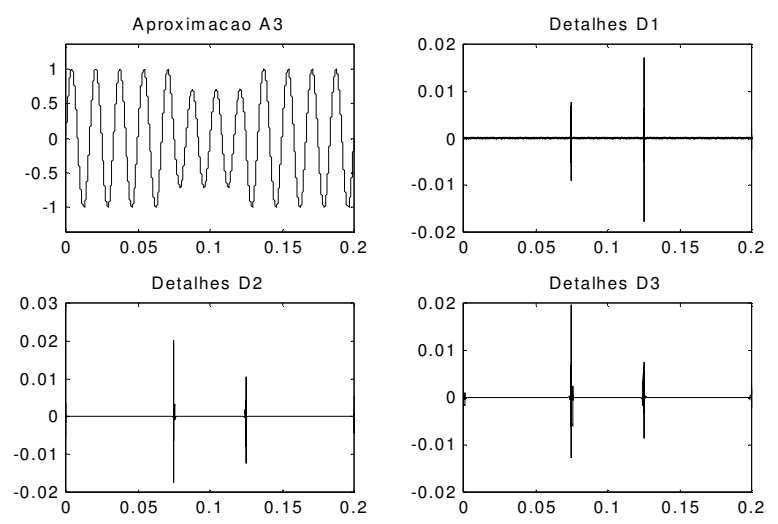

Figura 6. Decomposição de um sag de 30\% em ARM utilizando a função base $\mathrm{db} 4$.

\subsection{Swell}

Outro distúrbio pode ser caracterizado por um aumento da tensão do sistema (swell - aumento entre $10-80 \%$ no valor eficaz da tensão com duração entre meio ciclo a 1 minuto) e freqüentemente ocorre nas fases sãs de um circuito trifásico, quando ocorre um curto circuito em uma única fase (Dugan, 1996).

A Fig.7 ilustra um swell típico encontrado no sistema elétrico. Um aumento de $30 \%$ no valor de pico da tensão por um período de aproximadamente 3 ciclos pode ser observado.

Na Fig.8 são ilustrados resultados da utilização da base sym 2 que indicam (da mesma forma que as bases db2 e 3, sym3 e coif2) a presença não só do distúrbio swell (detalhes D1), mas também componentes de freqüências típicas de distorções harmônicas (detalhes D2 e D3), que são inexistentes no sinal estudado. Já as bases Symlets de ordem superior a três $(\operatorname{sym} M, M=4, \ldots, 7)$, da mesma forma que as bases $\operatorname{db} N(N=4, \ldots, 8)$ e coif $P(P=3,4$ e 5$)$, são capazes de detectar e localizar corretamente distúrbios existentes.

A Fig.9 mostra os resultados obtidos através de ARM, para o mesmo distúrbio swell da Fig. 7, utilizando a base $\mathrm{db} 3$.

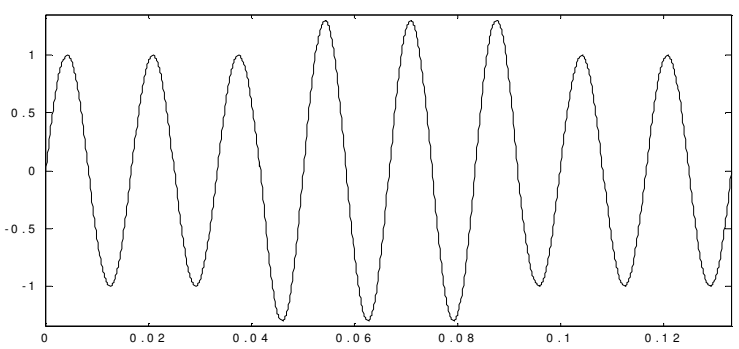

Figura 7. Distúrbio Swell típico de $30 \%$.
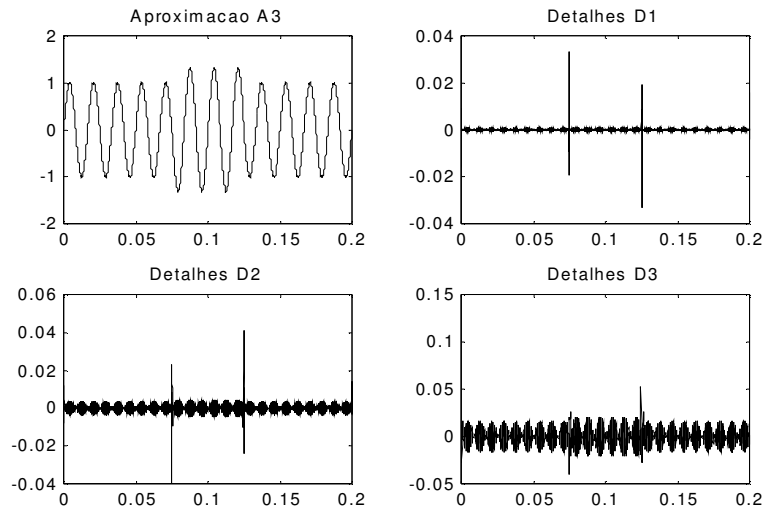

Figura 8. Decomposição de um swell de 30\% em ARM utilizando a função base sym2.

\subsection{Distorções Harmônicas}

Ainda com respeito à QE, podemos citar as distorções harmônicas que consistem basicamente de qualquer distorção não desejável do sinal sobre o sistema. Neste caso, os sinais de tensões e ou correntes senoidais apresentam freqüências que são 
múltiplos inteiros da frequiência na qual o sistema é projetado para operar (usualmente $50 \mathrm{ou} 60 \mathrm{~Hz}$ ). As distorções harmônicas são originárias de características não lineares de dispositivos e cargas sobre o sistema de energia (Dugan, 1996). A Fig.10 ilustra a presença de harmônicos de segunda e quinta ordem em um sinal senoidal puro.
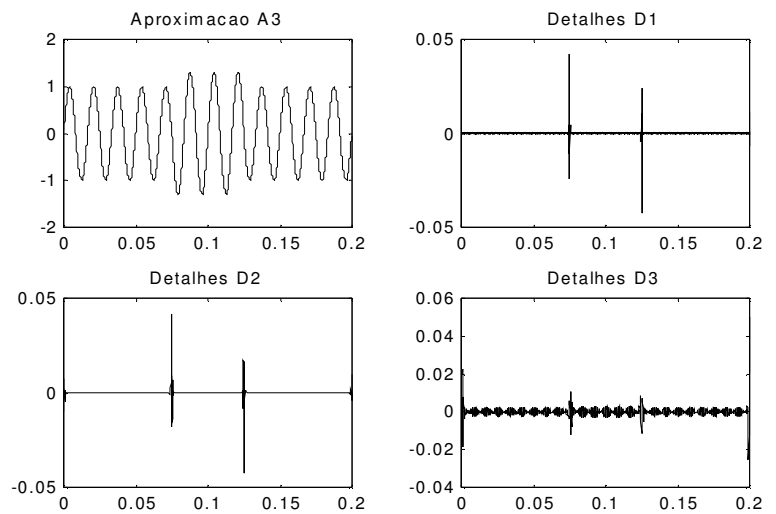

Figura 9. Decomposição de um swell de 30\% em ARM utilizando a função base db3.

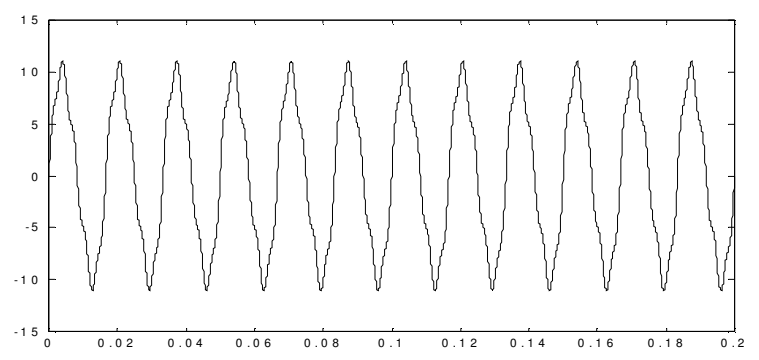

Figura 10. Sinal senoidal com inclusão de harmônicos de segunda e quinta ordem.

As Fig. 11 e Fig.12 ilustram os resultados decorrentes da utilização das bases coif1 e db6, respectivamente. Como pode ser visto na Fig. 11, a Wavelet coif1 apresenta resultados que indicam a presença não somente das componentes de baixa freqüência (D3 e D4), mas também componentes de alta frequiência (D1 e D2). As componentes de baixa frequência caracterizam os conteúdos harmônicos incorporados ao sinal e as altas freqüências são características típicas de ruídos.

Já na análise com a utilização da db6, Fig. 12, pode-se perceber que esta indica somente a presença de componentes de baixa frequência.

Similarmente aos distúrbios sag e swell, as mesmas bases $\operatorname{db} N(N=4, \ldots, 8), \operatorname{sym} M(M=4, \ldots, 7)$ e coif $P(P=3,4$ e 5$)$ produziram resultados confiáveis quando aplicadas à distorções harmônicas.

\subsection{Ruídos}

Com respeito aos ruídos, estes podem ser definidos como sinais elétricos não desejáveis, contendo espectro de freqüências abaixo de $200 \mathrm{kHz}$, superposto à tensão e/ou corrente do sistema de energia. A faixa de frequiência e o nível da amplitude dependem da fonte que produz o ruído e das características do sistema, sendo a amplitude típica inferior a 1\% da tensão fundamental (Dugan, 1996).

A Fig.13 mostra um exemplo típico de ruído encontrado nos SEPs. O ruído incorporado no sinal senoidal puro possui uma amplitude equivalente a $1 \%$ do valor de pico da tensão.
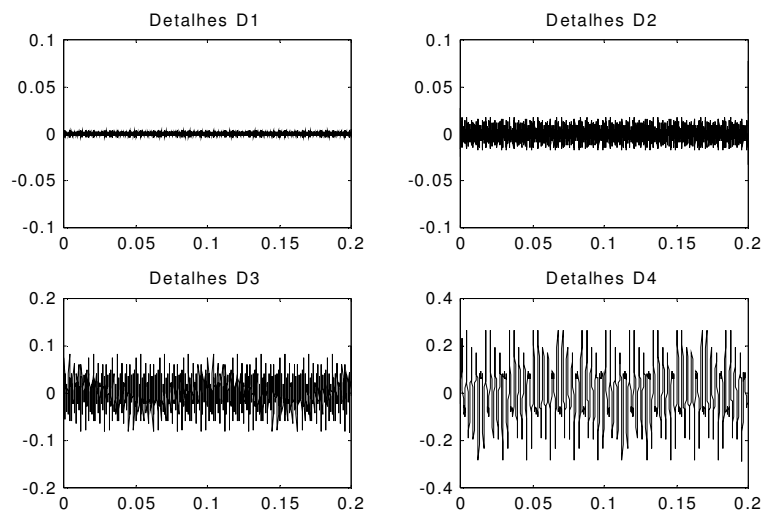

Figura 11. Decomposição de um sinal senoidal contendo distorções harmônicas de segunda e quinta ordem em ARM utilizando a função base coif1.
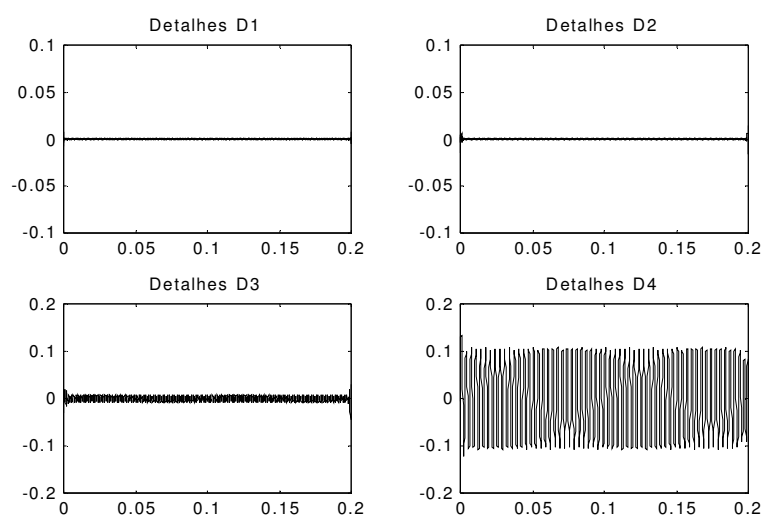

Figura 12. Decomposição de um sinal senoidal contendo distorções harmônicas de segunda e quinta ordem em ARM utilizando a função base db6.

Na Fig.14 é ilustrado o resultado de ARM do sinal em estudo, utilizando a Wavelet mãe db8.

Pode-se observar a presença de componentes tanto de altas como de baixas frequências, sendo predominantes as componentes de altas frequências, características de ruído, que constituem os coeficientes de detalhes D1 e D2.

Para análise de ruídos, similarmente aos outros distúrbios analisados, as mesmas Wavelets mãe $\mathrm{dbN}$ $(N=4, \ldots, 8), \operatorname{sym} M(M=4, \ldots, 7)$ e $\operatorname{coif} P(P=3,4$ e 5$)$ produziram resultados satisfatórios. 


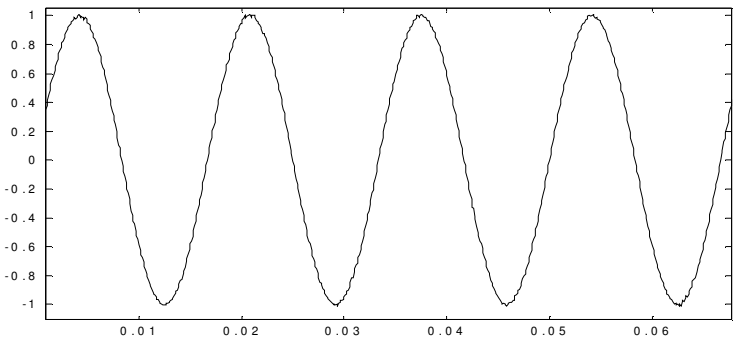

Figura 13. Sinal senoidal com inclusão de $1 \%$ de ruído.
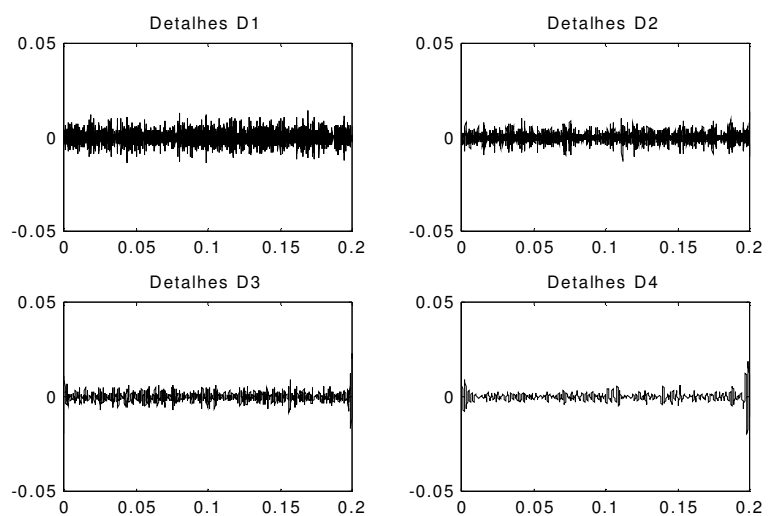

Figura 14 - Decomposição de um sinal senoidal contendo $1 \%$ de ruído em ARM utilizando a função base $\mathrm{db} 8$.

\section{Conclusões}

O presente trabalho apresentou um estudo com análise de comportamento de diversas famílias de bases Wavelets, tendo sido analisadas somente as bases ortogonais, aplicadas à $\mathrm{QE}$, com o objetivo de identificar quais destas bases melhor se adequam ao estudo em questão.

A técnica de ARM, utilizando Wavelets, consiste na decomposição de um dado sinal em versões que correspondem a componentes de altas frequências (detalhes) e baixas frequências (aproximações). Através destas versões de detalhes e aproximações somos capazes de detectar e localizar diversos distúrbios ligados à $\mathrm{QE}$, uma vez que as bases utilizadas para a análise possuam características que permitam distinguir os níveis de frequências do sinal original e do distúrbio. Desta forma, este trabalho propôs um estudo de quatro tipos de Wavelets mães: Haar, Daubechies, Symlet e Coiflet, que formam um grupo de vinte e uma bases diferentes, tendo-se restringido somente às bases ortogonais. Estas foram aplicadas à análise dos distúrbios sag, swell, distorções harmônicas e ruídos, que ocorrem com frequência nos SEPs.

A análise de tais distúrbios foi realizada em ARM tendo-se identificado algumas bases Wavelets como mais adequadas para o estudo de fenômenos ligados à QE. O comportamento da função base Wavelet é fundamental no desempenho das análises, uma vez que Wavelets com comportamentos mais suaves permitem melhor resolução no domínio da frequiência, enquanto que Wavelets que possuem grandes variações em pequenos intervalos de tempo caracterizam melhor resolução no domínio do tempo.

Pôde ser observado que aumentando a ordem das Wavelets mães ortogonais, seus comportamentos em suavidade oferecem melhor resolução em frequência. Sendo assim, as Wavelets de Daubechies e Symlet de ordem superior a três e Coiflets de ordem superior a dois oferecem melhores resultados, isto em relação às bases Wavelets ortogonais utilizadas neste trabalho para análise de distúrbios ligados à QE. Tal resultado, associado à facilidade de cálculos que a envolve, justifica a ampla utilização da Wavelet de Daubechies de quarta ordem (db4) para análises em SEP. Por outro lado, por apresentarem comportamentos com menor suavidade, as demais bases $(\mathrm{db} N, N=1, \ldots, 3, \operatorname{sym} M, M=1, \ldots, 3$ e $\operatorname{coif} P P$ = 1 e 2) são inviáveis na aplicação em destaque neste trabalho.

\section{Agradecimentos}

À Capes pelo suporte financeiro, ao Laboratório de Sistemas de Energia Elétrica, do Departamento de Engenharia Elétrica da EESC e ao Dr. Mário Oleskovicz, pós-doutorando em QE na USP/EESC, pela revisão e sugestões neste artigo.

\section{Referências Bibliográficas}

ANEEL - Agência Nacional de Energia Elétrica (2000), "Resolução N. ' 24".

Daubechies, I. (1996). Where do Wavelets Come From? - A Personal Point of View, Proceedings of the IEEE, EUA, 84(4): 510-513.

Daubechies, I. (1992). Ten Lectures on Wavelets, Society for Industrial and Applied Mathematics, Philadelphia, Pennsylvania.

Dugan, R.C. et al. (1996). Electrical Power Systems Quality, McGraw-Hill.

Gomes, J. ; Velho, L. ; (1998), From Fourier Analysis to Wavelets Course Notes - Siggraph, IMPA Rio de Janeiro, Brasil.

Huang S. J. et al. (1998). Application of wavelets to classify power system disturbances. Electric Power Systems Research, 47 Feb.:87-93.

Kim, C.H.; Aggarwal, R. (2000). Wavelet transforms in power systems. Power Engineering Journal Apr.:81-87.

Santoso S. et al. (2000). Characterization of Distribution Power Quality Evernts with Fourier and Wavelet Transforms. IEEE Transactions on Power Delivery, EUA, 15(1): 247-254.

Santoso S. et al. (1996). Power Quality Assessment via Wavelet Transform Analysis. IEEE Transactions on Power Delivery, EUA, 11(2): 924-930. 